Cognition in narrow-striped mongooses, Mungotictis decemlineata, a Malagasy carnivore species

\author{
Dissertation \\ for the award of the degree \\ “Doctor of Philosophy" (Ph.D.)
}

Division of Mathematics and Natural Sciences

of the Georg-August-Universität Göttingen

within the doctoral program Biology

of the Georg-August University School of Science (GAUSS)

submitted by

Bako Nandrianina Rasolofoniaina

from Antananarivo, Madagascar

Göttingen, 2020 



\section{Thesis committee}

Prof. Dr. Peter Kappeler, Department of Sociobiology/Anthropology, Johann-Friedrich-Blumenbach Institute of Zoology and Anthropology, Georg-August University Göttingen, and Behavioral Ecology and Sociobiology Unit, German Primate Center Leibniz Institute for Primate Research, Göttingen

Dr. Dietmar Zinner, Cognitive Ethology Laboratory, German Primate Center Leibniz Institute for Primate Research, Göttingen

Dr. Claudia Fichtel, Behavioral Ecology and Sociobiology Unit, German Primate Center Leibniz Institute for Primate Research, Göttingen

\section{Members of the Examination Board}

First reviewer: Prof. Dr. Peter Kappeler

Second reviewer: PD Dr. Oliver Schülke, Department of Behavioural Ecology, Johann-FriedrichBlumenbach Institute of Zoology and Anthropology, University Göttingen

Further members of the Examination Board:

Prof. Dr. Mark Maraun, Johann-Friedrich-Blumenbach Institute of Zoology and Anthropology, University Göttingen

Dr. Claudia Fichtel

Dr. Tanya Behne, Department of Developmental Psychology, Georg-Elias-Müller-Institute of Psychology, Georg-August University Göttingen

Dr. Dietmar Zinner

Date of the oral examination: 13.02.2020 


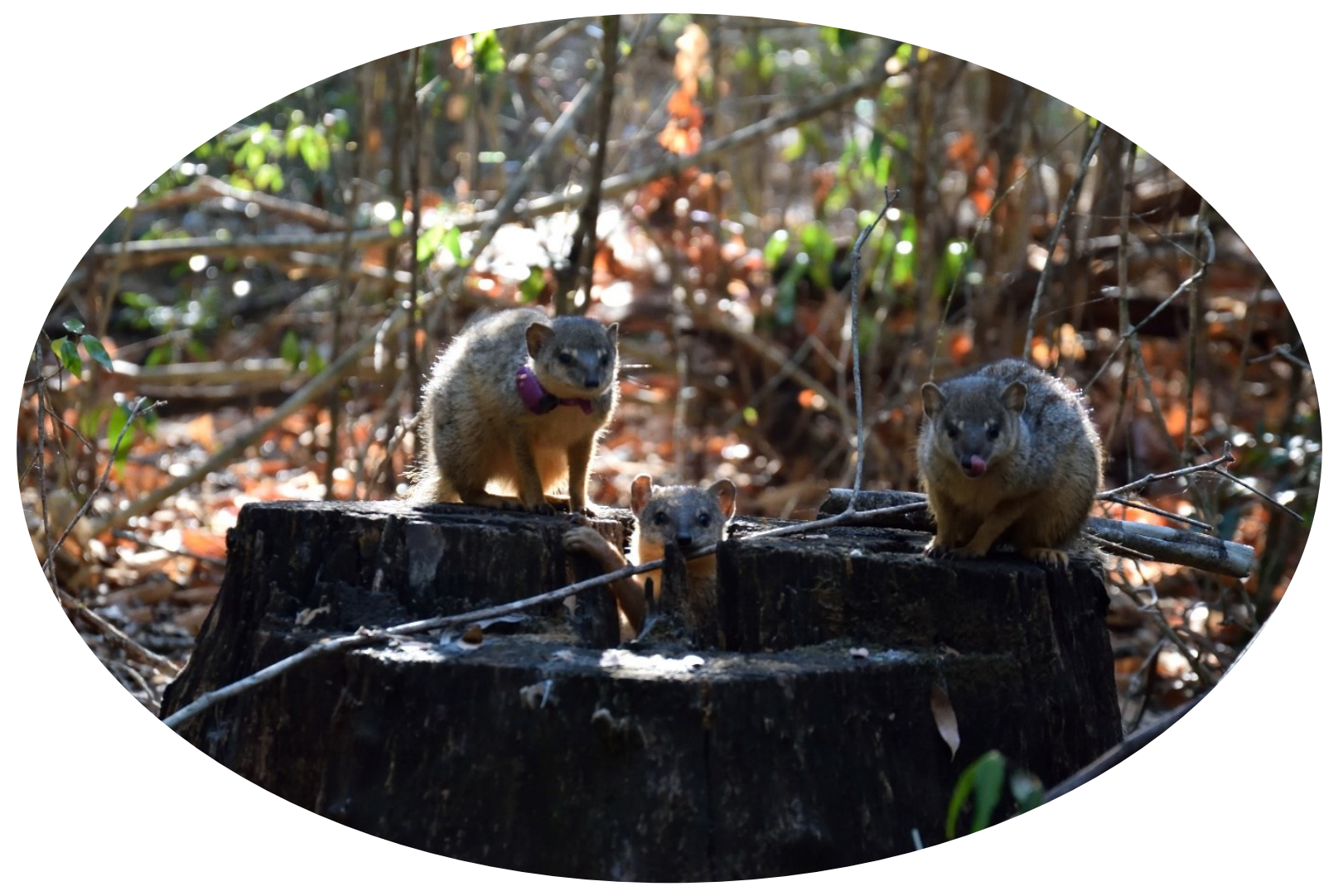




\section{Table of Contents}

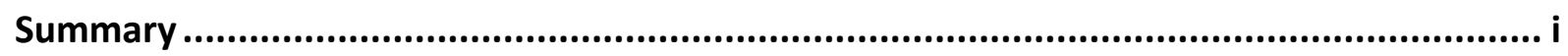

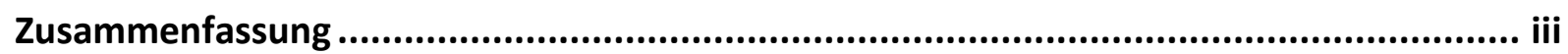

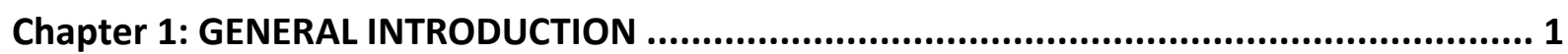

Evolution of cognition and individual differences in cognitive performances..................... 2

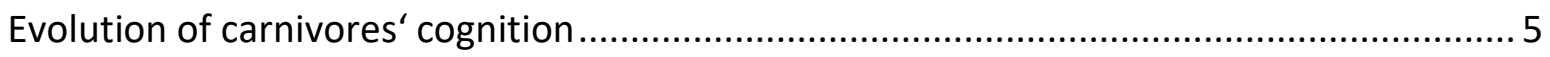

Confounding variables driving individual differences in cognitive performances ............... 7

Cognitive traits' candidates for the psychometric test battery ….................................. 8

Study species: narrow-striped mongooses (Mungotictis decemlineata - grandidier, 1867)11

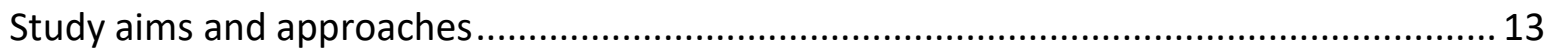

Chapter 2: Wild narrow-striped mongooses use social information to enhance behavioural

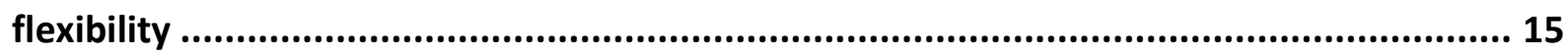

Chapter 3: Trial-and-error, but not causal performance, supports problem solving in an extractive forager carnivoran species ................................................................ 30

Chapter 4: Neophobia and social facilitation in narrow-striped mongooses .................... 53

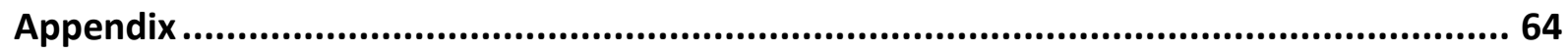

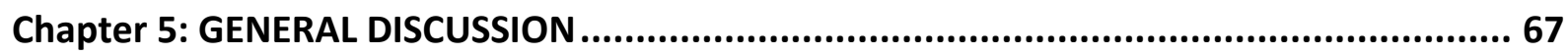

Individual differences in cognitive performances in narrow-striped mongooses ..............67

Relationship between neophobia and individual cognitive performances ...................... 71

Comparison to the cognitive abilities of other Carnivore species .................................... 72

Estimation of general intelligence factor " $\mathrm{g}$ " in the $M$. decemlineata ................................. 74

Conclusion and reflections regarding to the evolution of intelligence in carnivores .......... 75

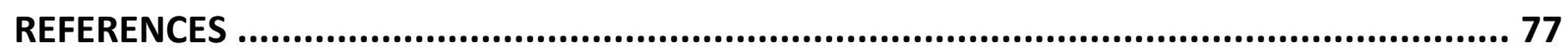

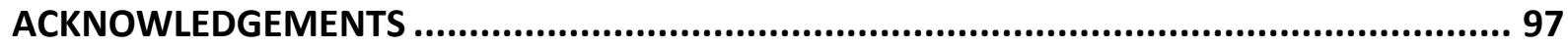

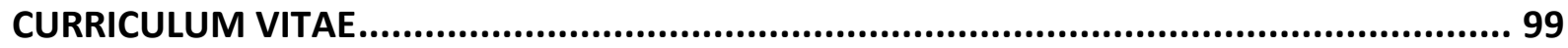

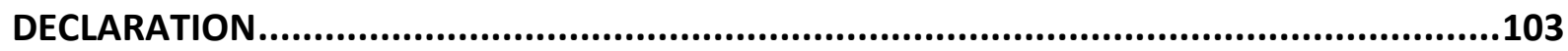





\section{Summary}

Carnivores include a wide variety of species that differ in social organization and brain-size, but these two characteristics do not seem to be linked to each other. Additionally, previous studies found no evidence of relationship between social organisation and cognitive abilities in carnivores since solitary and social species exhibited similar cognitive performances. Therefore, the social intelligence hypothesis, which assumes that the demand for sociality influenced the increase in brain-size, was rejected to not explain the evolution of intelligence fully in carnivores. Besides, carnivores exhibit a diversity of ecological adaptations, by inhabiting a diverse type of habitat. Their challenging environment was assumed to have boosted the evolution of intelligence within this taxon, which is supported by the cognitive buffer hypothesis stating that larger brain size evolved in response to harsh environment. However, despite the great diversity found among carnivores in terms of socio-ecological characteristics, most studies on cognition focused on comparing species with similar habitat, not allowing disentangling the primary factor driving the evolution of cognition. Investigating the cognitive abilities of species that exhibit socio-ecological characteristics different to the species that have been addressed previously could help elucidate the evolution of carnivore cognition.

Therefore, in this thesis, I provide new comparative data by examining the cognitive abilities of the narrow-striped mongooses (Mungotictis decemlineata), a Malagasy carnivores species, which is group living and inhabits a dry tropical forest. The aim of this thesis was to add data on the missing aspect of the existing studies on carnivores' cognition so far and to test $M$. decemlineata in a range of cognitive traits covering domain-general cognition, social cognition, and physical cognition. An essential step in the investigation of the evolution of intelligence consists of evaluating individual differences in cognitive abilities and their underpinning proximate factors. For this, I investigated the factors underlying individual differences in cognitive performances. I assessed individuals' cognitive abilities in a wild setting in an individually marked population of narrow-striped mongooses. The study was conducted in Kirindy Forest, Western Madagascar. From 2014 to 2017, to test cognitive abilities, I established a psychometric test battery whose tasks addressed cognitive traits involved in behavioural flexibility, inhibitory control, innovation problem-solving, social learning, and causal understanding. Additionally, to measure personality traits, I conducted 
novel object tests assessing individuals' neophobia. In total, I could test depending on the experiment up to 33 narrow-striped mongooses. To maximise the possibility of testing the individuals, only female narrow-striped mongooses were considered in this study. Since female narrow-striped mongooses were tested in their home ranges in a group set-up, the effect of social learning on cognitive performances was also examined.

I found that narrow-striped mongooses performed well in behavioural flexibility, innovative problem solving, social learning, and causal understanding. Additionally, inhibitory control promoted learning in narrow-striped mongooses. However, the effect of neophobia on individual performances differed between cognitive tasks. Neophobia did not covary with individuals' performances during the behavioural flexibility experiments and problem-solving tasks. Whereas, in the social learning task, less neophobic individuals were better at solving the task. Possible explanation for the variability of the direction of the relationship between personality traits and cognitive performance might be that there are other related factors such as intrinsic factors underlying this relationship. Future studies should take into consideration these proximate factors when examining the relationship between personality traits and cognitive performance.

Individuals utilised social information in order to switch the previously learned contingencies during the behavioural flexibility task. Additionally, the use of social information facilitated learning in the social learning task, and the presence of skilled individuals improved the learning of naïve individuals. This reliance of female narrow-striped mongooses on social learning appears to be related to the fact that they live in stable group and synchronise their activity continuously.

In conclusion, $M$. decemlineata performed comparably in the addressed cognitive domains not only to meerkats (Suricata suricatta), a closely related African carnivore taxon, but also to other carnivore species, such as spotted hyenas (Crocuta crocuta), racoons (Procyon lotor), and wolves (Canis lupus). Thus with this study, I contributed to the investigation of cognition in carnivores by providing new comparative data. In the future, research should consider more interspecific comparisons, and studies should analyse the indepth link between individuals' cognitive abilities, natural behaviours, ecological and lifehistory factors, as well as fitness in order to understand fully how intelligence in carnivores evolved. 


\section{Zusammenfassung}

Die Ordnung der Raubtiere (Carnivora) beinhaltet eine Vielzahl von Arten, die sich in ihrer sozialen Organisation und Gehirngröße unterscheiden. Gemäß der Social Intelligence Hypothesis sind Arten, die in größeren Sozialverbänden leben, besonders intelligent und haben im Laufe der Evolution ein größeres Gehirn entwickelt. Bei den Raubtieren scheinen diese Zusammenhänge allerdings nicht zu bestehen. Bisherige Studien konnten keinen Zusammenhang zwischen sozialer Organisation und kognitiven Fähigkeiten finden, da solitäre und gruppenlebende Arten in kognitiven Experimenten gleich abschnitten, d.h. die Social Intelligence Hypothesis kann die Evolution der Intelligenz der Raubtiere nicht erklären. Raubtiere verfügen außerdem über vielfältige ökologische Adaptionen, da sie in unterschiedlichen Arten von Habitaten vorkommen. Diese herausfordernden Lebensräume sollen die Evolution der Intelligenz innerhalb des Taxas angetrieben haben, denn gemäß der Cognitive Buffer Hypothesis entwickeln Arten im Laufe der Evolution ein größeres Gehirn als Antwort auf anspruchsvolle Umweltbedingungen. Trotz dieser großen Vielfalt der sozioökologischen Eigenschaften der Raubtiere konzentrieren sich die meisten kognitiven Studien darauf, Arten mit gleichen Habitaten zu vergleichen und können daher den primären Faktor, der ihre kognitive Evolution antreibt, nicht bestimmen. Wenn wir jedoch die kognitiven Fähigkeiten von Arten untersuchen die andere sozio-ökologischen Eigenschaften haben als die bisher untersuchten Arten, kann dies helfen die kognitive Evolution der Raubtiere zu verstehen.

Mit meiner Doktorarbeit trage ich deshalb zu den bisherigen Studien über Kognition bei Raubtieren neue Vergleichsdaten bei, indem ich die kognitiven Fähigkeiten einer madagassischen Raubtierart, dem Schmalstreifenmungo (Mungotictis decemlineata), untersuche. $M$. decemlineata ist gruppenlebend und kommt in trockenen, tropischen Wäldern vor. Das Ziel meiner Arbeit war es, M. decemlineata in verschiedenen kognitiven Fähigkeiten zu testen, welche die Bereiche domaingenerelle, soziale und physikalische Kognition abdecken. Ein wichtiger Schritt bei der Erforschung der Evolution der Intelligenz besteht darin, individuelle Unterschiede in kognitiven Fähigkeiten und die proximaten Ursachen, die diesen Unterschieden zugrunde liegen, zu untersuchen. Daher, habe ich mögliche Faktoren untersucht, die individuelle Unterschiede in den kognitiven Fähigkeiten verursachen könnten. 
Die Studie wurde in Kirindy Forest, im westlichen Madagaskar von 2014 bis 2017 durchgeführt. Es wurden wildlebende, individuell markierte Schmalstreifenmungos direkt in ihren Streifgebieten im Freiland in ihren kognitiven Fähigkeiten getestet. Dafür habe ich eine psychometrische Testbatterie etabliert, deren Tests Verhaltensflexibilität, inhibitorische Kontrolle, innovatives Problemlösen, soziales Lernen und kausales Verständnis umfassen. Des Weiteren habe ich einen Novel Object Test durchgeführt, um die Neophobie der Tiere zu testen. Alles in allem konnte ich je nach Kognitionstest bis zu 33 Schmalstreifenmungos testen. Nur weibliche Schmalstreifenmungos wurden getestet, um die Testmöglichkeiten in den natürlichen Streifgebieten zu erhöhen. Da die Weibchen in ihren Gruppen getestet wurden, habe ich auch den Effekt von sozialem Lernen auf die kognitive Performanz der Tiere in den Experimenten untersucht.

Meine Ergebnisse zeigen, dass Schmalstreifenmungos gute Fähigkeiten in Verhaltensflexibilität, innovatives Problemlösen, soziales Lernen und kausales Verständnis haben. Inhibitorische Kontrolle erleichterte das Lernen der Individuen. Wie sich Neophobia auf das Abschneiden der Tiere in den kognitiven Tests auswirkte war jedoch vom kognitiven Test abhängig. Neophobie kovarierte nicht mit der Perfomance im Verhaltensflexibilitätstest und Problem Lösungen Experimente. Im Gegensatz dazu, waren weniger neophobe Individuen besser im sozialen Lernen. Eine mögliche Erklärung hierfür ist, dass die Art der Beziehung zwischen Persönlichkeitsmerkmalen und kognitiver Leistung in den Tests sehr variabel sein kann und von anderen, verwandten Faktoren wie z.B. intrinsischen Faktoren abhängig sein kann. Zukünftige Studien sollten daher diese proximaten Faktoren berücksichtigen, wenn sie den Zusammenhang von Persönlichkeitsmerkmalen und Kognition untersuchen.

Die Individuen benutzten soziale Information um flexibel im Verhaltensflexibilitätstest zu lernen. Auch beim sozialen Lernen nutzen die Tiere soziale Information und die Anwesenheit von fähigen Tieren, die bereits im Test gelernt hatten, erleichterte das Lernen für unerfahrene Tiere. Der Gebrauch von sozialem Lernen bei den weiblichen Schmalstreifenmungos scheint mit der Tatsache zusammenzuhängen, dass sie in stabilen sozialen Gruppen leben und ihre Aktivitäten synchronisiert haben.

Meine Arbeit zeigt, dass $M$. decemlineata in den getesteten kognitiven Fähigkeiten nicht nur vergleichbar mit den Erdmännchen (Suricata suricatta), einer nahverwandten afrikanischen Raubtierart, sondern auch vergleichbar mit anderen Raubtierarten wie 
Tüpfelhyänen (Crocuta crocuta), Waschbären (Procyon lotor) und Wölfen (Canis lupus) abschneidet. Daher unterstützen die Ergebnisse dieser Doktorarbeit tragen zur Erforschung der Kognition bei Raubtieren bei, indem ich neue Vergleichsdaten bereitstelle. Zukünftige Studien sollten sich auf interspezifische Vergleiche konzentrieren und im Detail die Verbindung zwischen kognitiven Fähigkeiten, Verhalten, ökologischen und life history Faktoren sowie Fitness untersuchen, um letztendlich die Evolution der Intelligenz der Raubtiere vollständig verstehen zu können. 


\section{Chapter 1: GENERAL INTRODUCTION}

How cognition evolved is one of the main questions of behavioural ecologists and thus, in the last decade many studies have been performed to shed a light on. One primary step to understand the evolution of cognition is to examine individual differences in cognitive performances within a population. This attempt allows understanding the mechanisms underlying cognitive abilities, how cognitive abilities are shaped by the socio-ecological traits of species and shape functional behaviours, and how they relate to fitness (Thornton et al. 2014; Rowe and Healy 2014; Boogert et al. 2018). Additionally, within species, individuals are known to differ considerably in their cognitive abilities due to influences of cognitive or noncognitive factors, pointing out how selection might act on cognitive traits (Rowe and Healy 2014; Boogert et al. 2018).

Another step that can be performed to comprehend the evolution of cognition is to examine cognition across a diverse range of taxa, which enables researchers to carry out comparative studies (Plotnik and Clayton 2015). For instance, most studies investigated cognitive abilities across a range of cognitive domains in primate and bird taxa (for example: Auersperg et al., 2014; Beran and Hopkins, 2018; Bugnyar, 2013; Griffin et al., 2014; MacLean et al., 2014; Schmitt et al., 2012), while in the carnivore taxa only some species were examined in few cognitive domains (e.g., Daniels et al., 2019; Johnson-Ulrich et al., 2018; Thornton and Samson, 2012). Likewise, in reptiles, cognitive studies have only emerged recently (e.g., Noble et al. 2012; Damas-Moreira et al. 2018). In order to investigate a range of cognitive domains, the establishment of psychometric test battery is a powerful tool to assess individual differences in cognitive abilities (Thornton et al. 2014; Shaw and Schmelz 2017). A psychometric test battery is a systematic approach to examine cognitive traits belonging to the physical and social domains relevant to the socioecological characteristics of a given species (Herrmann et al. 2010; Schmitt et al. 2012; Krasheninnikova et al. 2019), but also cognitive traits addressed in experimental psychology, for example in the domain-general cognitive abilities (Isden et al. 2013; Morand-Ferron et al. 2016). Besides, examining the influences of confounding variables such as individual characteristics on cognitive performances enables one to thoroughly understand the causes of individual differences and the structure of cognition, i.e. how different cognitive traits relate to each other (Morand-Ferron et al. 2016; Völter et al. 2018). In addition to using psychometric test 
batteries, conducting cognitive experiments in a wild setting is put forward, as it allows identifying cognitive traits that might be relevant to the ecology of the tested species (Thornton et al. 2014). Therefore, the present study will contribute to this field of research by conducting a psychometric test battery involving several cognitive tasks targeting different aspect: such as examining cognitive traits belonging to the physical and social domains and considering aspects such as performances in the domain-general cognition. Moreover, factors driving individual differences in cognitive performances will be the main focus of this dissertation.

The overall goal of this dissertation is to evaluate cognitive performances across several cognitive domains or aspects of cognition in a carnivore group-living species and to examine influences that might affect these cognitive performances. In the following sections, I will start by describing the evolution of cognition and the necessity to examine individual differences in cognitive abilities. Then, I will review what is known concerning cognition among the carnivore taxon, and I will highlight why it is important to address this research in carnivores. Next, I will discuss relevant cognitive domains for species that are related to their socio-ecological traits. After, I will focus on the potential proximate factors that might underpin individual differences in cognitive performances. After that, I will emphasize why the narrow-striped mongoose (Mungotictis decemlineata), a carnivore species, is a candidate model for addressing the primary goal of this research. Finally, I will present the objectives and predictions, as well as the structure of my dissertation.

\section{Evolution of cognition and individual differences in cognitive performances}

Cognition is defined as the neuronal processes underlying perception, acquisition, retention, and use of information (Shettleworth 2009). From an evolutionary perspective, cognitive abilities have been shaped by non-social and social selective pressures, ultimately allowing animals to better survive in their ecological niche and to maximize their fitness (Holekamp 2007; Dunbar and Shultz 2007). Consequently, depending on the selective pressures, cognitive abilities fall into physical and social domains. In the physical domain, cognitive skills refer to the physical understanding of the environment, and are underpinned by the necessity of finding and acquiring food, and dealing with problem-solving, such as foraging technique (Plotnik and Clayton 2015). While in the social domain, cognitive abilities evolved under the pressure of social behaviours such as cooperation and competition (Byrne 1996). 
These cognitive abilities are involved in the perception and the understanding of the relationship with conspecifics, as well as in learning from conspecifics (Tomasello 2000; Plotnik and Clayton 2015; Wascher et al. 2018).

Over decades, cognitive abilities have been investigated mainly through studying brain size (Deaner et al., 2007; Kotrschal et al., 2013; Pérez-Barbería et al., 2007; Street et al., 2017). Indeed, larger brain size has been associated with superior cognitive abilities, as it possesses higher computational power to process information (e.g., Kotrschal et al. 2013; Buechel et al. 2018; Horschler et al. 2019). Ecologically, having a larger brain size has been seen as advantageous in several aspects such as influencing behavioural responses (e.g., van der Bijl et al. 2015), allowing to infer higher ability to colonise new environments in birds (Sol et al. 2005; Fristoe et al. 2017), to increase survival (Kotrschal et al. 2015) and to reduce extinction risks in carnivores (Abelson 2019). Several non-exclusive and complementary hypotheses explaining the link between the evolution of cognition at the inter-specific level, brain-size, and species' socioecological characteristics have been suggested. First, the "general intelligence hypothesis" suggests that species with larger brains have evolutionary advantages by being cognitively more efficient than other species (Deaner et al., 2007). Next, the "ecological intelligence hypothesis" states that cognitive demands in response to the fluctuating environment, diet, distribution of high-value food, and the use of extractive foraging, were the driving force in brain size evolution (Holekamp 2007; Rosati 2017). For instance, food-hoarding species exhibit higher performance in spatial memory (e.g., Smulders et al., 2010). This assumption is also supported by the "foraging hypothesis," which states that species with sizeable dietary breath or generalists should rely on high cognitive abilities due to their use of a variety of foraging techniques (Benson-Amram and Holekamp 2012; Vonk and Beran 2012; Vonk et al. 2012; MacLean et al. 2014). Not dissimilar, the "cognitive buffer hypothesis" suggests that enlarged brains confer advantages to individuals by having higher behavioural flexibility or general intelligence, allowing coping with environmental challenges (Sol 2009; Sol et al. 2016a). Additionally, the "social intelligence hypothesis" (also called "social brain hypothesis") suggests that individuals living in stable groups developed greater intelligence in response to the cognitive demands that come along with the constraints of group living, such as competition, cooperation, and coordination among group members (Byrne 1996; Dunbar and Shultz 2007, 2017; Pérez-Barbería et al. 2007; Amici et al. 2008). Initially, more complex social groups were proposed to favour 
higher social intelligence compared to less complex social groups (Dunbar and Shultz 2007; Johnson-Ulrich 2017). However, many comparative studies on various taxa have found mixed findings on the social intelligence hypothesis, such as positive correlations between relative brain size (or neocortex size) and group size in primates (MacLean et al. 2013; Dunbar and Shultz 2017), mating systems in bats (Pitnick et al. 2006), pair bonds in birds (Fedorova et al. 2017), and monogamy in fish (Pollen et al. 2007). Moreover, the social intelligence hypothesis is well supported in primates, as several studies showed that sociality co-evolved with brain size (Reader et al. 2011; Seyfarth and Cheney 2015; Street et al. 2017). However, in carnivores, for example, the social intelligence hypothesis failed to explain the difference of performances found across carnivores, and instead, the cognitive buffer hypothesis was suggested to best explain the evolution of intelligence in this taxa (Vonk 2016a; Holekamp and Benson-Amram 2017).

However, brain size is not always an available tool for estimating cognitive abilities, especially considering comparative studies across taxa. Besides, cognitive processes are challenging to observe in nature, therefore, the use of experimental tasks represents a pivotal option to measure cognitive performance (Thornton et al. 2014; Rowe and Healy 2014). Another approach to investigate the evolution of cognition is to understand the mechanisms underpinning variation in cognitive abilities at the individual level. Indeed, studying cognitive abilities at the individual level is a crucial step permitting to quantify and to evaluate relationships between factors and cognitive performances, and this relationship might reflect how selection acts on cognitive abilities (Rowe and Healy 2014; Boogert et al. 2018). One approach advocated to comprehend the evolution of animals' cognitive abilities is the use of a psychometric test battery, which involves several experiments dealing with different cognitive domains (Thornton et al. 2014; Shaw and Schmelz 2017). Also, assessing cognitive abilities of animals in their natural habitat became more crucial in the last years due to the ecological validity, which has associated opportunities to identify potential fitness consequences of cognitive abilities (Isden et al. 2013; Thornton et al. 2014).

Conducting a psychometric test battery also allows identifying whether a single general intelligence factor ("g" factor) underlies the variation in performances among the individuals of a given species, which represents the structure of the measured cognitive abilities (Shaw et al. 2015; Arden and Adams 2016). The "g" factor is commonly known from cognitive studies in humans. It is linked to better life outcomes in humans, such as health 
status, life expectancy, and brain resilience (e.g., Deary et al. 2010). Due to this critical relationship of the " $\mathrm{g}$ " factor with fitness proxies, it would be interesting to know whether there is a structure of cognitive abilities underpinning cognitive abilities in non-human animals. Many studies started to investigate the presence of the " $\mathrm{g}$ " factor in non-human animals and demonstrated its presence in few taxa (mice: (Galsworthy et al. 2002); chimpanzees: (Banerjee et al. 2009); dogs: (Arden and Adams 2016); birds: (Isden et al. 2013; Shaw et al. 2015)). However, the presence of the " $g$ " factor in non-human animals remains much debated because of the methodologies used to assess the " $\mathrm{g}$ " factor (Burkart et al. 2016; van Horik et al. 2018). However, the " $\mathrm{g}$ " factor is not the main scope of this dissertation and will be addressed preliminarily in further chapter.

\section{Evolution of carnivores' cognition}

The explanation of the evolution of intelligence in carnivores is still disputed. Carnivores do not show a clear-cut relationship between relative brain size and sociality (Dunbar and Shultz 2007a; Pérez-Barbería et al. 2007; Finarelli and Flynn 2009), although they include species that vary mainly in both, relative brain size and social organisation (Holekamp et al. 2007; Finarelli and Flynn 2009; Schneider and Kappeler 2014). Besides, in carnivores, the direction of the relationship between sociality and cognitive performances is mixed. Indeed, in a study comparing social cognitive performances between spotted hyenas (Crocuta crocuta) and cercopithecine primates, performances in social cognition in these two taxa were found to converge (Holekamp and Benson-Amram 2017). Spotted hyenas exhibited similar social cognitive abilities to the cercopithecine primates, such as kin recognition and cooperation, supporting the social brain hypothesis (Holekamp and Benson-Amram 2017). However, when aspects of general intelligence cognition, that involves nonsocial cognition, are considered, findings are mixed. For instance, carnivore species with larger brain size, but solitary, demonstrated higher cognitive performances and were comparable to the performances of apes in nonsocial discrimination task and categorisation task (e.g., Vonk and Galvan, 2014; Vonk and Johnson-Ulrich, 2014). In a social discrimination task, though, bears (Ursus americanus) failed to solve the task compared to chimpanzees (Pan troglodytes) (Vonk and Johnson-Ulrich 2014).

Moreover, in a study comparing problem-solving performances in several species of carnivores, brain-size relative to body size predicted success in solving the tasks and not 
sociality (Benson-Amram et al. 2016). On the contrary, in a study comparing performances of social carnivores with solitary carnivores in a problem-solving task, social species were better problem solvers than the solitary ones (Borrego and Gaines 2016). Indeed, social species [lions (Panthera leo) and spotted hyenas] displayed better performances in solving innovative problem-solving tasks compared to asocial species [leopards (Panthera pardus) and tigers (Panthera tigris)]. Furthermore, sociality was found to be associated with innovative performances. Therefore, the authors argued that the good performances of social carnivores in the nonsocial task suggest that social carnivores show good performances in cognitive abilities linked to social and ecological problems.

Together, the absence of a correlation between brain-sizes and social organisations, and the mixed variation on the relationship between sociality and cognitive performances in carnivores call in question the application of the social intelligence hypothesis for this taxon. A recent study suggested that the cognitive buffer hypothesis (hereafter $\mathrm{CBH}$ ) best explains the evolution of general intelligence in carnivores (Holekamp and Benson-Amram 2017). The $\mathrm{CBH}$ posits that large brains evolved to cope with the socio-ecological challenges in the environment (Sol 2009; Sol et al. 2016a). Moreover, the CBH suggests that large brains facilitate the production of behaviours through domain-general cognition (i.e., learning and innovation) in order to cope with ecological challenges (Sol 2009). For that, the CBH seems to support the mixed findings on domain-general cognitive performances and brain sizes on carnivores as mentioned previously.

As predicted by the $\mathrm{CBH}$, species living in challenging habitats will exhibit advanced cognitive abilities in the domain of general intelligence. For instance, raccoons (Procyon lotor) that inhabit urbanised areas possess high behavioural flexibility (Daniels et al. 2019). Besides, carnivores inhabit a variety of habitats, such as savannah (e.g., hyenas), forest (e.g., bears), and urbanised habitats (e.g., racoons), and exhibit variation of cognitive performances spanning in the domain-general cognition and domain-specific cognition like social cognition. Most of the cognition studies were conducted in social species inhabiting open habitat (e.g., hyenas (Benson-Amram and Holekamp 2012), meerkats: Suricata suricatta (Thornton and Samson 2012)), in solitary species inhabiting closed habitat (e.g., black bears (Vonk and Beran 2012)), and in species inhabiting the urbanised area (e.g., raccoons (Stanton et al. 2017)). However, the cognitive abilities of social carnivores' species inhabiting forest habitat remain untested, allowing to test whether their cognitive 
adaptations differ. Thus, the actual study will contribute to comparative data respective to this aspect.

\section{Confounding variables driving individual differences in cognitive performances}

Cognitive performances can be influenced by non-cognitive factors driving individual differences (Thornton and Lukas 2012; Morand-Ferron et al. 2016; Boogert et al. 2018). One major non-cognitive factor is personality traits, which are acknowledged to influence individuals' cognitive abilities (Carere and Locurto 2011; Sih and Del Giudice 2012; Griffin et al. 2015). Personality traits refer to an individual reaction to environmental stimuli that fall in either positive response - attraction or negative response - avoidance, with these variants being categorised either fast types or slow types (Réale et al. 2007). Personality traits are stable behavioural differences consistent over time, which are influenced by different facets of the ecology and the biology of animals, and influence the probability of survival, and shape life-history (Reale et al. 2010). Indeed, personality traits affect individuals' learning strategies and how individuals respond to change (Dall et al. 2004; Sih and Del Giudice 2012). Specifically, proactive individuals are fast learners, routine-like or rigid in facing changes, and risk-prone; while reactive individuals are slower learners but more flexible in adapting to changes, and risk aversive (Coppens et al. 2010; Sih and Del Giudice 2012).

For instance, neophobia, which is the avoidance of novel stimuli, has ecological importance for species as it has a primary benefit against danger in a high-risk environment (Greggor et al. 2015; Crane and Ferrari 2017). Indeed, individuals exhibiting higher neophobia can avoid risky encounters or costs from learning, such as traveling or sampling, and increase their survival consequently (Greenberg 2003). However, being neophobic can also have adverse effects, as neophobia hampers the probability of learning, the exploration of new resources, and influences an individual's competitive ability negatively (Greenberg 2003; Cole and Quinn 2012). Mainly, neophobia is known to hinder an individual's learning ability, thus, more neophobic individuals will display weaker learning performances (Sih and Del Giudice 2012). In group-living animals, the negative effect of neophobia on learning can be overcome by social facilitation and social information (Forss et al. 2017). Indeed, individuals' latency to approach novel stimuli could be reduced in a group context due to shared risk (e.g. (Thornton and Samson 2012; Benson-Amram and Holekamp 2012). 
Moreover, neophobic individuals may profit from the presence of skilled individuals to learn faster. For instance, in blue-tits (Cyanistes caeruleus), naïve individuals were able to solve a task in the presence of demonstrators compared to individuals belonging to groups without demonstrators (Aplin et al. 2013).

Persistence or task-directed motivation is another category of personality trait that is underpinned by necessity and feeding motivation, and is well known to drive individual differences in problem-solving performances (Guez and Griffin 2016; Madden et al. 2018; Amici et al. 2019). Defined as the engagement of an individual to a problem-solving apparatus, independently of specific motor action, persistence is mostly associated with proactive personality traits (Guez and Griffin 2016). Persistence is suggested to be the key for problem-solving because increased persistence mostly enhances the problem-solving ability and the generation of novel behaviour (Benson-Amram and Holekamp 2012; reviewed in Griffin and Guez 2014). Indeed, the more persistent an individual is in manipulating the problem-solving apparatus can potentially increase the probability of finding a solution for a task than at less persistent individual. Moreover, persistence is seen as effective as learning because of the same result it provides on solving problems or generating new behaviour, therefore, putting into question the cognition behind problemsolving tasks (Thornton and Samson 2012; Guez and Griffin 2016).

\section{Cognitive traits' candidates for the psychometric test battery}

As ecology and sociality shaped cognitive skills necessary in the functional behaviours of a species, it is necessary to include aspects of domain-general cognition and domain-specific cognition relating to the species' socio-ecological characteristic (Sol 2009; van Horik and Emery 2011; Rosati 2017). Domain-general cognition refers to cognitive abilities that encompass several domains, which allows individuals to respond rapidly and flexibly to changes in their environment, to develop new behaviours and to solve problems (van Horik and Emery 2011; Auersperg et al. 2012). In contrast, domain-specific cognition, for example, social cognition, is expected in social species because of the need of the individuals to deal with the advantages and costs of social interactions (Johnson-Ulrich 2017). Due to their ecological relevance for a given species, it is, therefore, crucial to consider these cognitive domains in designing test batteries. 


\section{Domain general cognitive abilities}

Behavioural flexibility is an aspect of cognition linked to enhanced domain-general cognitive ability, allowing individuals to adapt their behaviours flexibly according to the changes in their habitat (Sol 2009; Mikhalevich et al. 2017). Behavioural flexibility is involved in decision-making in either ecological or social context (Shettleworth 2001; Chittka et al. 2009). Besides, executive function is complementary to behavioural flexibility (Tapp 2003; Amici et al. 2008). Executive function is per definition a combination of cognitive abilities, such as inhibitory control and working memory, allowing individuals to flexibly control their behaviours (Tapp 2003; Chiappe and MacDonald 2005; Horschler et al. 2019). One main component of executive function is inhibitory control, which is the ability to inhibit prepotent behaviour (MacLean et al. 2014). Inhibitory control is involved in many different processes, either ecological or social. On the one hand, inhibitory control is suggested to be strongly linked to the ecological niche of a species (Rosati 2017). For instance, in a comparative study on the inhibitory control capacity of several primate species, inhibitory control was strongly predicted by the species' dietary breadth, with species characterised with larger dietary breadth having better inhibitory control (MacLean et al. 2014). This result was explained to be due to the fact that species with larger dietary breadth may show higher cognitive flexibility, as they exploit a large variety of food (MacLean et al. 2014).

Individuals vary in their flexibility, therein influencing their learning strategies or cognitive styles (Sih and Del Giudice 2012). Individual differences in behavioural flexibility are mostly acknowledged to be influenced by personality traits, which spread along the proactive-reactive behavioural axis (Réale et al. 2007; Carere and Locurto 2011; Sih and Del Giudice 2012; Greggor et al. 2015). For instance, proactive individuals are known to be faster in learning when encountering a new situation, while reactive individuals are more cautious and take more time in learning. However, when it comes to an altered situation, reactive individuals become faster learners, as they do not form routines like proactive individuals (Sih and Del Giudice 2012). Several studies revealed these patterns [e.g. (Guenther et al. 2014; Gibelli and Dubois 2017; Mazza et al. 2018)], but contrary findings were also described [e.g. (Logan 2016a; Guido et al. 2017; Madden et al. 2018)], suggesting no clear-effect of personality traits on behavioural flexibility to date. However, most of the studies were conducted on group-living species without considering the possible effect of social settings on an individual's performance to be behaviourally flexible. Social context, though, can 
influence individuals' personality traits (Webster and Ward 2011; Greggor et al. 2016b), and cognitive abilities (Griffin and Guez 2015; Dalesman 2018). Hence, in my research here, I will provide insight into understanding how individual behavioural flexibility performances vary in a social context.

The ability to generate new behaviour is another proxy for domain-general cognition (Sol et al. 2016b). Innovation is the ability to provide a new solution to a new problem or an old problem when the solution is outdated (Lefebvre 2011; Auersperg et al. 2012). Innovation rate was linked to enhanced brain size, survival rate, and colonisation of new habitat (Lefebvre et al. 1997; Reader 2003; Sol et al. 2005). It is supported by the "technical intelligence hypothesis," which proposes that the presence of diverse technical skills involved in solving ecological problems (i.e., foraging) drove brain-enlargement (Overington et al. 2009; Navarrete et al. 2016). Behavioural innovation ability was identified in diverse taxa, especially with the assay of problem-solving (Isden et al. 2013; Griffin and Guez 2014). However, the mechanism underpinning performance in problem-solving is still disputed, as in most studies it resulted from the influence of persistence (e.g., Thornton and Samson 2012; Chow et al. 2016; Madden et al. 2018). Therefore, in my thesis, I will seek to disentangle the process underlying problem-solving abilities.

\section{Physical cognition}

Causal understanding ability is an aspect of physical cognition, which focusses on the understanding of spatial object relationships (Taylor et al. 2010a). Across taxa, causal understanding ability is well investigated in apes and corvids ( $\mathrm{O}^{\prime}$ Connell and Dunbar 2005; Albiach-Serrano and Call 2014; Smirnova et al. 2015; Davidson et al. 2017). However, among the carnivores' taxa, the presence of causal understanding ability is still ambiguous. For instance, dogs failed to show causal understanding probably due to domestication processes (Bräuer et al. 2006), and in racoons (Procyon lotor) the presence of this ability is uncertain as the species exhibited limited performances in a causal understanding task (Stanton et al. 2017). Consequently, in carnivores, the presence of causal understanding ability is limited to date.

Causal understanding ability has been suggested to influence individuals' performances in problem-solving. Especially, it allows making inference about resource location for extractive forager species (Bräuer et al. 2006). Moreover, it is a skill proposed to 
underlie problem-solving abilities (Tebbich et al. 2016). However, in carnivores, a taxon exhibiting good performances in problem-solving abilities (e.g., Thornton and Samson 2012; Benson-Amram and Holekamp 2012), the impact of causal understanding on problemsolving abilities is unknown. This aspect is also lacking for carnivore species characterised with an extractive foraging ecology. Thus, this dissertation will contribute to the state of the art.

\section{Social cognition}

Concerning cognitive abilities in the social domain, social learning is a cognitive skill that is present in almost all group-living animals, even with limited social interactions (Kendal et al. 2010; Riley et al. 2017; Gager 2019). Social learning relies on the transfer of social information between conspecifics, and the use of social information to adapt individual's behaviours in many ecological contexts, leading to the transmission of behaviours across a population (Aplin 2016). Concerning carnivores' social cognition, hyenas exhibited limited social learning because social information accounted only for local enhancement and not for improving individuals' performances (Benson-Amram et al. 2014). This finding is puzzling as hyenas exhibit good performances in other aspect of social cognition such as cooperative problems (Holekamp et al. 2007). However, meerkats (Thornton and Malapert 2009) and banded mongooses (Mungos mungo) (Müller and Cant 2010) show evidence of social learning as individuals tend to perform techniques used by skilled individuals in social diffusion. Moreover, teaching, a highly derived form of social learning, is present in meerkats and banded mongooses. Pups in meerkats learn skills to handle prey by observing adults (Thornton 2006). Likewise, young banded mongooses are likely to imitate the foraging technique exhibited by adult individuals (Müller and Cant 2010). However, from these studies on carnivores mentioned above, patterns of social learning in this taxon appear to be highly variable. Therefore, in this study, I will provide further comparative data in another species of carnivores on the aspect of social cognition.

\section{Study species: narrow-striped mongooses (Mungotictis decemlineata - grandidier, 1867)}

To shed light on the addressed gaps before, investigating individual differences in cognitive performances on a carnivore species with socio-ecological characteristics that were not yet 
considered before would be ideal. This will allow examining whether the $\mathrm{CBH}$ is applying to the explanation of the cognitive performances in other species of carnivores.

The carnivore taxon includes species with a wide variety of social organisations, which inhabit a variety of habitat. However, cognitive studies in carnivores include social species living in open habitat (e.g., Thornton and Samson 2012; Benson-Amram et al. 2014), solitary species living in closed habitat (e.g., Amici et al. 2017) and urbanised areas (e.g., Stanton et al. 2017). Therefore, it would be interesting to examine cognitive abilities in a species differing in socio-ecological characteristics to the species studied before.

Indeed, within the carnivore taxon, the narrow-striped mongoose (Mungotictis decemlineata) is the right candidate for investigating mechanisms underpinning individual differences in cognitive performances due to its socio-ecological characteristics different from the other carnivore species studied previously. The narrow-striped mongoose is a Malagasy carnivore species that belongs to the family of Eupleridae (Veron et al. 2017) and shares a common ancestor with the African mongooses the Herpestidae (Yoder et al. 2003). The narrow-striped mongoose is a forest-dwelling carnivore species with a relatively slow life history (Schneider and Kappeler 2016). Besides, characterised by a sexual segregation organisation, the females live in stable group year-round (called "unit"). These groups follow a matrilineal hierarchy, always den and forage together, while the males roam solitarily during the mating season (Schneider and Kappeler 2016). It would thus be expected that narrow-striped mongooses rely on social information during their activities, to learn from group members, and to coordinate their behaviours. Female narrow-striped mongooses are territorial and occupy exclusive territory with small overlap (Schneider and Kappeler 2016), allowing to relocate the female unit easily for multiple testing sessions. Besides, narrowstriped mongooses inhabit a dry deciduous forest subjected to substantial seasonal variation (Kappeler and Fichtel 2012; Schneider and Kappeler 2016). Species living in heterogeneous habitat, which undergo high seasonal variation, are known to exhibit better cognitive performances (González-Gómez et al. 2015). Therefore, individuals should be able to perform in behavioral flexibility and exhibit inhibitory control in order to manage an encounter with an individual of a different rank, predators, or novel stimuli. Moreover, previous research established that during their daily activities $M$. decemlineata uses both terrestrial and arboreal strata of their habitat and rest in sleeping trees during the night (Albignac 1976). They are opportunistic-generalist and extractive foragers, prey upon a 
variety of species, mainly on arthropods and insect larvae, by digging in the ground or excavating deadwood (Rasolofoniaina et al. 2019). Ecological generalism, especially diet generalism, is a predictor of innovativeness abilities because generalist species might encounter more novelties (Lefebvre et al. 1997; Ducatez et al. 2015b). Moreover, due to their extractive foraging behaviour, narrow-striped mongooses will require causal understanding ability in order to be efficient. Since narrow-striped mongooses undergo relatively significant high predation pressure (Hawkins and Racey 2008; Schneider and Kappeler 2016), individuals are expected to show neophobia when facing novel stimuli.

Furthermore, a wild population of habituated and marked individuals of narrowstriped mongooses is available in their natural habitat, permitting to conduct the cognitive experiments at the individual level.

\section{Study aims and approaches}

The present study will contribute to the field of research of cognition evolution by systematically investigating cognitive performances of a wild group-living carnivore species, M. decemlineata. Particularly, I aim to systematically examine cognitive abilities of M.decemlineata in a range of cognitive traits and to evaluate the proximate factors explaining individuals' variation on these cognitive performances. Furthermore, this investigation will add to existing studies that examined proximate factors influencing individual differences in cognitive performances in the wild. To reach these aims, I will conduct a psychometric test battery in a wild setting, based on replication of several cognitive experiments generally accepted within cognitive psychology and that were carried out in previous works. In order to investigate factors driving individual differences in cognitive performances, I will look primarily at the influence of personality traits, inhibitory control, and social influence on cognitive abilities. To assess personality trait, I will use object neophobia, since the individuals may show avoidance towards novel stimuli. Moreover, the psychometric test battery will be conducted during the dry season, when food is scarce, to attract the individuals during testing more.

In the different chapters of my thesis, I will first focus on the potential factors that might drive individual differences in learning strategies, which is behavioural flexibility (Chapter 2). Second, I will examine the presence of cognitive ability belonging to the social domain in the narrow-striped mongoose, and I will investigate which factors may influence 
the social learning strategy in the species (Chapter 3). Next, I will explore if the species uses cognitive ability belonging to the physical domain in order to enhance problem-solving performances (Chapter 4). In the end, I will review and discuss my findings in the general context (Chapter 5). In detail, the chapters are the following:

In Chapter 2 I will examine the influence of neophobia, inhibitory control, and social influence on behavioural flexibility of narrow-striped mongooses. Specifically, learning and flexibility abilities of narrow-striped mongooses are assessed with a discrimination and reversal learning tasks. This manuscript was submitted to the journal Ethology.

Chapter $\mathbf{3}$ is covering the aspect of physical cognition and its implication in innovative problem-solving in narrow-striped mongooses. I will primarily investigate the influences of causal understanding ability and personality traits on problem-solving performances in extractive foraging tasks.

The focus of Chapter 4 is on the aspect of social cognition. Mainly, I will elaborate on whether narrow-striped mongooses use social learning and which factors influence its social learning strategy. This manuscript was submitted to the journal Animal Cognition.

In Chapter 5 I will summarise the obtained results and discuss them in broader perspectives. Moreover, the limitations encountered during this study and the outlooks will be addressed. 


\section{Chapter 2}

"Wild narrow-striped mongooses use social information to enhance behavioural flexibility"

Bako Rasolofoniaina ${ }^{1}$, Peter M. Kappeler ${ }^{1,2}$, Claudia Fichtel ${ }^{2}$

${ }^{1}$ Dept. Sociobiology/Anthropology, Johann-Friedrich-Blumenbach Institute of Zoology and Anthropology, University Göttingen, Germany

${ }^{2}$ Behavioral Ecology and Sociobiology Unit, German Primate Center Leibniz Institute for Primate Research, Göttingen, Germany

This chapter is published in Ethology (2020) 00: 1-14 https://doi.org/10.1111/eth.13123 


\title{
Wild narrow-striped mongooses use social information to enhance behavioural flexibility
}

\author{
Bako Rasolofoniaina $^{1}$ (D) | Peter M. Kappeler ${ }^{1,2}$ | Claudia Fichtel $^{2}$ (iD
}

${ }^{1}$ Dept. Sociobiology/Anthropology, JohannFriedrich-Blumenbach Institute of Zoology and Anthropology, University of Göttingen, Göttingen, Germany

${ }^{2}$ Behavioral Ecology and Sociobiology Unit, German Primate Center, Leibniz Institute for Primate Research, Göttingen, Germany

\section{Correspondence}

Bako Rasolofoniaina, Dept. Sociobiology/ Anthropology, Johann-Friedrich-

Blumenbach Institute of Zoology and Anthropology, University of Göttingen, Göttingen, Germany.

Email:brasolofoniaina@gmail.com

Funding information

Deutscher Akademischer Austauschdienst, Grant/Award Number: 57129429

Editor: Christian Rutz

\begin{abstract}
Behavioural flexibility allows animals to adapt their behaviour to changing situations in their current habitat. Flexibility is involved in behaviours comprising decision-making in their ecological or social environment. However, the ability to behave flexibly can co-vary with an individual's personality and its level of inhibitory control, so that previous work has not discerned any consistent pattern in the direction of the relationship among these traits. Our aim was, therefore, to examine the influence of neophobia, inhibitory control, and social learning on behavioural flexibility performance in wild narrow-striped mongooses (Mungotictis decemlineata) in Kirindy Forest, Madagascar. To this end, we conducted novel object tests to assess neophobia, a cylinder task to assess inhibitory control, and a discrimination and reversal learning task to quantify behavioural flexibility in a natural group setting. We found that neophobia did not correlate with learning performance either in the discrimination learning task or in the reversal learning task. Further, individuals exhibiting more inhibitory control learned faster during the initial learning task, but not in the reversed task, suggesting that inhibitory control facilitated individuals' learning abilities but not behavioural flexibility. Finally, opportunities for social learning correlated with individuals' performance during the reversal learning task. Thus, in narrow-striped mongooses, social learning seems to facilitate behavioural flexibility, in addition to individual learning, in cognitively more challenging situations, such as a reversal learning condition.
\end{abstract}

\section{KEYWORDS}

behavioural flexibility, carnivores, inhibitory control, Mungotictis decemlineata, neophobia, social learning opportunities

\section{1 | INTRODUCTION}

Cognitive processes from different cognitive domains underlie animals' decision-making and the resulting behavioural output in solving various physical or social problems (Morand-Ferron et al., 2016; Taborsky \& Oliveira, 2012). In particular, animals benefit from behavioural flexibility to manage decision-making in social and non-social contexts (Chittka et al., 2009; Shettleworth, 2001). Behavioural flexibility is an essential cognitive ability that allows animals to adapt their behaviour to current changes in their habitat, such as changes in food availability or predation risk (Audet \& Lefebvre, 2017; Roth \& Dicke, 2005). Behavioural flexibility varies among individuals and is influenced by

This is an open access article under the terms of the Creative Commons Attribution License, which permits use, distribution and reproduction in any medium, provided the original work is properly cited.

(c) 2020 The Authors. Ethology published by Wiley-VCH GmbH. 
variation in personality traits, which are known to influence other cognitive abilities as well (Boogert et al., 2018; Griffin et al., 2015). Depending on the personality type, variants in behavioural flexibility have either been categorised into fast types that form quick routines, or slow types that are more flexible in encountering and re-learning a new situation (Herborn et al., 2014; Réale et al., 2007; Sih \& Del
Giudice, 2012). For instance, neophobia, an ecologically relevant personality trait that reflects how individuals deal with new stimuli such as predators or food (Greggor et al., 2015), is known to hamper learning performance (Webster \& Lefebvre, 2001).

No clear pattern in the direction of the relationship between behavioural flexibility and personality traits has been found to

TAB LE 1 Summary of studies investigating the effect of personality traits on behavioural flexibility using discrimination and reversal learning tasks

\begin{tabular}{|c|c|c|c|c|}
\hline Species & Personality traits & Cognitive task & $N$ individuals & $\begin{array}{l}\text { Socio-ecological } \\
\text { characteristic }\end{array}$ \\
\hline $\begin{array}{l}\text { Bank voles (Myodes } \\
\text { glareolus) }\end{array}$ & Activity and boldness & $\begin{array}{l}\text { Olfactory associative learning } \\
\text { (Y-maze task) }\end{array}$ & 86 & Group-living \\
\hline $\begin{array}{l}\text { Wild cavies and guinea } \\
\text { pigs* (Cavia aperea and } \\
\text { Cavia porcellus) }\end{array}$ & $\begin{array}{l}\text { Boldness, socio-positive } \\
\text { behaviours and } \\
\text { aggressiveness }\end{array}$ & $\begin{array}{l}\text { Symbol associative learning and } \\
\text { reversal learning tasks }\end{array}$ & $\begin{array}{l}21 \text { wild cavies and } 21 \\
\text { guinea pigs }\end{array}$ & $\begin{array}{l}\text { Group-living } \\
\text { *Domestic }\end{array}$ \\
\hline Wild cavies (Cavia aperea) & $\begin{array}{l}\text { Activity, boldness, and } \\
\text { aggressiveness }\end{array}$ & $\begin{array}{l}\text { Symbol associative learning and } \\
\text { reversal learning tasks }\end{array}$ & 18 & Group-living \\
\hline $\begin{array}{l}\text { Woodpecker finches } \\
\text { and small tree finches } \\
\text { (Cactospiza pallida and } \\
\text { Camarhynchus parvulus) }\end{array}$ & Neophobia & $\begin{array}{l}\text { Learned-non reward and } \\
\text { perseverance conditions (each } \\
\text { with discrimination and reversal } \\
\text { learning tasks) }\end{array}$ & $\begin{array}{l}8 \text { woodpecker finches } \\
\text { and } 8 \text { small tree } \\
\text { finches }\end{array}$ & Group-living \\
\hline $\begin{array}{l}\text { Carib grackles (Quiscalus } \\
\text { lugubris) }\end{array}$ & Boldness and neophobia & Colour discrimination task & 21 & Group-living \\
\hline $\begin{array}{l}\text { Chimango Caracara } \\
\text { (Milvago chimango) }\end{array}$ & Neophobia & $\begin{array}{l}\text { Colour discrimination and reversal } \\
\text { learning }\end{array}$ & 11 & Group-living \\
\hline
\end{tabular}

\begin{tabular}{|c|c|c|c|c|}
\hline $\begin{array}{l}\text { Zebra finches (Taeniopygia } \\
\text { guttata) }\end{array}$ & Neophobia & $\begin{array}{l}\text { Two colour discrimination tasks and } \\
\text { one reversal task }\end{array}$ & 22 & Group-living \\
\hline $\begin{array}{l}\text { Pheasants (Phasianus } \\
\text { colchicus) }\end{array}$ & Exploration & $\begin{array}{l}\text { Two discrimination tasks: spatial } \\
\text { location (2014) and colour (2015) } \\
\text { (both including acquisition and } \\
\text { reversal learning phases) }\end{array}$ & In $2014: 80$ / in $2015: 74$ & Group-living \\
\hline $\begin{array}{l}\text { Great-tailed grackles } \\
\text { (Quiscalus mexicanus) }\end{array}$ & $\begin{array}{l}\text { Exploration, risk aversion, } \\
\text { and neophobia }\end{array}$ & $\begin{array}{l}\text { Colour association task and reversal } \\
\text { learning task }\end{array}$ & 8 & Group-living \\
\hline $\begin{array}{l}\text { Red junglefowl (Gallus } \\
\text { gallus) }\end{array}$ & Boldness and exploration & $\begin{array}{l}\text { Alteration of rewarded stimulus } \\
\text { task and intra-maze task (each with } \\
\text { association and reversal learning } \\
\text { tasks) }\end{array}$ & 62 & Group-living \\
\hline
\end{tabular}

$\begin{array}{lllll}\begin{array}{l}\text { Mallards (Anas } \\ \text { platyrhynchos) }\end{array} & \text { Exploration } & \begin{array}{c}\text { X-maze with two tasks: learning and } \\ \text { reinforcement phases }\end{array} & 10 & \text { Group-living } \\ \text { Goats (Capra hircus) } & \text { Exploration and sociability } & \text { Colour discrimination task } & 16 & \text { Domestic } \\ \text { Pigeons (Columba livia) } & \text { Exploration } & \text { Visual discrimination task } & 12 & \text { Group-living }\end{array}$


date, however (Table 1). For instance, in an odour cue association experiment, more active and bolder captive bank voles (Myodes glareolus) learned faster during acquisition learning, whereas less active and shyer individuals learned the reversed contingencies of the task faster (Mazza et al., 2018). In contrast, in a visual discrimination task, less explorative goats (Capra hircus) were better learners than more explorative ones (Nawroth et al., 2017). Moreover, in wild Chimango caracara (Milvago chimango) less neophobic animals performed better in the reversal learning task, but neophobia did not explain individuals' learning performance in the corresponding discrimination learning task (Guido et al., 2017).

\begin{tabular}{|c|c|c|c|}
\hline Testing procedure & $\begin{array}{l}\text { Relationship between personality traits and } \\
\text { performance in discrimination learning task }\end{array}$ & $\begin{array}{l}\text { Relationship between personality traits and } \\
\text { performance in reversal learning task }\end{array}$ & Reference \\
\hline Alone & $\begin{array}{l}\text { More active and bolder individual learned } \\
\text { faster }\end{array}$ & Less active and shyer individuals learned faster & Mazza et al. (2018) \\
\hline Alone & $\begin{array}{l}\text { Guinea pigs with less socio-positive } \\
\text { behaviours learned faster, but no effect of } \\
\text { aggressiveness or boldness } \\
\text { Wild cavies with more socio-positive } \\
\text { behaviours, more aggressive and bolder } \\
\text { learned faster }\end{array}$ & $\begin{array}{l}\text { Guinea pigs with less socio-positive behaviours still } \\
\text { learned faster, and no effect of aggressiveness or } \\
\text { boldness } \\
\text { Less aggressive wild cavies learned faster but no } \\
\text { effect of socio-positive behaviours and boldness }\end{array}$ & $\begin{array}{l}\text { Brust and } \\
\text { Guenther (2015) }\end{array}$ \\
\hline Alone & $\begin{array}{l}\text { More active, bolder and more aggressive } \\
\text { individuals learned faster }\end{array}$ & $\begin{array}{l}\text { Less aggressive individuals learned faster but no } \\
\text { effect of activity nor boldness }\end{array}$ & $\begin{array}{l}\text { Guenther } \\
\text { et al. (2014) }\end{array}$ \\
\hline Alone & Not addressed & $\begin{array}{l}\text { More neophobic woodpecker finches learned faster } \\
\text { in the perseverance experiment - no effect of } \\
\text { neophobia on proportion of errors } \\
\text { For small finches, no effect of neophobia on both } \\
\text { measurements }\end{array}$ & $\begin{array}{l}\text { Tebbich } \\
\text { et al. (2012) }\end{array}$ \\
\hline Alone & No effect of exploration & No effect of exploration & $\begin{array}{l}\text { Guillette } \\
\text { et al. (2015) }\end{array}$ \\
\hline
\end{tabular}

Alone
$\begin{aligned} & \text { No effect of shyness nor neophobia } \\ & \text { Alone }\end{aligned}$
$\begin{aligned} & \text { No effect of neophobia on the measurements } \\ & \text { In task 1: less neophobic individuals learned } \\ & \text { faster } \\ & \text { In task 2: No effect of neophobia found } \\ & \text { In 2014: more explorative individuals after the } \\ & \text { release in the wild learned faster } \\ & \text { In 2015: no effect of early-life exploration }\end{aligned}$

\begin{tabular}{ll} 
Alone & Not addressed \\
\hline Alone & Not addressed
\end{tabular}

Not addressed

Less neophobic individuals learned faster for adults and juveniles

Less neophobic individuals made less error, only for juveniles

No effect of neophobia

In 2014: No effect of exploration after release in the wild

In 2015: more explorative individuals during earlylife assay learned faster

No effect of all personality trait

Alteration of rewarded stimulus task: Shyer individuals find faster the new cue, but no effect of exploration

Intra-maze task: no effect of boldness nor exploration

\begin{tabular}{l} 
Alone \\
$\begin{array}{l}\text { Not addressed } \\
\text { Alone } \\
\text { Alone } \\
\text { learned faster } \\
\text { In the generalisation testing: fast explorers } \\
\text { individuals discriminate better between two } \\
\text { stimuli }\end{array}$ \\
\hline
\end{tabular}

Fast explorers had a shorter reaction time and had a longer crossing time No effect of exploration on learning accuracy

Not addressed

Not addressed

\section{Ducatez}

et al. (2015)

Guido et al. (2017)

Gibelli and Dubois (2017)

\section{Madden}

et al. (2018)

Logan (2016)

Zidar et al. (2017)

Bousquet et al. (2015)

Nawroth et al. (2016)

Guillette et al. (2017) 
The failure to predict learning performance by personality traits can also stem from differences in species-specific socio-ecological adaptations, which are not represented by the test set-up. For example, in a comparative study of captive Brazilian guinea pigs (Cavia aperea) and domestic guinea pigs (Cavia porcellus), boldness and aggressiveness positively influenced the performance of Brazilian guinea pigs, but not that of domestic guinea pigs, in a symbol discrimination task (Brust \& Guenther, 2015). Moreover, Brazilian guinea pigs exhibiting more socio-positive behaviours learned faster, whereas the opposite pattern was found in domestic guinea pigs. In the reversed task of the same study, domestic guinea pigs exhibiting fewer socio-positive behaviours were faster learners. Likewise, less aggressive Brazilian guinea pigs learned to reverse the task faster. However, no effect of boldness was found on reversal learning speed. The negative correlations between socio-positive behaviour and learning performance in domestic guinea pigs were explained by the possibility that they are better in social learning than in individual learning. Given the fact that domestic guinea pigs have been kept with other individuals during domestication, they may have adapted towards relying more on social information (Brust \& Guenther, 2015).

In general, most studies addressing the influence of personality traits on learning performance in discrimination and reversal learning tasks used individual experimental settings instead of a social setting for group-living species (Table 1). However, group-living animals are exposed to social learning and may rely on social learning in addition to individual learning (Webster \& Laland, 2017). Accordingly, an individual experimental setting may not reflect the representative socio-ecological characteristics in the case of group-living species. Hence, to obtain a better understanding of a species' learning strategies, this aspect should be incorporated into any experimental design.

Other factors, such as inhibitory control, can also influence cognitive performance. Inhibitory control is essential during decision-making as it allows individuals to inhibit a pre-potent behaviour (Beran, 2015; Kabadayi et al., 2018). It is a component of executive control necessary for better performance in an altered situation (Tapp et al., 2003). Inhibitory control is also considered to promote behavioural flexibility (Amici et al., 2008). For instance, primate species performing better in a battery of inhibitory control tasks were suggested to be more behaviourally flexible (Amici et al., 2008). Species exhibiting elevated inhibitory control were characterised by higher fission-fusion dynamics compared with species living in cohesive, stable groups, presumably because inhibitory control is useful in cognitively managing changes in group size (Amici et al., 2008). Hence, behavioural flexibility and inhibitory control seem to be functionally related.

Only a handful of studies have explored the effect of inhibitory control on cognitive performance in other cognitive domains. For instance, a study of dogs applying three tasks of inhibitory control and four problem-solving tasks found inhibitory control to correlate both positively and negatively with individuals' cognitive performance (Müller et al., 2016). This incoherence was suggested to be due to the context-specificity of inhibitory control, that is, an individual's expression of inhibitory control can vary depending on the task (Bray et al., 2014; Müller et al., 2016). Other studies did not find a link between inhibitory control and cognitive performance for the same reason or because other confounding factors were not considered (Boogert et al., 2011; Johnson-Ulrich et al., 2018; Shaw, 2017). Hence, previous studies have not identified a uniform and straightforward direction for this relationship.

In recent years, studying cognition in the wild has been promoted as it allows better examination of the ecological relevance of cognitive variability (Cauchoix et al., 2017; Pritchard et al., 2016). However, studying cognition in the field also comes with its problems, such as distinguishing between individual learning and the effect of social context when testing group-living animals (MorandFerron et al., 2016). The presence of other individuals can facilitate learning acquisition, either by social learning from experts (Schnoell \& Fichtel, 2012), or social facilitation due to shared risks in a novel situation (Forss et al., 2017). However, the presence of others also comes with costs like competition among group mates. For instance, in Carib grackle (Quiscalus lugubris), feeding in groups was suggested to slow down innovative foraging behaviour, and lone birds were faster in attempting to contact a new foraging task. Here, this contrary finding was caused by an adjustment of the individual's feeding behaviour due to the higher food competition as predation risk was lower (Morand-Ferron et al., 2009). As effects of other individual's presence will not occur during individual testing, the experimental setting may then influence individual learning ability. Hence, it would be important to choose an experimental design that factors the social characteristic of a species in both wild and captive settings.

In this study, we exposed free-ranging narrow-striped mongooses (Mungotictis decemlineata) to a personality and several cognitive tests. The narrow-striped mongoose is an endemic Malagasy carnivore whose feeding ecology is characterised by extractive foraging for mostly arthropods (Rasolofoniaina et al., 2019), a foraging strategy generally thought to be associated with behavioural flexibility (Henke-von der Malsburg \& Fichtel, 2018). Moreover, narrow-striped mongooses live in sexually segregated units, with stable female ( $3.7 \pm 0.4$ individuals) and more transient male associations that are characterised by clear dominance relationships (Schneider \& Kappeler, 2016). Based on these socio-ecological characteristics, we reasoned that narrow-striped mongooses would learn flexibly, as individuals should show flexibility in order to deal with problems related to their socio-ecological niche, such as decision-making during foraging or encounters with individuals of different ranks.

We applied novel object tests and a cylinder task to assess neophobia and inhibitory control, respectively. Although neophobia may slow down individual learning performances (Webster \& Lefebvre, 2001), more neophobic individuals in a group may overcome their neophobia by using social information (Forss et al., 2017), which consequently might influence individual learning strategies. Since members of a female group of narrow-striped mongooses travel and forage together, more neophobic individuals might more readily rely on social learning to discover new resources or when 
facing new problems than less neophobic individuals. Moreover, inhibitory control is vital when an animal should detour an obstacle to reach a goal in the environment, such as food or a shelter (Kabadayi et al., 2018). Similarly, predators benefit from inhibitory control to optimise their hunting strategies. Hence, narrow-striped mongooses, which prey upon various types of animals, should exhibit inhibitory control when foraging.

To assess behavioural flexibility in narrow-striped mongooses, we used the reversal learning paradigm. This empirical tool involves training a subject with a discrimination learning task before abruptly reversing the contingencies with the reversal learning task (Bond et al., 2007). Discrimination abilities apply in many important contexts, such as foraging and predator or kin recognition (Pritchard et al., 2016). To succeed in a reversal learning task, individuals should ignore the previously learned behaviour, requiring both behavioural flexibility and inhibitory control (Cauchoix et al., 2017).

This study aimed to quantify individual variation in behavioural flexibility of wild narrow-striped mongooses and to examine whether neophobia, inhibitory control and social learning influence variation in learning strategies. To achieve these aims, we tested wild narrow-striped mongooses in a group setting and (a) assessed the personality trait neophobia via novel object experiments; (b) measured individual levels of inhibitory control in a cylinder task, and measured; (c) learning and behavioural flexibility with a discrimination learning and reversal learning task while accounting for social learning possibility.

\section{2 | METHODS}

\section{1 | Species and study site}

We studied narrow-striped mongooses between November 2014 and September 2017 in Kirindy Forest, a dry deciduous forest located in central western Madagascar (Kappeler \& Fichtel, 2012). We tested individuals from a marked population that were regularly captured with Tomahawk live traps, using dry fish as bait. Trapped animals were anaesthetised, measured and individually marked by either fitting them with a radio-collar or by shaving their tail with a unique pattern (see Schneider \& Kappeler, 2016). After full recovery from anaesthesia, animals were released near their group close to the trapping site.

Before the experiments, narrow-striped mongooses were trained to approach an experimental area by a sound generated by shaking a plastic jar containing dry cat food (see also Schnoell \& Fichtel, 2012). Novel object tests were conducted twice, once at the beginning and once at the end of testing, to assess repeatability in neophobia. The experiments on inhibitory control and discrimination and reversal learning were carried out between the personality tests (see below for details). Experiments were performed opportunistically whenever animals were relocated in the study area. Since males have larger home ranges $(83.4 \pm 23.7$ ha, $\bar{x} \pm S D)$ than females (37.2 \pm 11.9 ha) and roam solitarily (Schneider \& Kappeler, 2016), it was difficult to relocate them for the discrimination and reversal tasks. Therefore, males were only subjected to the novel object tests and the cylinder task, whereas females were additionally subjected the discrimination and reversal learning tasks. Because of their unusual social organisation characterised by sexual segregation, females were tested in their group, whereas males were tested alone.

\section{2 | Experimental procedures}

\subsection{1 | General testing procedure}

In all experiments, animals were located first, and the experimental apparatus was baited with 10 pieces of cat food out of sight of the individuals (about $50 \mathrm{~m}$ away) before the onset of a test. Animals were then lured to the experimental set-up by using the acoustic signal described above. An experiment started when the first individual entered a $3 \mathrm{~m}$ radius of an experimental area marked with a rope on the ground, and ended when the last individual left the experimental area. In order to avoid monopolisation of the experimental apparatus by specific individuals during tests, we presented several experimental apparatuses simultaneously, that is, one apparatus for each individual. For the cognitive tests, each such presentation was considered as one session. Within a session, an individual could perform several trials. A trial started when the animal manipulated the box by touching or biting, and ended when the animal moved away from the box at a distance greater than body length. Each individual could perform several trials until it left the experimental area. The apparatuses were not removed or re-baited after a trial, independent of whether the subject was successful or not. The session was finished after all individuals left the experimental area.

\subsection{2 | Measures of neophobia and inhibitory control}

\section{Novel object tests (measure of neophobia)}

We assessed differences between individuals $(N=26$ adult females, $N=2$ adult males, and $N=5$ juveniles of unknown sex, in total $N=33$ ) in neophobia by presenting a novel object next to a food reward (dry cat food) in an experimental area. The novel object was placed beside a wooden plate $(15 \times 15 \mathrm{~cm})$ containing food, surrounded with a metal circle with a diameter of $50 \mathrm{~cm}$ allowing precise estimation of the distance between the subject and the novel object. Individuals were previously habituated to the metal ring before conducting the novel object test. To assess the repeatability of neophobia, we conducted two novel object tests always administered in the same order: in the first novel object test, we presented a colourful plastic ball (12 cm of diameter; Figure 1.a.i) a

nd in the second novel object test a red plastic cup (11 cm diameter and $12 \mathrm{~cm}$ high; Figure 1.a.ii). The following variables (in seconds) were recorded to quantify neophobia-related behaviours: latency to enter the metal circle from the time of arrival, latency to contact the novel object and latency to feed on the cat food from entering the metal circle. If the animal was present within $3 \mathrm{~m}$ around the experimental area but did not enter the metal circle or did not approach 
(a) Novel object tests

i) $1^{\text {st }}$ novel object test $(N=33)$

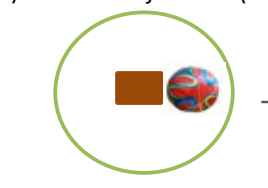

ii) $2^{\text {nd }}$ novel object test $(N=15)$

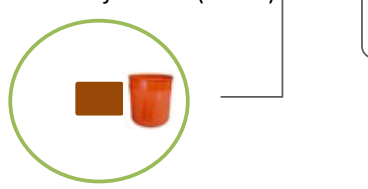

Behaviours measured for each novel object test:

- Latency to enter the ring

- Latency to contact the novel object

- Latency to feed next to the novel object

Repeatability for

Latency to feed next each behaviour $\longrightarrow$ to the novel object

$(N=15)$

$(R=0.439, P=0.04)$

Measure of neophobia

\section{(b) Cylinder task}

i) Opaque cylinder (learning sessions)
$\begin{aligned} & \mathrm{N} \text { trials until learning criterion } \\ & (80 \% \text { correct trials) }\end{aligned}$
$\begin{aligned} & N \text { participated }=17 \\ & N \text { learned }=16\end{aligned}$

der (testing sessions)

Proportion of successful trials out of 10 trials

$N$ participated $=16$

$N$ learned $=16$

\section{(c) Discrimination and reversal learning tasks}
i) Discrimination learning task

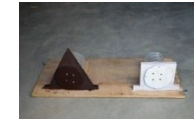
Black triangle accessible / white square blocked

\section{ii) Reversal learning task}

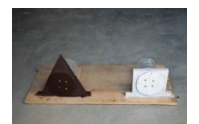
$\mathrm{N}$ trials until learning criterion ( $80 \%$ correct trials)
Discrimination learning speed
$N$ participated $=15$
$N$ learned $=12$
$\mathrm{N}$ trials until learning criterion $(80 \%$ correct trials)
Black triangle blocked / $N$ participated $=9 \longrightarrow$ learning speed
$N$ learned $=8$ white square accessible

FIGURE 1 Schematic overview of the different experiments carried out during this study. Each frame represents an experiment with the order in which the tests were conducted. The respective number of individuals that participated in and learned each task and the outcomes (behavioural variables) measured are mentioned, respectively

the novel object or the food, a capped latency that equalled the total duration of the experiment was noted for this individual.

The first novel object test was conducted at the beginning of the study. The second novel object was done 3 years later, except for one group recently marked at the end of the study, which was re-tested 4 months later (average time of $12.5 \pm 12.02$ months between the two tests, Rasolofoniaina et al., 2020).

\section{Cylinder task (measure of inhibitory control)}

To quantify individuals' ability to inhibit pre-potent behaviour, we used a cylinder task (MacLean et al., 2014). The testing apparatus consisted of a cylinder with one open end $(13 \times 5 \mathrm{~cm})$, fixed on a wooden board $(15 \times 15 \mathrm{~cm})$, in which a food reward (10 pieces of cat food) was placed near the closed edge of the cylinder. Prior to testing, subjects were trained to retrieve food from an opaque cylinder (Figure 1.b.i), and for the actual testing session, animals had to retrieve the food from a transparent cylinder (Figure 1.b.ii). To ensure that the individuals learned to retrieve food from the opaque cylinder, they had to reach a learning criterion of $80 \%$ of successful trials out of a minimum of 15 trials. This learning criterion was chosen to ensure that the individual's performance was above chance levels. After reaching the learning criterion, mongooses were tested with the transparent cylinder for ten trials. A trial was considered successful when the individual retrieved food from the opening with their paws or mouth. In contrast, a trial was considered as unsuccessful when the individual touched the cylinder with its paws and/or bit into the transparent cylinder. Depending on individuals' motivation, individuals were allowed to perform several sessions until they completed the 10 trials. Individual inhibitory control level was measured as the proportion of successful trials out of the first ten testing trials completed, with more correct trials representing a good inhibitory control ability (MacLean et al., 2014).

\subsection{3 | Measures of learning and behavioural flexibility}

\section{Discrimination learning task (measure of learning)}

The discrimination learning task required individuals to develop an association between a given cue and an accessible reward. To 
test discrimination learning, we used a colour, shape and location discrimination task consisting of a wooden apparatus having two compartments (Figure 1.c). Each compartment was set equidistant at the edge of a wooden board and was framed at the front by two different shapes of different colours: a black triangle $(8 \times 13 \mathrm{~cm})$ and a white square (each side of $8 \mathrm{~cm}$ ). The fronts of the compartments could be opened to obtain access to a food reward by swinging a wooden lid to the left or right. The body of the compartments was made out of transparent plastic bottles, which contained the food reward (10 pieces of cat food). For the discrimination task, the black triangle was the open compartment to retrieve food, and the white square compartment was made inaccessible by blocking the lid (Figure 1.c.i). To prevent individuals from making choices based on olfactory cues; both compartments were filled with dry cat food and the lids were equipped with small holes, allowing the odour of the cat food to disperse.

A trial, which corresponded to one manipulation of one of the lids of the two compartments, was scored as either successful (opening and retrieving food or not) or as unsuccessful (animal tried to open the blocked lid). As a successful trial, we considered the opening of the correct lid only. The subject learned the task when it reached a learning criterion set at $80 \%$ of correct trials. After all individuals learned the task, they were assigned to the reversal learning task.

\section{Reversal learning task (measure of behavioural flexibility)}

In the reversal learning task, the white square compartment was rewarded instead of the black triangle compartment, which was then blocked (Figure 1.c.ii). The experimental procedure was the same as in the discrimination task, and the learning criterion was set again to $80 \%$ correct trials.

\section{3 | Behavioural variables recorded}

During all tests, subjects were video-recorded with a camcorder (SONY HDR-CX 240), and videos were analysed using Boris (Friard \& Gamba, 2016). We measured individual learning speed as learning performance during the discrimination and reversal learning tasks. Learning speed was defined as the number of trials needed by an individual to reach the learning criterion or the reversal criterion, that is, the discrimination learning speed and reversal learning speed.

Since we tested the females in a group setting, we controlled for social learning opportunities that might influence learning abilities during the cylinder task, and the discrimination and reversal tasks. For social learning opportunities, we recorded the number of correct trials made by conspecific(s) seen by the focal individual during the discrimination and reversal tasks. Social learning opportunities were recorded for each individual from the start of the experiments until they reached the learning criterion. The identity of the conspecific(s) and the relationship between the individuals was not accounted for during social learning opportunities.

\section{3 | STATISTICAL ANALYSES}

We conducted all statistical analyses using R (R Core Team, 2017). Even though males were subjected only to the novel object and inhibitory control tasks, they were included in the analyses of these tests to increase sample size.

First, we examined the repeatability of the variables used in the novel object tests in the 15 individuals that participated in both novel object tests. Before the repeatability analyses, we log-transformed the measured behavioural variables to achieve normality. We estimated behavioural consistency within-subjects by calculating the point estimate $R$, using a linear mixed model (LMM)-based method for Gaussian data with the package "rptR" (Nakagawa \& Schielzeth, 2010). Bootstrapping was used to estimate standard errors (SE) and confidence intervals. Next, we retained the significantly repeatable behaviour and defined it as "neophobia." For further analyses, we used values of the latency to feed next to the novel object from the first novel object test as our measure of neophobia because more individuals participated in the first test. Individuals exhibiting longer latencies were categorised as more neophobic, whereas those with shorter latencies were considered as less neophobic.

Second, to examine whether individual inhibitory control levels measured with the cylinder task correlate with either social learning opportunities during the transparent cylinder task or neophobia, we used Spearman's rank correlation tests.

Third, we analysed the importance of potentially influential factors, such as neophobia, inhibitory control and social learning opportunities, on individual performances during the discrimination learning task by using Generalised Linear Mixed Models (GLMMs), as detailed below. For these models, we used the package "Ime4" (Bates et al., 2014) and all predictors were $z$-transformed (to a mean of 0 and a standard deviation of 1 ) before all analyses.

As very few juveniles participated in the task $(N=3)$, we did not include age as a factor in our analyses. In addition, as only females could be tested in the discrimination and reversal tasks, the corresponding analyses relied only on data from females that participated in all tasks. Due to our relatively small sample size, we were restricted to fit minimally complex models by including only one predictor per model (as in Daniels et al., 2019). Therefore, we could not test the influence of all predictors in a single model. Learning performance corresponds to the total number of trials made by an individual to reach the learning criterion ( $80 \%$ of correct trials), either during the discrimination learning task or the reversal learning task, which results in one value per individual, respectively. Therefore, individual identity was not included as random factor in our models. Prior to the GLMMs, we analysed whether social learning opportunities during the discrimination learning task correlated with neophobia by using Spearman's rank correlation test. We also tested whether social learning opportunities during the reversal learning task correlated with neophobia with a Spearman's rank correlation test.

To investigate factors influencing learning speed in the discrimination learning task, we conducted GLMMs with a Poisson error structure. 
We fitted three separate models by including discrimination learning speed as response variable and one of the following factors as fixed factor: neophobia, inhibitory control and social learning opportunities. As the members of a group were present at the testing arena for each test, we tested multiple individuals together at the same time. Therefore, we included group identity as random factor in these models.

To examine how learning performance in the reversal learning task was related to the initial learning speed during the discrimination learning task, neophobia, inhibitory control and the social learning opportunities during the reversal learning task, we used Spearman's rank correlation tests.

For all models, we compared the respective full model with the null model by using a likelihood ratio test. While this procedure is not without problems (Bolker et al., 2009), it was considered the best out of the available alternatives.

\section{4 | RESULTS}

We tested up to eight female groups of narrow-striped mongooses ( $N=26$ adult females and $N=5$ juveniles with unknown sex), with an average group size of $4 \pm 2$ individuals. Two adult solitary males were tested additionally for the personality and the inhibitory control tasks. Individual participation changed across the different tasks due to individual loss or to individuals' lack of motivation to approach the experimental area. The sample size of individuals participating in and solving (reaching learning criterion) the respective tasks, as well as the respective percentage of individuals that solved the tasks are summarised in Table 2. In addition, individuals' contributions to all tasks are summarised in Table 3.

\subsection{Novel object tests (measure of neophobia)}

Thirty-three individuals participated in the first novel object test and 15 individuals in the second novel object test. Only the latency to feed next to the novel object was significantly repeatable $(R=.439$, $p=0.04$ ), and thus used as measure of "neophobia" for further analyses. The latency to enter the ring and the latency to contact the novel object were not repeatable (Table 4).

\subsection{Cylinder task (measure of inhibitory control)}

Seventeen individuals participated in the learning session of the inhibitory control task, and 16 individuals reached the learning criterion with an average of $17.6 \pm 14.3$ trials. In the testing phase, the 16 individuals were tested with the transparent cylinder, which made, on average, $2.9 \pm 2.3$ errors among ten trials of testing, resulting in an average proportion of $0.7 \pm 0.23$ successes. Social learning opportunities during the transparent cylinder task did not correlate with the level of inhibitory control (Spearman's rank correlation test: Social learning opportunities: $r=.465, p=0.069, N=16$ ).

\subsection{Discrimination learning task (measure of learning)}

Fifteen individuals, including 11 adult females and four juveniles with unknown sex, participated in the discrimination task, and 12 individuals reached the learning criterion with an average of $22 \pm 12$ trials. Social learning opportunities during the discrimination learning task did not correlate with neophobia (Spearman's rank correlation test: Neophobia: $r=.160, p=0.619, N=12$ ). We found that neither neophobia nor social learning opportunities influenced discrimination learning speed (Table $5 \mathrm{a}$ and $5 \mathrm{~b}$ ). Ten out of the 12 individuals that learned the discrimination learning task also participated in the inhibitory control task, with individuals exhibiting higher inhibitory control learning faster (Figure 2; Table 5c).

\subsection{Reversal learning task (measure of behavioural flexibility)}

Nine individuals participated in the reversal learning task, but only eight individuals reached the learning criterion. They needed on

TAB LE 2 Number of individuals, which participated and solved by reaching learning criterion the respective tasks (blank cells correspond to tasks where learning is not required but only participation)

\begin{tabular}{|c|c|c|c|c|}
\hline Task & Number of groups tested & Participated & Solved & $\begin{array}{l}\text { Solved among } \\
\text { participants (\%) }\end{array}$ \\
\hline Novel object 1 & 8 & 33 & - & - \\
\hline Novel object 2 & 5 & 15 & - & - \\
\hline $\begin{array}{l}\text { Repeatability of novel object } \\
\text { tests }\end{array}$ & 5 & $\begin{array}{l}15 \text { (that participated in both novel } \\
\text { object tests) }\end{array}$ & - & - \\
\hline $\begin{array}{l}\text { Inhibitory control - learning } \\
\text { sessions }\end{array}$ & 5 & 17 & 16 & 94 \\
\hline $\begin{array}{l}\text { Inhibitory control - testing } \\
\text { sessions }\end{array}$ & 5 & 16 & - & - \\
\hline Discrimination task & 5 & 15 & 12 & 80 \\
\hline Reversal task & 4 & 9 & 8 & 89 \\
\hline
\end{tabular}


TABLE 3 Summary of individuals' contribution in the respective tasks (ID: individual identity; Sex: F: female; ?: unknown sex; M: male; yes: indicates participation; learner: indicates that the individual learned the task; blank: indicates no participation)

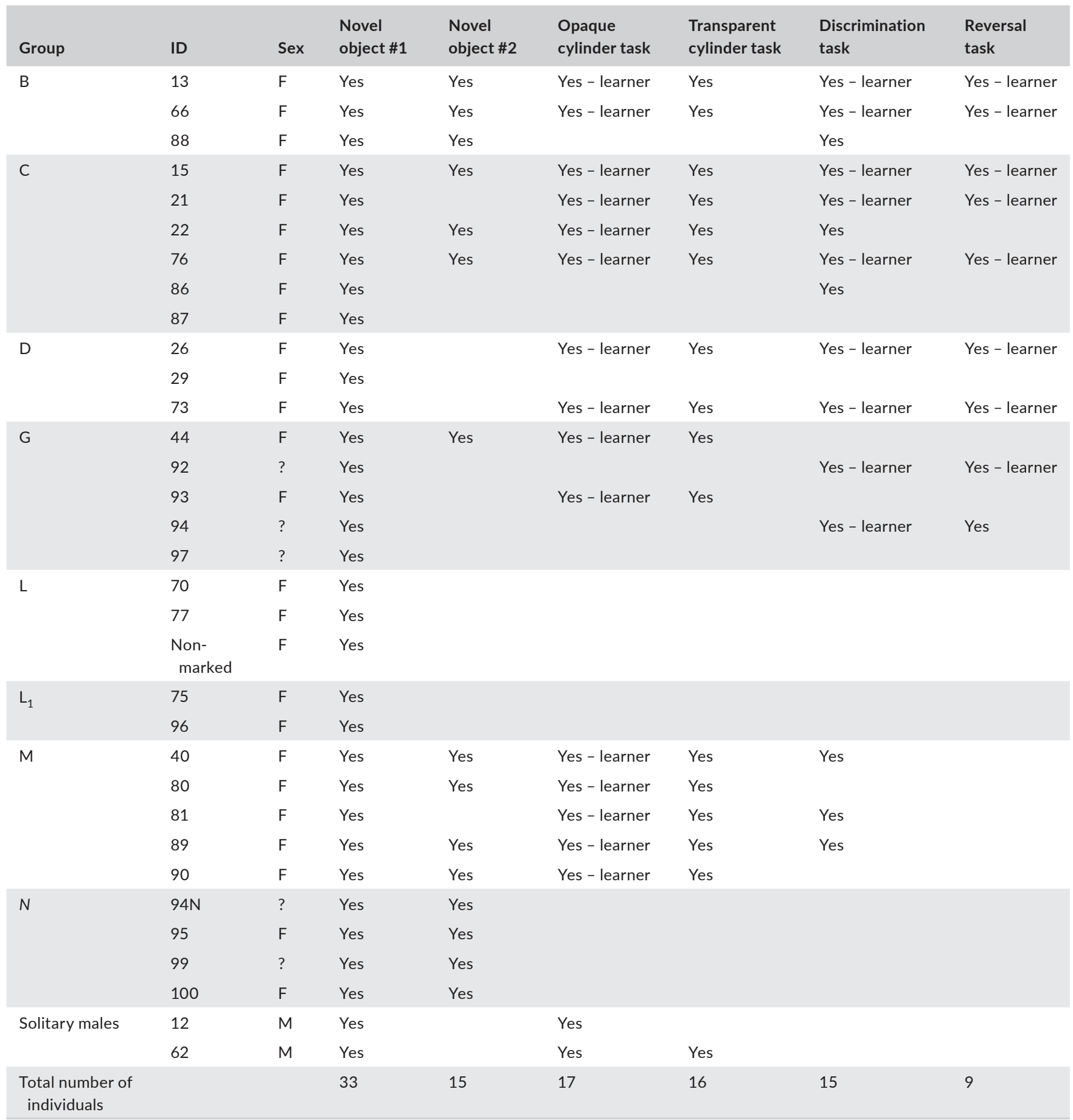

average $39 \pm 31$ trials to reach the learning criterion. Social learning opportunities during the reversal learning task did not correlate with neophobia (Spearman's rank correlation test: Neophobia: $r=.547$, $p=0.171, N=8$ ). We found that social learning opportunities correlated negatively with reversal learning speed (Spearman's rank correlation test: Social learning opportunities: $r=-.805, p=0.016$, $N=8$; Figure 3). Howev

er, neither learning speed during the discrimination task, nor neophobia or inhibitory control correlated with reversal learning speed
(Spearman's rank correlation test: Initial learning speed: $r=.558$, $p=0.149, N=8$; Neophobia: $r=-.243, p=0.056, N=8$; Inhibitory control: $r=.150, p=0.721, N=8)$.

\section{5 | DISCUSSION}

We characterised learning strategies of wild narrow-striped mongooses in a group setting by examining the relationship among neophobia, 
TA B LE $4 \bar{x}$ and standard deviations (SD) of each behaviour (latency to enter the ring, latency to contact the novel object, and latency to feed next to the novel object) (in seconds) measured from all individuals that participated in the first and second novel object test, and results of the repeatability analyses for each behaviour $(N=15)$

\begin{tabular}{|c|c|c|c|c|c|c|c|c|}
\hline \multirow[b]{2}{*}{ Behaviours } & \multicolumn{2}{|c|}{$\begin{array}{l}\text { First novel object test } \\
(\mathrm{N}=33)\end{array}$} & \multicolumn{2}{|c|}{$\begin{array}{l}\text { Second novel object test } \\
(\mathrm{N}=15)\end{array}$} & \multicolumn{4}{|c|}{ Repeatability } \\
\hline & $\overline{\mathbf{x}}$ & $S D$ & $\overline{\mathbf{x}}$ & $S D$ & $R$ & $p$ & SE & $\mathrm{Cl}$ \\
\hline Latency to enter the ring & 68.89 & 108.42 & 6.98 & 11.01 & 0.001 & 1 & 0.149 & {$[0-0.491]$} \\
\hline $\begin{array}{l}\text { Latency to contact the } \\
\text { novel object }\end{array}$ & 148.57 & 173.33 & 31.87 & 49.45 & 0.073 & 0.44 & 0.169 & {$[0-0.557]$} \\
\hline
\end{tabular}

Note: Bold values indicate statistically significant results at the significance threshold $p<0.05$.

Abbreviations: $\mathrm{Cl}$, confidence intervals at $95 \%$; $P$, $p$-value; $R$, point estimate for repeatability; $S E$, standard errors.

inhibitory control, and social learning opportunities in a discrimination and reversal learning paradigm. Neophobia did not correlate with learning performance in either task. Inhibitory control influenced learning abilities in the discrimination learning task, indicating that individuals exhibiting higher inhibitory control learned faster than those with less inhibitory control. Performance in the discrimination task did not correlate with performance during the reversal learning task. However, social learning opportunities correlated negatively with performance during the reversal learning task, suggesting that individuals that witnessed successful trials performed by other group members more often learned faster. Hence, social learning seemed to facilitate learning in a more challenging situation, such as the reversal learning condition.

\section{1 | Factors influencing discrimination learning}

Since our study was limited by sample size, we could not examine the relative importance of non-cognitive and cognitive factors on learning performance. Therefore, we will discuss our findings accordingly cautiously. First, we found that neophobia did not correlate with learning performance during the discrimination learning task and the reversal learning task, suggesting that neophobia does not explain learning and behavioural flexibility in narrow-striped mongooses. A meta-analysis examining the link between personality and cognition revealed that the relationship between these two traits does not depend on the type of learning test, whether it is a discrimination learning or reversal learning test, but rather on task design to infer personality (Dougherty \& Guillette, 2018). Notably, neophobia measured by a response to a predator correlated positively with learning performance whereas neophobia measured by exposure to a novel object did not consistently correlate positively with learning performance (Dougherty \& Guillette, 2018). As we measured neophobia in response to a novel object, our results are consistent with this general pattern.

Learning speed in the discrimination task was positively correlated with inhibitory control. Since our apparatus was made of two

TABLE 5 Parameter estimates from the Generalised Linear Mixed Models assessing variation of learning speed in the discrimination learning task, with corresponding full-null-model comparisons (bold values indicate statistically significant results at the significance threshold $p<0.05$ )

\begin{tabular}{|c|c|c|c|c|c|c|c|c|}
\hline \multirow[b]{2}{*}{ Variable response } & \multirow[b]{2}{*}{ Fixed effect } & \multirow{2}{*}{$\begin{array}{l}\text { Parameter } \\
\text { estimates }\end{array}$} & \multicolumn{6}{|c|}{ Likelihood ratio tests: full-null model comparisons } \\
\hline & & & SE & $z$ & $p$ & $\chi^{2}$ & $d f$ & $p$ \\
\hline \multirow[t]{7}{*}{ Learning speed } & \multicolumn{8}{|l|}{ a. Effect of neophobia } \\
\hline & Intercept & 3.105 & 0.133 & 23.234 & $<0.001$ & & & \\
\hline & $z$-transformed neophobia & 0.042 & 0.074 & 0.563 & 0.573 & & & \\
\hline & Intercept & 3.065 & 0.137 & 22.232 & $<0.001$ & & & \\
\hline & $\begin{array}{l}\text { z-transformed social learning } \\
\text { possibilities }\end{array}$ & -0.159 & 0.113 & -1.413 & 0.158 & & & \\
\hline & \multicolumn{8}{|l|}{ c. Effect of inhibitory control } \\
\hline & Intercept & 3.129 & 0.149 & 20.952 & $<0.001$ & & & \\
\hline
\end{tabular}

Abbreviations: $\chi^{2}$, Chi-squared test; $d f$, degree of freedom; $p, p$-value; SE, standard error; $z, z$-statistic value. 


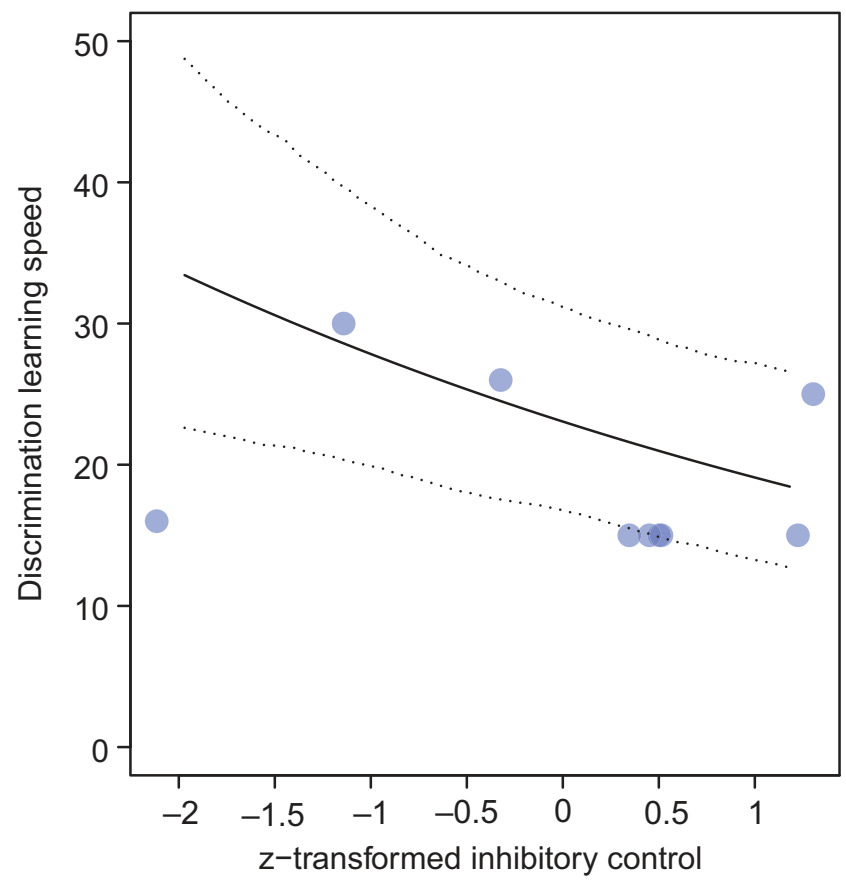

FIGURE 2 Influence of inhibitory control on individuals' discrimination learning speed during the discrimination learning task: individuals with a higher proportion of success during the cylinder task required fewer trials to learn the discrimination learning task. Discrimination learning speed, that is, the number of trials needed by individuals to reach the learning criterion is depicted on the $y$-axis. Z-transformed inhibitory control levels are depicted on the $x$-axis, with negative values representing individuals with low inhibitory control, whereas positive values represent individuals with high inhibitory control. Each circle represents an individual that learned the discrimination learning task. The continuous line depicts the fitted model, and the dotted lines depict its bootstrapped $95 \%$ confidence intervals

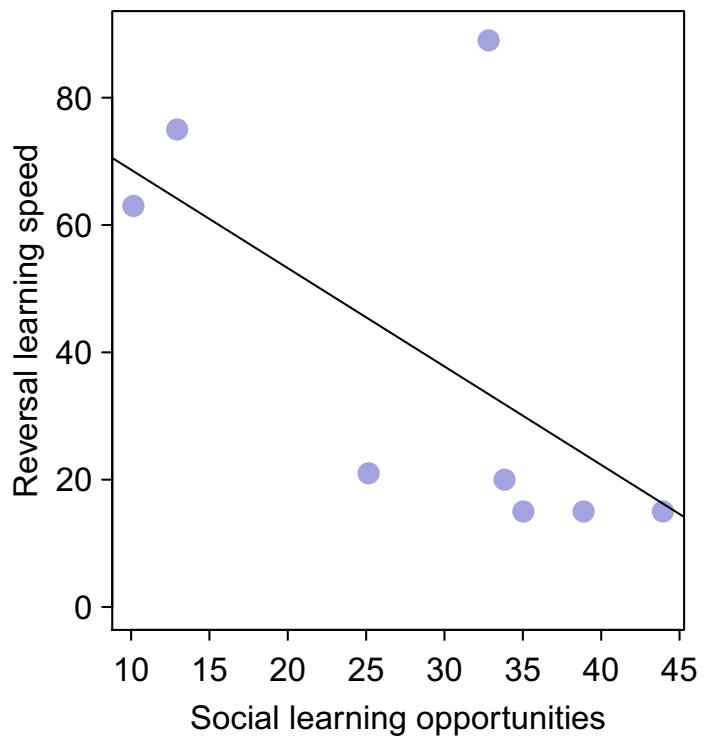

FIGURE 3 Individual's social learning opportunities as a function of individual's reversal learning speed: individuals that witnessed correct trials more often made fewer trials to learn the reversal learning task transparent compartments that both contained food, inhibitory control was required to avoid following only visual and/or odour cues and inhibiting the urge to open the wrong lid. Our results are similar to those of a study linking inhibitory control to problem-solving abilities in meerkats (Suricata suricatta), where more innovative individuals exhibited better inhibitory control (Thornton \& Samson, 2012). Specifically, meerkats that exhibited more inhibitory control in manipulating the non-functional parts of the apparatuses reduced their solving time progressively across trials. Likewise, in our study, higher inhibitory control appeared to promote narrow-striped mongooses' learning performance. Social learning opportunities, however, did not account for learning speed in the discrimination learning task, which suggests that narrow-striped mongooses learned this task individually.

\section{2 | Factors correlating with reversal learning}

Inhibitory control did not correlate with reversal learning speed. In contrast to our findings, in Mme. Berthe's and grey mouse lemurs (Microcebus berthae, M. murinus) and New Zealand robins (Petroica longipes), inhibitory control promoted behavioural flexibility (Henkevon der Malsburg \& Fichtel, 2018; Shaw et al., 2015). However, inhibitory control did not co-vary with behavioural flexibility in a repeated innovation task in spotted hyenas (Crocuta crocuta, JohnsonUlrich et al., 2018). Hyenas had to open a multi-access box, offering different openings on each side of the box to examine repeated innovations. Inhibitory control, which was assessed with the same cylinder task as in our study, did not promote innovation. Instead, more proactive behaviour, including high persistence, motor diversity and activity, but low neophobia co-varied with innovation rates. Most likely because several opening options were simultaneously available, not requiring to inhibit an already learned solution (JohnsonUlrich et al., 2018). Hence, the link between inhibitory control and measures of behavioural flexibility is ambiguous and may also depend on task design.

We found that social learning opportunities correlated negatively with reversal learning speed in narrow-striped mongooses. In principle, reversed contingencies are more challenging to acquire, and narrow-striped mongooses needed more trials to reach the learning criterion in the reversal than in the discrimination learning task. In addition, learning performance in the discrimination task did not correlate with learning performance in the reversal learning task. Hence, individuals may have, in addition to individual learning, relied on social information to solve this more challenging task. Since we could test only females in the discrimination and reversal learning tasks, their social characteristics may facilitate social learning. Narrow-striped mongoose females live in stable social units, and group members rely on each other when foraging or travelling, which offer many opportunities for social learning. However, the effect of individual learning and social learning could not be teased apart with our study design, since we accounted only statistically for the possibility of individuals to 
use social learning. Nevertheless, our results indicate the ability of female narrow-striped mongoose to use both learning strategies flexibly, since we did not find any effect of social learning opportunities during the discrimination learning task. The reliance on social information might also explain why inhibitory control did not correlate with learning performance during the reversal learning task. Social information was probably sufficient to compensate for the difficulty of the reversed task. In contrast, narrow-striped mongooses may have relied solely on individual learning during the discrimination learning task, where inhibitory control might have promoted their ability to learn the correct lid.

Finally, the present study suffers from limitations of the small sample size, especially in the discrimination and reversal learning tests. Consequently, we could not address the relative importance or the joint effect of non-cognitive and cognitive factors on discrimination and reversal learning. Although a small sample size is often an unavoidable limitation when conducting cognition in the wild (Morand-Ferron et al., 2016), it may inflate the Type 1 error rate by running multiple analyses (Forstmeier et al., 2017), hence, our results should be considered accordingly. In addition, we could only test females in the discrimination and reversal learning tests due to the idiosyncrasies of this species' social system (Schneider \& Kappeler, 2016). Hence, future studies involving more individuals and especially males are required to examine whether a sex difference in social organisation entails a sex difference in social learning.

\section{6 | CONCLUSIONS}

Taken together, our study revealed that inter-individual differences in cognitive performance can be linked to inhibitory control, which might promote individual learning. Our results also indicate that narrow-striped mongooses seemed to rely on social information to solve a reversal learning task. More generally, our study also highlights the importance of applying test designs that consider a species' social characteristics to obtain a better understanding of factors influencing individual variation in cognitive performance.

\section{ACKNOWLEDGEMENTS}

We thank Léonard Razafimanantsoa and Rodin Rasoloarison for administrative and logistic support, Remy d'Ampataka and the staff of the Kirindy Research station for their help with fieldwork. We thank Henning Lahmann for his help with data mining. We thank the collaboration of the Département de Biologie Animale of the University of Antananarivo, the Ministère de I'Environnement, de I'Ecologie, de la Mer et des Forêts and the CNFEREF Morondava for authorising our research in Kirindy. B.R. was financially supported by the "Deutscher Akademischer Austauschdienst" (funding program/-ID: 57129429). Finally, we thank two anonymous reviewers for their constructive comments.

\section{CONFLICT OF INTEREST}

The authors declare that they have no competing interests.

\section{AUTHOR CONTRIBUTION}

B.R. and C.F. designed the study. B.R. conducted the experiments and conducted the videos analyses. B.R. and C.F. analysed the data. B.R., P.M.K. and C.F. wrote the paper. All authors gave final approval for publication.

\section{ETHICAL APPROVAL}

Research protocols and experimental procedures were approved by the Ministry for the Environment, Water and Forests of Madagascar.

\section{DATA AVAILABILITY STATEMENT}

Data are available upon request.

\section{ORCID}

Bako Rasolofoniaina iD https://orcid.org/0000-0003-0506-329X

Claudia Fichtel iD https://orcid.org/0000-0002-8346-2168

\section{REFERENCES}

Amici, F., Aureli, F., \& Call, J. (2008). Fission-fusion dynamics, behavioral flexibility, and inhibitory control in primates. Current Biology, 18(18), 1415-1419. https://doi.org/10.1016/j.cub.2008.08.020

Audet, J.-N., \& Lefebvre, L. (2017). What's flexible in behavioral flexibility? Behavioral Ecology, 28(4), 943-947. https://doi.org/10.1093/ beheco/arx007

Bates, D., Mächler, M., Bolker, B., \& Walker, S. (2014). Fitting linear mixed-effects models using Ime4. ArXiv Preprint ArXiv:1406.5823. Retrieved from http://arxiv.org/abs/1406.5823

Beran, M. J. (2015). The comparative science of "self-control": What are we talking about? Frontiers in Psychology, 6, 51.

Bolker, B. M., Brooks, M. E., Clark, C. J., Geange, S. W., Poulsen, J. R., Stevens, M. H. H., \& White, J.-S.-S. (2009). Generalized linear mixed models: A practical guide for ecology and evolution. Trends in Ecology \& Evolution, 24(3), 127-135. https://doi.org/10.1016/j. tree.2008.10.008

Bond, A. B., Kamil, A. C., \& Balda, R. P. (2007). Serial reversal learning and the evolution of behavioral flexibility in three species of North American corvids (Gymnorhinus cyanocephalus, Nucifraga columbiana, Aphelocoma californica). Journal of Comparative Psychology, 121(4), 372-379. https://doi.org/10.1037/0735-7036.121.4.372

Boogert, N. J., Anderson, R. C., Peters, S., Searcy, W. A., \& Nowicki, S. (2011). Song repertoire size in male song sparrows correlates with detour reaching, but not with other cognitive measures. Animal Behaviour, 81(6), 1209-1216. https://doi.org/10.1016/j.anbeh av.2011.03.004

Boogert, N. J., Madden, J. R., Morand-Ferron, J., \& Thornton, A. (2018). Measuring and understanding individual differences in cognition. Philosophical Transactions of the Royal Society B: Biological Sciences, 373(1756), 20170280. https://doi.org/10.1098/rstb.2017.0280

Bousquet, C. A. H., Petit, O., Arrivé, M., Robin, J.-P., \& Sueur, C. (2015). Personality tests predict responses to a spatial-learning task in mallards, Anas platyrhynchos. Animal Behaviour, 110, 145-154. https:// doi.org/10.1016/j.anbehav.2015.09.024

Bray, E. E., MacLean, E. L., \& Hare, B. A. (2014). Context specificity of inhibitory control in dogs. Animal Cognition, 17(1), 15-31. https://doi. org/10.1007/s10071-013-0633-z

Brust, V., \& Guenther, A. (2015). Domestication effects on behavioural traits and learning performance: Comparing wild cavies to guinea pigs. Animal Cognition, 18(1), 99-109. https://doi.org/10.1007/s1007 1-014-0781-9

Cauchoix, M., Hermer, E., Chaine, A. S., \& Morand-Ferron, J. (2017). Cognition in the field: Comparison of reversal learning performance 
in captive and wild passerines. Scientific Reports, 7(1), 1-10. https:// doi.org/10.1038/s41598-017-13179-5

Chittka, L., Skorupski, P., \& Raine, N. E. (2009). Speed-accuracy tradeoffs in animal decision making. Trends in Ecology \& Evolution, 24(7), 400407. https://doi.org/10.1016/j.tree.2009.02.010

Daniels, S. E., Fanelli, R. E., Gilbert, A., \& Benson-Amram, S. (2019). Behavioral flexibility of a generalist carnivore. Animal Cognition, 22(3), 387-396. https://doi.org/10.1007/s10071-019-01252-7

Dougherty, L. R., \& Guillette, L. M. (2018). Linking personality and cognition: A meta-analysis. Philosophical Transactions of the Royal Society B: Biological Sciences, 373(1756), 20170282. https://doi.org/10.1098/ rstb.2017.0282

Ducatez, S., Audet, J. N., \& Lefebvre, L. (2015). Problem-solving and learning in Carib grackles: Individuals show a consistent speed-accuracy trade-off. Animal Cognition, 18(2), 485-496. https://doi. org/10.1007/s10071-014-0817-1

Forss, S. I. F., Koski, S. E., \& van Schaik, C. P. (2017). Explaining the paradox of neophobic explorers: The social information hypothesis. International Journal of Primatology, 38(5), 799-822. https://doi. org/10.1007/s10764-017-9984-7

Forstmeier, W., Wagenmakers, E.-J., \& Parker, T. H. (2017). Detecting and avoiding likely false-positive findings - a practical guide: Avoiding false-positive findings. Biological Reviews, 92(4), 1941-1968. https:// doi.org/10.1111/brv.12315

Friard, O., \& Gamba, M. (2016). BORIS: A free, versatile open-source event-logging software for video/audio coding and live observations. Methods in Ecology and Evolution, 7(11), 1325-1330. https://doi. org/10.1111/2041-210X.12584

Gibelli, J., \& Dubois, F. (2017). Does personality affect the ability of individuals to track and respond to changing conditions? Behavioral Ecology, 28(1), 101-107. https://doi.org/10.1093/beheco/arw137

Greggor, A. L., Thornton, A., \& Clayton, N. S. (2015). Neophobia is not only avoidance: Improving neophobia tests by combining cognition and ecology. Current Opinion in Behavioral Sciences, 6, 82-89. https:// doi.org/10.1016/j.cobeha.2015.10.007

Griffin, A. S., Guillette, L. M., \& Healy, S. D. (2015). Cognition and personality: An analysis of an emerging field. Trends in Ecology \& Evolution, 30(4), 207-214. https://doi.org/10.1016/j.tree.2015.01.012

Guenther, A., Brust, V., Dersen, M., \& Trillmich, F. (2014). Learning and personality types are related in cavies (Cavia aperea). Journal of Comparative Psychology, 128(1), 74-81. https://doi.org/10.1037/ a0033678

Guido, J. M., Biondi, L. M., Vasallo, A. I., \& Muzio, R. N. (2017). Neophobia is negatively related to reversal learning ability in females of a generalist bird of prey, the Chimango Caracara, Milvago chimango. Animal Cognition, 20(4), 591-602. https://doi.org/10.1007/s1007 1-017-1083-9

Guillette, L. M., Hahn, A. H., Hoeschele, M., Przyslupski, A.-M., \& Sturdy, C. B. (2015). Individual differences in learning speed, performance accuracy and exploratory behaviour in black-capped chickadees. Animal Cognition, 18(1), 165-178. https://doi.org/10.1007/s1007 1-014-0787-3

Guillette, L. M., Naguib, M., \& Griffin, A. S. (2017). Individual differences in cognition and personality. Behavioural Processes, 134, 1-3. https:// doi.org/10.1016/j.beproc.2016.12.001

Henke-von der Malsburg, J., \& Fichtel, C. (2018). Are generalists more innovative than specialists? A comparison of innovative abilities in two wild sympatric mouse lemur species. Royal Society Open Science, 5(8), 180480. https://doi.org/10.1098/rsos.180480

Herborn, K. A., Heidinger, B. J., Alexander, L., \& Arnold, K. E. (2014). Personality predicts behavioral flexibility in a fluctuating, natural environment. Behavioral Ecology, 25(6), 1374-1379. https://doi. org/10.1093/beheco/aru131

Johnson-Ulrich, L., Johnson-Ulrich, Z., \& Holekamp, K. (2018). Proactive behavior, but not inhibitory control, predicts repeated innovation by spotted hyenas tested with a multi-access box. Animal Cognition, 21(3), 379-392. https://doi.org/10.1007/s10071-018-1174-2

Kabadayi, C., Bobrowicz, K., \& Osvath, M. (2018). The detour paradigm in animal cognition. Animal Cognition, 21(1), 21-35. https://doi. org/10.1007/s10071-017-1152-0

Kappeler, P. M., \& Fichtel, C. (2012). A 15-year perspective on the social organization and life history of sifaka in Kirindy Forest. In P. M. Kappeler \& D. P. Watts (Eds.), Long-term field studies of primates (pp. 101-121). Berlin, Heidelberg: Springer.

Logan, C. J. (2016). Behavioral flexibility in an invasive bird is independent of other behaviors. PeerJ, 4, e2215. https://doi.org/10.7717/ peerj. 2215

MacLean, E. L., Hare, B., Nunn, C. L., Addessi, E., Amici, F., Anderson, R. C., Aureli, F., Baker, J. M., Bania, A. E., Barnard, A. M., Boogert, N. J., Brannon, E. M., Bray, E. E., Bray, J., Brent, L. J. N., Burkart, J. M., Call, J., Cantlon, J. F., Cheke, L. G., ... Zhao, Y., 2014). The evolution of self-control. Proceedings of the National Academy of Sciences of the United States of America, 111(20), E2140-E2148.

Madden, J. R., Langley, E. J. G., Whiteside, M. A., Beardsworth, C. E., \& van Horik, J. O. (2018). The quick are the dead: Pheasants that are slow to reverse a learned association survive for longer in the wild. Philosophical Transactions of the Royal Society B: Biological Sciences, 373(1756), 20170297. https://doi.org/10.1098/rstb.2017.0297

Mazza, V., Eccard, J. A., Zaccaroni, M., Jacob, J., \& Dammhahn, M. (2018). The fast and the flexible: Cognitive style drives individual variation in cognition in a small mammal. Animal Behaviour, 137, 119-132. https:// doi.org/10.1016/j.anbehav.2018.01.011

Morand-Ferron, J., Cole, E. F., \& Quinn, J. L. (2016). Studying the evolutionary ecology of cognition in the wild: A review of practical and conceptual challenges: Evolutionary ecology of cognition in the wild. Biological Reviews, 91(2), 367-389. https://doi.org/10.1111/ brv.12174

Morand-Ferron, J., Overington, S., Cauchard, L., \& Lefebvre, L. (2009). Innovation in groups: Does the proximity of others facilitate or inhibit performance? Behaviour, 146(11), 1543-1564. https://doi. org/10.1163/156853909X450131

Müller, C. A., Riemer, S., Virányi, Z., Huber, L., \& Range, F. (2016). Inhibitory control, but not prolonged object-related experience appears to affect physical problem-solving performance of pet dogs. PLoS One, 11(2), e0147753. https://doi.org/10.1371/journal.pone.0147753

Nakagawa, S., \& Schielzeth, H. (2010). Repeatability for Gaussian and non-Gaussian data: A practical guide for biologists. Biological Reviews. 85(4), 935-956. https://doi.org/10.1111/j.1469-185X.2010.00141.x

Nawroth, C., Baciadonna, L., \& McElligott, A. G. (2016). Goats learn socially from humans in a spatial problem-solving task. Animal Behaviour, 121, 123-129. https://doi.org/10.1016/j.anbehav.2016.09.004

Nawroth, C., Prentice, P. M., \& McElligott, A. G. (2017). Individual personality differences in goats predict their performance in visual learning and non-associative cognitive tasks. Behavioural Processes, 134, 43-53. https://doi.org/10.1016/j.beproc.2016.08.001

Pritchard, D. J., Hurly, T. A., Tello-Ramos, M. C., \& Healy, S. D. (2016). Why study cognition in the wild (and how to test it)?. Journal of the Experimental Analysis of Behavior, 105(1), 41-55. https://doi. org/10.1002/jeab.195

R Core Team (2017). R: A language and environment for statistical computing. Vienna, Austria: R Foundation for Statistical Computing. Retrieved from https://www.R-project.org/

Rasolofoniaina, B., Kappeler, P. M., \& Fichtel, C. (2020). Neophobia and social facilitation in narrow-striped mongooses. Animal Cognition. https://doi.org/10.1007/s10071-020-01429-5

Rasolofoniaina, B., Razafy, P., Andrianarimisa, A., Razafimahatratra, E., \& Kappeler, P. M. (2019). Feeding ecology of the bokiboky, Mungotictis decemlineata (family Eupleridae). Malagasy Nature, 13, 152-161.

Réale, D., Reader, S. M., Sol, D., McDougall, P. T., \& Dingemanse, N. J. (2007). Integrating animal temperament within 
ecology and evolution. Biological Reviews, 82(2), 291-318. https:// doi.org/10.1111/j.1469-185X.2007.00010.x

Roth, G., \& Dicke, U. (2005). Evolution of the brain and intelligence. Trends in Cognitive Sciences, 9(5), 250-257. https://doi.org/10.1016/j. tics.2005.03.005

Schneider, T. C., \& Kappeler, P. M. (2016). Gregarious sexual segregation: The unusual social organization of the Malagasy narrow-striped mongoose (Mungotictis decemlineata). Behavioral Ecology and Sociobiology, 70(6), 913-926. https://doi.org/10.1007/s00265-016-2113-3

Schnoell, A. V., \& Fichtel, C. (2012). Wild redfronted lemurs (Eulemur rufifrons) use social information to learn new foraging techniques. Animal Cognition, 15(4), 505-516. https://doi.org/10.1007/s1007 1-012-0477-y

Shaw, R. C. (2017). Testing cognition in the wild: Factors affecting performance and individual consistency in two measures of avian cognition. Behavioural Processes, 134, 31-36. https://doi.org/10.1016/j. beproc.2016.06.004

Shaw, R. C., Boogert, N. J., Clayton, N. S., \& Burns, K. C. (2015). Wild psychometrics: Evidence for 'general' cognitive performance in wild New Zealand robins, Petroica longipes. Animal Behaviour, 109, 101111. https://doi.org/10.1016/j.anbehav.2015.08.001

Shettleworth, S. J. (2001). Animal cognition and animal behaviour. Animal Behaviour, 61(2), 277-286. https://doi.org/10.1006/anbe.2000.1606

Sih, A., \& Del Giudice, M. (2012). Linking behavioural syndromes and cognition: A behavioural ecology perspective. Philosophical Transactions of the Royal Society B: Biological Sciences, 367(1603), 2762-2772. https://doi.org/10.1098/rstb.2012.0216

Taborsky, B., \& Oliveira, R. F. (2012). Social competence: An evolutionary approach. Trends in Ecology \& Evolution, 27(12), 679-688. https://doi. org/10.1016/j.tree.2012.09.003
Tapp, P. D., Siwak, C. T., Estrada, J., Head, E., Muggenburg, B. A., Cotman, C. W., \& Milgram, N. W. (2003). Size and reversal learning in the beagle dog as a measure of executive function and inhibitory control in aging. Learning \& Memory, 10(1), 64-73. https://doi.org/10.1101/ Im.54403

Tebbich, S., Stankewitz, S., \& Teschke, I. (2012). The relationship between foraging, learning abilities and neophobia in two species of Darwin's finches. Ethology, 118(2), 135-146. https://doi. org/10.1111/j.1439-0310.2011.02001.x

Thornton, A., \& Samson, J. (2012). Innovative problem solving in wild meerkats. Animal Behaviour, 83(6), 1459-1468. https://doi. org/10.1016/j.anbehav.2012.03.018

Webster, M. M., \& Laland, K. N. (2017). Social information use and social learning in non-grouping fishes. Behavioral Ecology, 28(6), 15471552. https://doi.org/10.1093/beheco/arx121

Webster, S. J., \& Lefebvre, L. (2001). Problem solving and neophobia in a columbiform-passeriform assemblage in Barbados. Animal Behaviour, 62(1), 23-32. https://doi.org/10.1006/anbe.2000.1725

Zidar, J., Balogh, A., Favati, A., Jensen, P., Leimar, O., \& Løvlie, H. (2017). A comparison of animal personality and coping styles in the red junglefowl. Animal Behaviour, 130, 209-220. https://doi.org/10.1016/j. anbehav.2017.06.024

How to cite this article: Rasolofoniaina B, Kappeler PM, Fichtel C. Wild narrow-striped mongooses use social information to enhance behavioural flexibility. Ethology. 2020;00:1-14. https://doi.org/10.1111/eth.13123 


\title{
Chapter 3
}

\section{"Trial-and-error, but not causal performance, supports problem solving in an extractive forager carnivoran species"}

\author{
Bako N. Rasolofoniaina ${ }^{1}$, Peter M. Kappeler ${ }^{1,}$, Claudia Fichtel $^{2}$ \\ ${ }^{1}$ Dept. Sociobiology/Anthropology, Johann-Friedrich-Blumenbach Institute of Zoology and Anthropology, \\ University Göttingen, Germany \\ ${ }^{2}$ Behavioral Ecology and Sociobiology Unit, German Primate Center Leibniz Institute for Primate \\ Research, Göttingen, Germany
}

Manuscript under preparation

Authors' contributions. B.N.R and C.F. designed the study. B.N.R conducted the experiments and conducted the videos analyses. B.N.R. and C.F. analysed the data. B.N.R., P.M.K. and C.F. wrote the paper. 


\begin{abstract}
Causal understanding and instrumental learning can underpin problem-solving abilities in animals. However, most previous studies investigated only the influence of one of these factors, not allowing the disentanglement of the primary mechanism permitting innovative problem-solving. Although causal understanding has been demonstrated in other taxa such as birds and primates, it remains inconclusive among carnivores. Moreover, to date, no study has investigated the implications of causal understanding in problem-solving in carnivores, although several studies have demonstrated good problem-solving performances in this taxon. Here, we studied the influences of causal understanding, instrumental learning, and personality traits, such as persistence and neophobia, on individuals' likelihood to solve extractive foraging problems. We addressed these questions by testing wild narrow-striped mongooses (Mungotictis decemlineata), a generalist and extractive forager carnivore species. Our results provided evidence that individuals who manipulated more often the apparatuses' functional parts solved the tasks faster. However, causal understanding did not influence individuals' performance in problem-solving. Besides, the proportion of functional parts manipulated did not decrease between successes, indicating that they did not learn instrumentally. Moreover, none of persistence, neophobia, and social influence affected individuals' ability to solve the tasks. We, therefore, conclude that problem-solving in narrow-striped mongooses is mainly due to trial-and-error.
\end{abstract}

Keywords: problem-solving, carnivores, Mungotictis decemlineata, causal understanding, perceptual feedback 


\section{Introduction}

Individuals face everyday challenges in their environment, requiring them to find a solution to a new problem or finding a new solution when an old solution is outdated [1]. Innovative problem-solving allows individuals to apply new behaviour to exploit unfamiliar or complex resources, thereby avoiding costs like competition or harsh environmental conditions $[1,2]$. Innovation has been examined across taxa [e.g., 3-6] and is suggested to be linked to a species' foraging ecology $[7,8]$. This link forms the core of the "technical intelligence hypothesis," which suggests that the factors influencing species' feeding ecologies, such as dietary breadth and food accessibility, may influence their performance in problemsolving [7-10].

When producing new behaviours to solve problems, animals should rely on causal understanding and/or instrumental learning $[11,12]$. On the one hand, causal understanding allows inferring how one event leads to another one, and it is deduced from sensory information [13]. Causal understanding is an aspect of physical cognition that is ecologically relevant to infer hidden resources and their extraction $[14,15]$. Therefore, causal understanding is a necessary skill for extractive foragers [14]. For example, in New Caledonian crows (Corvus moneduloides), causal understanding explained individuals' performance in solving complex physical problems [13]. New Caledonian crows were trained initially with a trap tube task and then tested with four different versions of the same task to examine whether they used causal understanding or associative learning to solve the task. Successful individuals solved the tasks that shared the same causal feature (i.e., the trap) and not the task with associative cues, suggesting that they relied on causal understanding [13]. Similarly, chimpanzees (Pan troglodytes) and gorillas (Gorilla gorilla gorilla) use causal understanding to be efficient and flexible in problem-solving tasks [16]. The causal understanding ability of these two ape species was first assessed with a task where the individuals had to remove horizontal straws to drop food rewards. When re-tested with a transfer task with the same properties, the apes performed the same solution to access the food. Likewise, in three species of lemurs (Varecia variegata, Lemur catta, Microcebus murinus), individuals displayed causal understanding in solving mean-ends problems by being successful above chance in different setups of the task [5].

However, some studies revealed that some species failed to use causal understanding when solving problems. For instance, dogs (Canis lupus familiaris) were trained with several combinations of the string-pulling task differing in their difficulties [17]. Dogs were successful in the most straightforward 
string presentation, a single perpendicular string connected to the reward. However, dogs were unsuccessful in solving problems when the string was presented with an angle or several strings were combined, suggesting that dogs failed to understand the causal properties of the task in general [17]. Similarly, when tested with tasks based on the means-ends connection of two boards connected with rewards, dogs were unsuccessful in solving the task where the boards were discontinuous. However, they succeeded in the task with more perceptual properties. This finding suggested that dogs relied more on perceptual cues than on a causal understanding of the task [18].

Novel behaviour can also be due to instrumental learning, which is driven by the perceptual-motor feedback from the interaction with the task [12,19-22]. Perceptual motor feedback is the repetition of actions that bring the reward closer [22]. For instance, in four species of apes (bonobos: Pan paniscus, chimpanzees, gorillas, and orangutans: Pongo abelii), individuals could solve problem-solving tasks by benefitting from visual feedback of the effect of their actions [23]. In tasks involving a sequence of coordinated actions, individuals depended on the visibility of the movement of the reward through the tasks. Likewise, in a string-pulling task, naïve New Caledonian crows were able to solve the task equally to experienced individuals, when a mirror was mounted to provide visual feedback of the action progress [24]. In a similar vein, innovative Carib grackles (Quiscalus lugubris) contacted the openable lid of a foraging apparatus more often than the individuals who failed in innovation, which suggested that successful individuals responded to the lid movement differently from the unsuccessful individuals [20]. However, most previous studies looked at the effect of either causal understanding or instrumental learning on problem-solving abilities (but see [26]), not allowing disentangling primary factor driving behavioural innovation.

Individuals vary in their ability to innovate as a function of two intrinsic traits. A recent meta-analysis found that personality traits are strong predictors of innovation, with individuals characterised by less fear of novelty and higher persistence being better innovators [27]. Several studies also supported the effect of persistence on problem-solving performance [29-31]. However, many studies revealed either a positive or negative relationship between neophobia and problem-solving performance, and some reported the absence of a relationship [reviewed in 23]. Since, neophobia, the fear of novelty, is a significant personality trait relating to how an individual responds to environmental stimuli. It might hamper individuals' ability to interact with novel apparatuses, slowing down the individuals' performances to be effective [32]. Hence, neophobia should be controlled for in studies of innovative problem-solving. 
Although carnivores are known to be good problem-solvers [29,31,33,34], the influence of causal understanding is poorly investigated in this taxon compared to other taxa like birds [e.g., 13,31-33] and primates [e.g., 5,16,34]. Few studies examined the presence of causal understanding skills in wolves and dogs [14,17,39], banded mongooses (Mungos mungo) [40], and racoons (Procyon lotor) [33], suggesting that they have a limited causal understanding. However, the implication of causal understanding ability in problem-solving abilities in carnivores remains unexplored, although this taxon includes extractive forager species.

In the present study, we evaluate the causal understanding of another carnivore species, the narrowstriped mongoose (Mungotictis decemlineata), and examine its influence on innovative problem-solving abilities. We fully capture the factors that influence individuals' capacity to solve problems and generate novel behaviour by conducting the experiments in a social setting. Narrow-striped mongooses are a forest-dwelling species, extractive foragers, and characterised by a generalist diet [41]. The large dietary breadth of ecological generalists is assumed to be linked to better performance in behavioural innovation [1], and extractive foraging behaviour is an indicator of the presence of causal understanding ability [14]. In fact, narrow-striped mongooses mostly extract food from trees, deadwood, or mollusc shells [41,42]. Because female narrow-striped mongooses live in stable groups year-round [43], social influence might affect problem-solving performances in addition to other factors such as neophobia, persistence, and causal understanding. Based on previous works on other species, we predicted that (i) causal understanding or instrumental learning or both would influence problem-solving performance, and that (ii) social influence, especially for more neophobic individuals, and motivational factor would drive individual variation in problem-solving abilities.

\section{Materials and methods}

Study subjects and general experimental protocol

From November 2014 to September 2017, up to 33 individuals from seven female groups in an individually-marked population of free-ranging narrow-striped mongooses were studied in Kirindy Forest, western Madagascar. The following procedure was applied for all experiments: first, the groups were located within their territories using radio-tracking. Next, the test apparatuses were baited out of sight of the subjects and placed in the experimental area. Then, the individuals were attracted to approach the experimental area with an acoustic signal. After that, the testing started and was videorecorded using a camcorder (SONY H DR-CX 240). For each testing, several apparatuses equalling the 
number of individuals were presented to the subjects to avoid monopolisation by the dominant individual. A presentation is called a session. A session started when an individual entered the experimental arena of $3 \mathrm{~m}$ radius, and it ended when the last individual left the arena $[45,46]$. The participation of the individuals depended on their motivation to approach the experimental area. Therefore, the number of individuals participating in the experiments differed.

\section{Neophobia}

We assessed neophobia using two separate novel object tests with a similar experimental setting. The novel object was presented alongside a wooden plate containing food (dry cat food). Both components were placed in the middle of a metal circle, allowing accurate estimation of the distance between the subject and the novel object. Before the novel object tests, individuals were familiarised to approach the metal ring only. We presented one experimental set-up per individual to avoid monopolisation by the dominant individual. We used a coulourful plastic ball for the first novel object test and a red plastic cup for the second one. We conducted the first novel object test at the beginning of the study, whereas the second novel object three years later (except for one group marked at the end of the study, the two tests were conducted 4 months apart; average time interval of $12.5 \pm 12$ months between the two tests). From the two novel object tests, we measured the latencies taken by the subject to enter the metal circle, to contact the novel object, and to feed next to the novel object. We assessed the repeatability of each latency to determine neophobia $[45,46]$.

\section{Causal understanding task}

To examine causal understanding, we tested the narrow-striped mongooses with the shape task [see 14], which is constituted of two wooden squares (each $5 \mathrm{~cm} \times 5 \mathrm{~cm}$ ) placed equidistantly on a rectangular wooden board $(35 \mathrm{~cm} \times 15 \mathrm{~cm} \times 3 \mathrm{~cm}$ ) (Figure 1.1). A reward (one piece of dry cat food) was placed under one of the squares, causing it to incline. During a trial, a subject was allowed to choose between the two squares. The choice of the individual was correct if it chose the inclined square and incorrect if it chose the other square. The position of the inclined square was randomised (left or right) across trials. Cat food powder was applied under the flat square to avoid odour cues. Individual performance in the causal understanding task was measured based on a learning criterion of $80 \%$ correct trials out of a minimum of 12 trials and will be used in further analyses. 


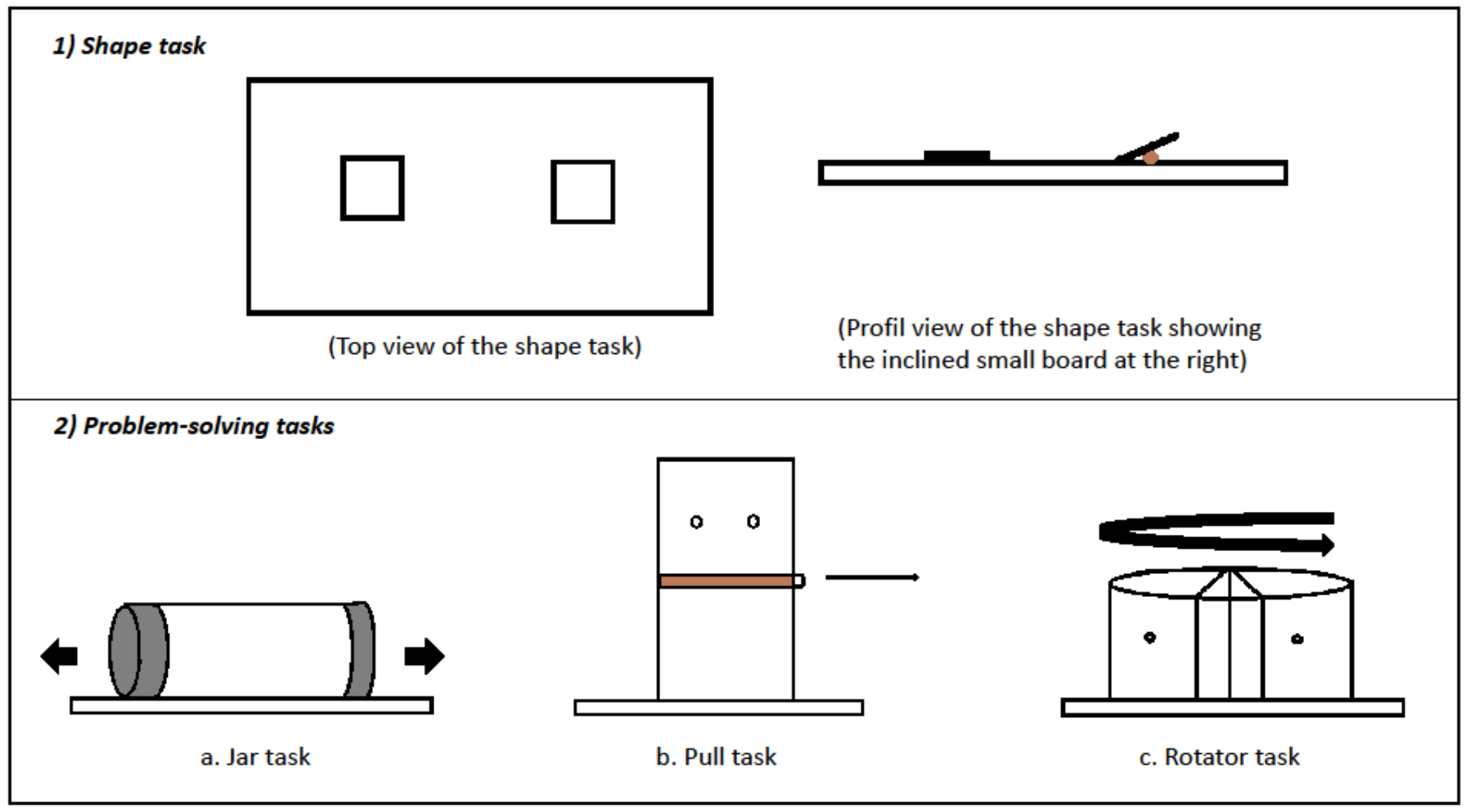

Fig 1. The apparatuses used to test causal understanding ability and problem-solving abilities: (1) the shape task and (2) the three problem-solving tasks: (a) the jar task, (b) the pull task, and (c) the rotator task 


\section{Problem-solving tasks}

To test innovativeness, we applied three different problem-solving tasks: the jar, the pull, and the rotator tasks; Figure 1.2.a-b-c) previously used in a study in meerkats [29], adapted to the size of the narrow-striped mongooses.

The jar task. The first problem-solving task was made of a plastic cylinder (non-functional part) $(10 \mathrm{~cm} \times 6.4 \mathrm{~cm})$ closed at the sides with aluminium foil (functional parts) that could be opened easily. The body of the plastic cylinder was provided with small holes in order to let the odour dissipate. In order to access the reward placed inside the cylinder, the subject had to remove the aluminium foil at the sides of the box.

The pull task. The second problem-solving task was made of a plastic bottle (non-functional part: $20.9 \mathrm{~cm} \times 6.4 \mathrm{~cm} \times 6.4 \mathrm{~cm}$ ) provided with a round wooden lid (functional part: $6.4 \mathrm{~cm}$ of diameter) at the middle of the bottle, dividing the bottle into two parts. The rewards were placed in the upper part of the bottle, and the lid could be pulled out to obtain access to the rewards. In addition, the upper part of the bottle was provided with small holes to let the odour to dissipate.

The rotator task. The third problem-solving task was made with a round plastic box (nonfunctional part: $5 \mathrm{~cm}$ height) with the interior body of the plastic box divided into two compartments (big and small). The reward was placed in the small compartment. The top of the box (functional part: 12 $\mathrm{cm}$ of diameter) was made of transparent plastic and with a mechanism allowing it to be rotated. The top was provided with an opening of the same size as the small compartment, and the subject had to rotate the top of the box until the opening matched the small compartment to access the rewards.

Each box was fixed on a wooden board $(15 \mathrm{~cm} \times 15 \mathrm{~cm} \times 3 \mathrm{~cm})$ to give stability to the apparatuses. Moreover, to avoid any order effect, each group was tested with a different order of the three tasks.

\section{Problem-solving tasks scoring}

We quantified behavioural variables (defined in Table 1) from the video recordings using the software BORIS [44], which were included in the further analyses. We recorded behavioural variables as quantified in the earlier study in meerkats [29], which are the following: the success latency as a measurement of individual performance in each problem-solving task and the proportion of manipulation of the functional parts of the apparatuses. Additionally, we measured the individual's contact attempt toward the tasks, , and persistence which represents the engagement of the individual with the task or task-directed motivation [21]. We also measured the proportion of social influence as we tested the subjects in a natural group setting. 
Table 1. Ethogram of the behaviours recorded from the video analyses on the three problem-solving tasks and their respective descriptions

Variables

Success latency
Description

Time spent manipulating the task actively in seconds, from the first contact with the box until opening the task correctly and retrieving food reward.

We recorded the time until the individuals succeed once the tasks (first success latency) and the time between the first and the second successes made by the individuals (second success latency).

Proportion of manipulation of Proportion of the number of times manipulating the functional parts functional part of the apparatuses to the total number of times manipulating the functional and non-functional parts

Contact attempt Time spent in contact with the task (includes all attempts to contact the apparatuses less than a head length, such as touching, sniffing, except tail contact)

Persistence Ratio of time spent manipulating actively the task to the time spent in contact with the task

Social influence Proportion of time spent with conspecific(s) at the experimental area during the testing session

\section{Statistical analyses}

We performed all statistical analyses using R statistical software [48]. Linear mixed models were conducted using the package Ime4 [49].

First, we examined the presence of neophobia in narrow-striped mongooses by calculating the repeatability of the variables measured in the individuals that participated in the two novel object tests $(\mathrm{N}=15)$. Before the repeatability analyses, we log-transformed the measured behavioural variables to 
achieve normality. We estimated behavioural consistency within-subjects by calculating the point estimate $R$, using a linear mixed model (LMM)-based method for Gaussian data with the package "rptR" [50] (Nakagawa \& Schielzeth, 2010). Bootstrapping was used to estimate standard errors (SE) and confidence intervals. Next, we retained the significantly repeatable behaviour, defined it as "neophobia". For further analyses, we used the values of the latency to feed next to the novel object from the first novel object test as our measure of neophobia because more individuals participated in the first test. Individuals exhibiting longer latencies were categorised as more neophobic, whereas those with shorter latencies were considered as less neophobic.

Second, we examined whether causal understanding performance co-varies with neophobia. For this, we conducted a Spearman's rank correlation test between neophobia and causal understanding performance of the individuals that reached the learning criterion. Likewise, we examined whether individuals' persistence until their first successes in every three problem-solving tasks co-varies with neophobia by using Spearman's rank correlation tests.

Next, we examined whether individuals' persistence differed within and between tasks. We conducted a two-ways repeated measure Anova to check whether individual's persistence differed between the first and the second successes (referred as "success time" hereafter) and between the three problem-solving tasks. Individuals that solved twice the three problem-solving tasks $(\mathrm{N}=10)$ were included in this analysis.

Then, we examined whether the proportion of manipulation of functional parts differed between the two successes and between tasks. Reduction in the manipulating the functional parts may indicate that the individuals became more efficient [29]. For this, we conducted a Generalised Linear Mixed Model (GLMM) with a "binomial" structure. In the model, we included the number of manipulations of the functional parts and non-functional parts per individual until the first and the second time they solved the tasks as response variable (using the "cbind" function in R). Success time, task, and social influence were added as fixed effects. The interaction term between success time and task was included in the model, and when non-significant, the single terms were included. Since social influence might affect the probability an individual to manipulate a part of the apparatuses by observing other individuals, we included it as fixed effect. In addition, subject was included as random intercept and tasks as random slope.

Finally, we examined influences on individuals' success latencies in the three problem-solving tasks by conducting a Linear Mixed Model (LMM). Success latencies were included as a response variable, and causal understanding performance, neophobia, social influence, persistence, the 
proportion of manipulation of the functional parts, success time, and tasks were included as fixed effects. Before conducting the LMM, we transformed all variables in order to achieve normality. The variable response (success latency) was transformed with a logarithmic transformation, and the numerical fixed effects (causal understanding performance, neophobia, social influence, persistence, and the proportion of manipulation of the functional parts) were transformed each with $z$ transformation (to a mean of 0 and a standard deviation of 1 ).

To simplify our model, we checked for possible two-way interactions between the fixed effects and tested the significance of the interaction term before including them in the final model. If the interaction term was significant, we included it in the final model rather than the single terms. When applicable, Tukey's pairwise comparison was applied as post-hoc test for the categorical fixed effects (which are success time and tasks). We also included subject's identity as random intercept and tasks as random slope.

For the mixed models, we checked for collinearity between the fixed effects using the function "vif" of the package car. We tested for the significance of the full models against respective null models using likelihood ratio test. The significance of the fixed effects was examined using the drop1 function.

\section{Results}

\section{Novel object tests}

We could test 33 individuals for the first novel object test and 15 individuals for the second novel object test. The latency to feed next to the novel object was significantly repeatable over time $(R=0.439, p=$ $0.04)$, whereas the latency to enter the ring $(R=0.001, p=0.149)$ and the latency to contact the novel object $(R=0.073, p=0.44)$ were not repeatable. Therefore, we consider the latency to feed next to the novel object as neophobia.

\section{Shape task and problem-solving tasks}

We could test in total 19 narrow-striped mongooses belonging to five female groups out of the seven female groups with an average group size of $4 \pm 2$ individuals. Individual participation changed across the tasks due to individual loss or individuals' lack of motivation to approach the experimental area. The sample size of individuals participating in and solving the tasks and their respective percentages of solving tasks, are summarised in table 2. 
Table 2. Number of individuals that participated in the three problem-solving tasks and in the shape task

\begin{tabular}{lllllll}
\hline Task & $\begin{array}{c}\text { N } \\
\text { participated }\end{array}$ & $\begin{array}{c}\text { N solved } \\
\text { for the } \\
\text { first time }\end{array}$ & $\begin{array}{c}\text { Percentages } \\
\text { of individuals } \\
\text { that solved } \\
\text { for the first } \\
\text { time (\%) }\end{array}$ & $\begin{array}{c}\text { N solved } \\
\text { for the } \\
\text { second } \\
\text { time }\end{array}$ & $\begin{array}{c}\text { Percentages } \\
\text { of } \\
\text { individuals } \\
\text { that solved } \\
\text { for the } \\
\text { second time } \\
\text { (\%) }\end{array}$ & N learned \\
\hline Jar task & 17 & 17 & 100 & 13 & 76.47 \\
\hline Pull task & 16 & 16 & 100 & 15 & 93.75 \\
\hline Rotator task & 18 & 18 & 94.73 & 17 & 94.44 & \\
\hline Shape task & 18 & & & & & 16 \\
\hline
\end{tabular}

a. Causal understanding performance and neophobia

Eighteen individuals participated in the causal understanding task. However, only 16 individuals succeeded in solving the task, after an average of $17.25 \pm 8.14$ trials. The other two individuals did not complete the minimum number of trials required for the task. However, we included them in the further analyses by calculating the proportion of correct choices they made divided by the minimum number of trials required, resulting in low performances. Causal understanding performances did not correlate with individuals' neophobia level (Spearman's rank correlation test: $r=0.413, p=0.088, \mathrm{~N}=18$ ).

\section{b. Persistence and neophobia}

In each of the three problem-solving tasks, individuals' persistence during the first success latency did not correlate with neophobia (Spearman's rank correlation tests: jar task: $r=-0.193, p=0.455, \mathrm{~N}=17$; pull task: $r=0.247, p=0.355, \mathrm{~N}=16$; rotator task: $r=0.263, p=0.343, \mathrm{~N}=18$ ). Concerning the difference in persistence within and between tasks, we found neither an effect of success time (first and second success latencies) nor an effect of tasks (two-ways repeated measures Anova: $F_{(2,18)}=0.062$, $p=0.939)$.

c. Difference in proportion of manipulation of functional parts within and between tasks

In the jar task, individuals manipulated the functional parts with an average proportion (mean \pm standard deviation: SD) of $0.58 \pm 0.2$ until the first time they solved the task, and an average proportion (mean \pm SD) of $0.56 \pm 0.2$ until the second success. In the pull task, individuals manipulated the 
functional parts with an average proportion (mean \pm SD) of $0.42 \pm 0.2$ until the first time they solved the task, and an average proportion (mean \pm SD) of $0.48 \pm 0.2$ until the second time they solved the task. In the rotator task, the individuals manipulated the functional parts with an average proportion (mean \pm $\mathrm{SD}$ ) of $0.73 \pm 0.2$ until the first success, and an average proportion (mean $\pm S D$ ) of $0.70 \pm 0.2$ until the second success. The model examining the difference in proportion of manipulation of functional parts within and between tasks was significant $\left(\chi^{2}=39.004, \mathrm{df}=4, p<0.001\right)$. We did not find any difference within tasks in the proportion of manipulation of functional parts $(p=0.528$; Table 3$)$, indicating that the individuals did not improve efficiency between the first and the second time they solved the tasks. However, we found that the proportion of manipulation of functional parts differed between tasks in general, with the individuals manipulating more often the functional parts in the rotator task $(p<0.001$; Figure 2; Table 3).

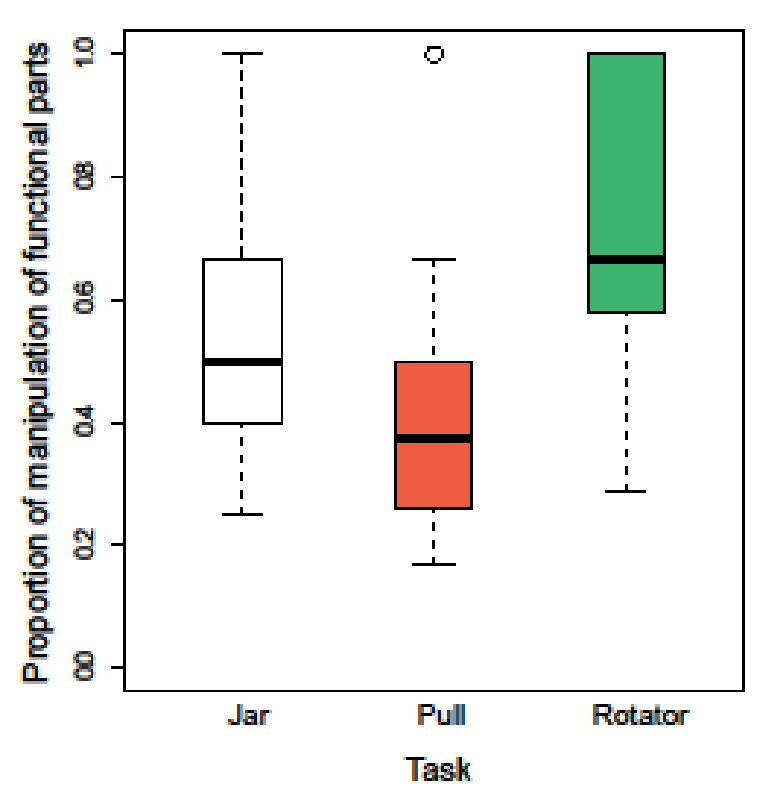

Fig 2. Proportion of manipulation of functional parts between tasks: individuals manipulated more often the functional parts in the rotator tasks compared to the jar and pull tasks 
Table 3. Parameter estimates of the GLMM examining the effects of task, time and social influence on the proportion of manipulation of functional parts

\begin{tabular}{|c|c|c|c|c|c|c|c|c|c|}
\hline \multirow[b]{2}{*}{ Variable response } & \multirow[b]{2}{*}{ Term } & \multicolumn{6}{|c|}{ Parameter estimates } & \multirow[b]{2}{*}{$z$} & \multirow[b]{2}{*}{$p$} \\
\hline & & Est & SE & $\begin{array}{l}\text { Lower } \\
\mathrm{Cl}\end{array}$ & $\begin{array}{l}\text { Upper } \\
\mathrm{Cl}\end{array}$ & Min & $\max$ & & \\
\hline \multirow{5}{*}{$\begin{array}{l}\text { Proportion of } \\
\text { manipulation of } \\
\text { functional parts }\end{array}$} & Intercept & -0.262 & 0.330 & -0.911 & 0.389 & -0.334 & -0.126 & -0.793 & 0.427 \\
\hline & Pull task & -0.406 & 0.246 & -0.897 & 0.077 & -0.533 & -0.278 & -1.648 & 0.099 \\
\hline & Rotator task & 0.770 & 0.229 & 0.318 & 1.224 & 0.673 & 0.836 & 3.348 & $<0.001$ \\
\hline & Time second & 0.110 & 0.175 & -0.232 & 0.458 & 0.040 & 0.171 & 0.630 & 0.528 \\
\hline & Social influence & 0.004 & 0.392 & -0.776 & 0.771 & -0.208 & 0.235 & 0.012 & 0.990 \\
\hline
\end{tabular}

Est: estimate; SE: standard error; $\mathrm{Cl}$ : confidence interval; Min: minimum estimated coefficient; Max: maximum estimated coefficient; $z$ : $z$-value; $p$ : $\mathrm{p}$-value

d. Influences on success latencies

Individual's average latency to the first success was $29.57 \pm 25.98$ seconds (mean $\pm S D ; N=17$ ) in the jar task, $47.58 \pm 39.63 \mathrm{~s}$ (mean $\pm \mathrm{SD} ; \mathrm{N}=16$ ) in the pull task, and $82.73 \pm 113.57 \mathrm{~s}$ (mean $\pm \mathrm{SD} ; \mathrm{N}=19$ ) in the rotator task. From the first time success until the second success, individuals $(N=13)$ solved the jar with an average latency of $20.13 \pm 14.26 \mathrm{~s}$ (mean \pm SD), the pull task with an average latency of $45.30 \pm 37.30$ $S($ mean $\pm S D ; N=15)$, and the rotator task with an average latency of $57.03 \pm 53.19 \mathrm{~s}$ (mean $\pm S D ; N=$ 17).

We examined influences on the problem-solving performances of all individuals that solved once or twice the three problem-solving tasks (96 observations). The interaction between the proportion of manipulation of functional parts and task was not significant $(p=0.606)$, as well as the interaction between neophobia and social influence $(p=0.199)$. Therefore, we included all the single terms in the model. The model examining influences on problem-solving performance was significant $\left(\chi^{2}=33.339\right.$, $d f$ $=5, p<0.001)$. We found that the proportion of manipulation of functional parts influenced success latencies, with the individuals manipulating the functional parts more frequently solving the tasks faster $(p<0.001$, Figure 3, Table 4,). In addition, we found an effect of task on success latencies $(p=0.004$, Table 4). The post-hoc test revealed that individuals needed more time to solve the pull and rotator tasks than the jar task (Figure 4; Table 4). Specifically, the success latencies during the rotator task differed from the success latencies during the jar task (Tukey's test: rotator task versus jar task: $p<0.001)$, and the success latencies during the rotator task differed from the success latencies during the pull task (Tukey's test: rotator task versus pull task: $p=0.006$ ). But, success latencies during the pull task 
did not differ from the success latencies during the jar task (Tukey's test: pull task versus jar task: $p=$ 0.704). However, there was no effect of success time on success latencies in the three problem-solving tasks $(p=0.474)$, suggesting that the individuals did not improve their solving performances.

We did not find any effect of neophobia $(p=0.763)$ nor persistence $(p=0.441)$ on success latencies. Social influence did not affect also individuals' ability to solve the three tasks $(p=0.359)$. In addition, individuals' causal understanding performance did not influence success latencies $(p=0.413$, Table 4).

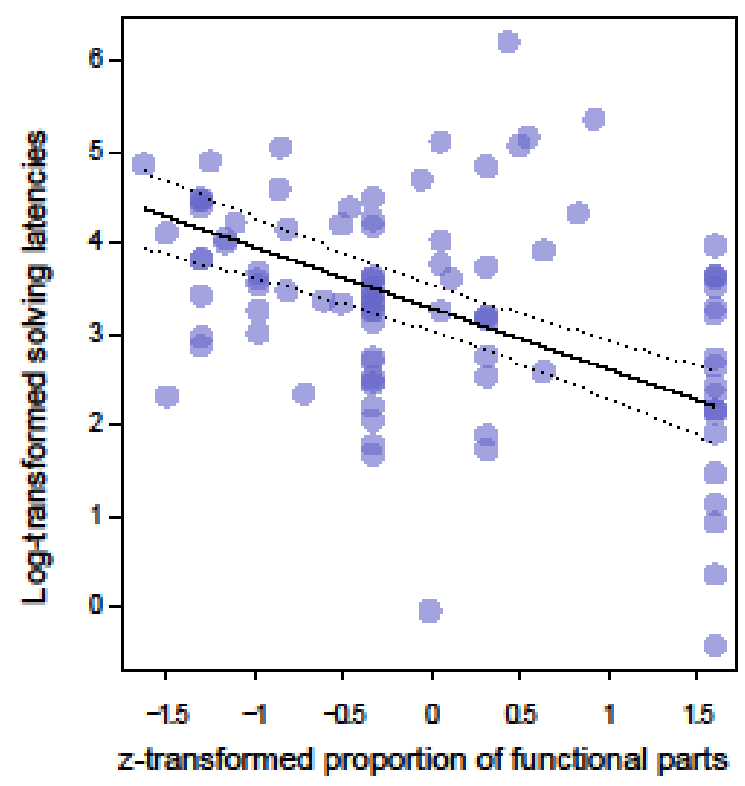

Fig 3. Influence of proportion of manipulation of functional parts on success latencies: individuals that manipulated the functional parts more often solved the problem-solving tasks faster. Log-transformed success latencies are depicted on the $y$-axis. Z-transformed proportion of manipulation of functional parts is depicted on the $x$-axis, with negative values representing individuals that manipulated less the functional parts, whereas positive values represent individuals that manipulated the functional parts more often. Each circle represents an individual that solved the three problem solving tasks until the first and/or the second successes. The continuous line depicts the fitted model, and the dotted lines depict its bootstrapped 95\% confidence intervals. 


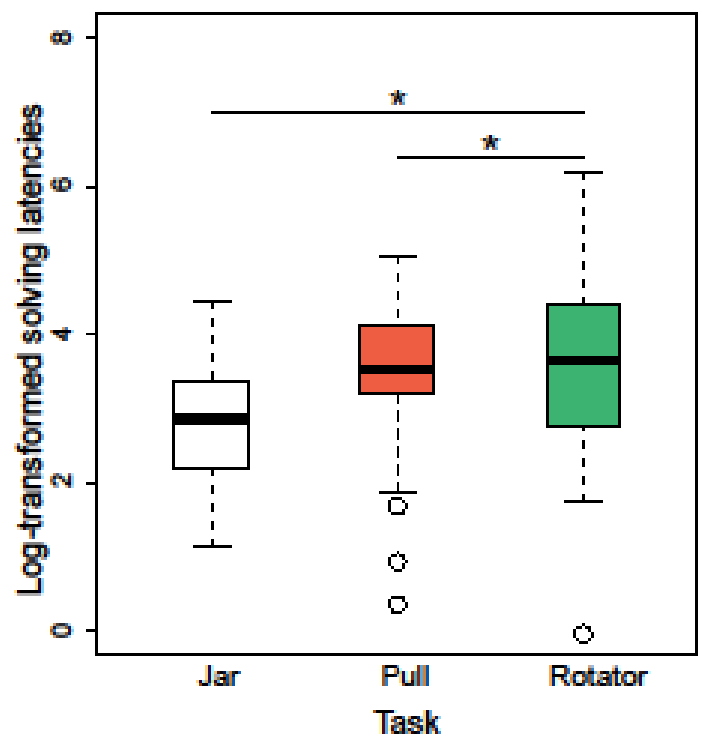

Fig 4. Effect of task on success latencies in problem-solving tasks: individuals required more time to solve the pull and rotator tasks compared to the jar task

Table 4: Parameters estimates of the linear mixed model (LMM) examining the influences on problem-solving performances

\begin{tabular}{|c|c|c|c|c|c|c|c|c|c|c|}
\hline \multirow[b]{2}{*}{ Variable response } & \multirow[b]{2}{*}{ Term } & \multicolumn{6}{|c|}{ Parameter estimates } & \multicolumn{3}{|c|}{$\begin{array}{l}\text { Likelihood test ratio } \\
\text { using drop1 function }\end{array}$} \\
\hline & & Est & SE & $\begin{array}{l}\text { Lower } \\
\mathrm{Cl}\end{array}$ & $\begin{array}{l}\text { Upper } \\
\mathrm{Cl}\end{array}$ & Min & $\max$ & $\chi^{2}$ & $d f$ & $p$ \\
\hline \multirow[t]{9}{*}{ Success latencies } & Intercept & 2.889 & 0.210 & 2.474 & 3.301 & 2.800 & 3.169 & $\mathrm{a}$ & a & a \\
\hline & Neophobia & -0.039 & 0.129 & -0.269 & 0.193 & -0.063 & 1.162 & 0.090 & 1 & 0.763 \\
\hline & Social influence & 0.090 & 0.093 & -0.089 & 0.267 & 0.065 & 0.157 & 0.839 & 1 & 0.359 \\
\hline & Persistence & -0.069 & 0.088 & -0.248 & 0.108 & -0.121 & -0.035 & 0.592 & 1 & 0.441 \\
\hline & Pull task & 0.179 & 0.225 & -0.241 & 0.626 & 0.072 & 0.238 & 10.939 & $2^{b}$ & $0.004^{b}$ \\
\hline & Rotator task & 1.083 & 0.281 & 0.553 & 1.618 & 0.966 & 1.218 & a & a & a \\
\hline & Time & -0.112 & 0.156 & -0.395 & 0.196 & -0.206 & -0.050 & 0.510 & 1 & 0.474 \\
\hline & $\begin{array}{l}\text { Proportion of } \\
\text { manipulation of } \\
\text { functional parts }\end{array}$ & -0.671 & 0.100 & -0.866 & -0.473 & -0.743 & -0.601 & 31.944 & 1 & $<0.001$ \\
\hline & $\begin{array}{l}\text { Causal understanding } \\
\text { performance }\end{array}$ & 0.116 & 0.140 & -0.156 & 0.398 & 0.020 & 0.288 & 0.669 & 1 & 0.413 \\
\hline
\end{tabular}

Est: estimate; SE: standard error; Cl: confidence interval; Min: minimum estimated coefficient; Max: maximum estimated coefficient; df: degree of freedom; z: z-value; $p$ : $p$-value 


\section{Discussion}

This study aimed to investigate factors influencing problem-solving abilities in wild narrow-striped mongooses. We used extractive problem-solving experiments applied before in meerkats to examine whether instrumental learning and/or causal understanding elicit performances in problem-solving. Individuals that partook in the problem-solving tasks were also successful in the causal understanding task. However, we found that individuals' problem-solving performances are due to instrumental learning, and not to causal understanding, as the individuals manipulating more often the functional parts of the apparatuses solved the tasks faster. However, we did not find any improvement in success latencies within tasks, and the individuals appeared not to have improved their efficiency in manipulating the functional parts within tasks. In contrast to previous studies, persistence did not affect individuals' problem-solving performances. In addition, problem-solving performances did not covary with neophobia or social influence.

We found that the individuals that manipulated the functional parts of the apparatuses more often were faster in solving the three solving-problem tasks. This outcome suggests that narrowstriped mongooses might have extracted a general rule on the functionality of the openable features of the tasks. Generalisation of feature functionality was also found, for instance, in New Caledonian crows. Individuals tested with different tasks that differ in the characteristics provided had the same solving success, suggesting that they acquired the general mechanisms of the apparatuses [51]. However, the narrow-striped mongooses did not enhance their efficiency in manipulating the functional parts within tasks, indicating that they did not learn the tasks instrumentally. Likewise, meerkats performed similarly in the same experimental set-up [29], as the time spent handling the functional parts was not reduced for the individuals that solved the tasks three times. Perhaps more trials are needed to observe learning effect. In addition, we found that the individuals manipulated the functional part of the rotator task more often than the jar and pull tasks, suggesting that the rotating lid movement might have provided visual feedback for the subjects. Such perceptual motor feedback was demonstrated in previous studies to support problem-solving performances $[20,23,24]$. However, more elaborated experiments will be needed to observe such effect, like the use of control setup. Therefore, since the narrow-striped mongooses did not learn instrumentally, it appears that the individuals relied on trial-and-error to solve the extractive problem-solving tasks.

Neither neophobia nor persistence predicted problem-solving performances in narrowstriped mongooses. Neophobia did not influence the likelihood to solve the problem-solving tasks, indicating that all personality types could solve the tasks. In a similar vein, neophobia did not affect the latency to solve problem-solving tasks in great tits (Parus major) [52]. A recent meta-analysis on innovation [27], but also a review [21], support this finding, suggesting that neophobia does not 
necessarily influence innovative problem-solving performance, although it may interfere with individuals' interaction with the tasks. It is possible that the effect of neophobia manifests in the approach of the task, which we did not address in the current study, and not for solving it. In addition, social influence did not influence problem-solving performances. Since social influence might allow individuals to overcome their neophobia [53], and neophobia did not influence solving performance, this outcome is conclusive.

In contrast to other studies [e.g., 21,26,37], persistence failed to explain individuals' performance in problem-solving. Indeed, most of the narrow-striped mongooses, which participated in the problem-solving tasks, solved the tasks twice, and individuals' persistence did not differ within or between tasks. Our results indicate that most of the narrow-striped mongooses engaged equally in the three problem-solving tasks. Moreover, Amici et al. showed that although persistence is wellknown to correlate positively with innovative performances, persistence is a weaker facilitator of innovation and is not the primary influence of innovation [27].

We did not find any difference between the first and second success latencies of the problem-solving tasks, indicating that the narrow-striped mongooses did not improve their solving time. Our result is similar to the finding in meerkats, where no difference was found between the first and the second success latencies [29]. Similarly, pheasants (Phasianus colchicus) did not improve their success latencies even after several presentations of the same task, which might be due to the fact that innovation is the by-product of a mainly motivational trait, i.e., persistence, and not cognition [30]. However, in our study, we did not find any influence of persistence on problemsolving performances, ruling out this possibility. In addition, the proportion of manipulation of functional parts did not differ between the first and second successes, indicating that the individuals did not improve their efficiency in manipulating the functional parts with time. A similar result was found in meerkats, where the individuals did not reduce the handling time of the functional parts [29]. The failure of individuals to enhance their efficiency in manipulating the functional parts within tasks is consistent with the individuals' inability to improve their success latencies with only two successes, which supports the notion that problem-solving performance is driven by trial-and-error in our study.

Narrow-striped mongooses learned the shape task above chance in our study, indicating that this species possesses causal understanding ability. However, the individuals' causal understanding performance in the shape task did not influence individuals' performance in the problem-solving tasks. Perhaps, it is because all individuals solved the task, which did not drive pronounced variation in performances. The shape task has been conducted before to assess the ability of apes, old world monkeys, and domestic dogs to make causal inferences about the location of food [14]. It has been 
shown that apes were better performers because of their necessity to make inferences about hidden resources involved in their extractive foraging skills compared to domestic dogs [14]. However, the shape task is based on visual cues [14], and it could be that the problem-solving tasks did not address the same causal cues. Ideally, to overcome this ambiguity, examining problem-solving performances in transfer tasks, which means comparing individuals' performances on related tasks with and without specific causal features, would allow disentangling whether a species uses causal understanding ability to solve a given problem (see, for example [13]). In addition, future studies should control for perceptual-motor feedback in designing the task.

To conclude, our study contributes to the understanding of innovative problem-solving in carnivores, as well as the role of personality traits and causal understanding in this context. Our study indicates that narrow-striped mongooses relied only on trial-and-error from the manipulation of the functional parts to solve the tasks. Although, the narrow-striped mongooses possess causal understanding ability, it did not determine their success in problem-solving. Moreover, our study suggests that the shape task is probably not representative enough of the causal ability needed in extracting hidden food resources, in contrast to the findings of a previous study [14]. Therefore, future studies should consider a more elaborated task design to examine the link between causal understanding and extractive problem-solving.

\section{Acknowledgements}

We would like to thank Léonard Razafimanantsoa and Rodin Rasoloarison for administrative and logistic support, Remy d'Ampataka for his help with fieldwork and the staff of Kirindy for their support. We appreciate the collaboration with the Département de Biologie Animale of the University of Antananarivo, the Ministère de l'Environnement, de l'Ecologie, de la Mer et des Forêts and the CNFEREF Morondava for authorizing our research in Kirindy. Funding was provided to BNR by the "DAAD: Deutscher Akademischer Austauschdienst" (funding program/-ID: 57129429).

Conflict of Interest: The authors declare that they have no conflict of interest.

Ethical approval: All procedures performed in this study were in accordance with the ethical standards of the Ministère de l'Environnement, de l'Ecologie, de la Mer et des Forêts.

\section{References}

1. Reader SM, Laland KN. 2003 Animal Innovation: An Introduction. In Animal Innovation (eds SM Reader, KN Laland), pp. 3-36. Oxford University Press. (doi:10.1093/acprof:oso/9780198526223.003.0001) 
2. Serrano-Davies E, O'Shea W, Quinn JL. 2017 Individual foraging preferences are linked to innovativeness and personality in the great tit. Behav. Ecol. Sociobiol. 71, 161.

(doi:10.1007/s00265-017-2389-y)

3. Daniels SE, Fanelli RE, Gilbert A, Benson-Amram S. 2019 Behavioral flexibility of a generalist carnivore. Anim. Cogn. 22, 387-396. (doi:10.1007/s10071-019-01252-7)

4. Duffield C, Wilson AJ, Thornton A. 2015 Desperate Prawns: Drivers of Behavioural Innovation Vary across Social Contexts in Rock Pool Crustaceans. PLOS ONE 10, e0139050. (doi:10.1371/journal.pone.0139050)

5. Kittler K, Kappeler PM, Fichtel C. 2018 Instrumental problem-solving abilities in three lemur species (Microcebus murinus, Varecia variegata, and Lemur catta). J. Comp. Psychol. 132, 306-314. (doi:10.1037/com0000113)

6. Overington SE, Griffin AS, Sol D, Lefebvre L. 2011 Are innovative species ecological generalists? A test in North American birds. Behav. Ecol. 22, 1286-1293. (doi:10.1093/beheco/arr130)

7. Huber L, Gajdon GK. 2006 Technical intelligence in animals: the kea model. Anim. Cogn. 9, 295-305. (doi:10.1007/s10071-006-0033-8)

8. Vonk J. 2016 Advances in Animal Cognition. Behav. Sci. 6, 27. (doi:10.3390/bs6040027)

9. Byrne RW. 1997 The technical intelligence hypothesis: an additional evolutionary stimulus to intelligence. In Machiavellian intelligence II, pp. 289-311.

10. Navarrete AF, Reader SM, Street SE, Whalen A, Laland KN. 2016 The coevolution of innovation and technical intelligence in primates. Philos. Trans. R. Soc. B Biol. Sci. 371, 20150186. (doi:10.1098/rstb.2015.0186)

11. Tebbich S, Griffin AS, Peschl MF, Sterelny K. 2016 From mechanisms to function: an integrated framework of animal innovation. Philos. Trans. R. Soc. B Biol. Sci. 371, 20150195. (doi:10.1098/rstb.2015.0195)

12. Griffin AS, Diquelou M, Perea M. 2014 Innovative problem solving in birds: a key role of motor diversity. Anim. Behav. 92, 221-227. (doi:10.1016/j.anbehav.2014.04.009)

13. Taylor AH, Hunt GR, Medina FS, Gray RD. 2009 Do New Caledonian crows solve physical problems through causal reasoning? Proc. R. Soc. B Biol. Sci. 276, 247-254.

(doi:10.1098/rspb.2008.1107)

14. Bräuer J, Kaminski J, Riedel J, Call J, Tomasello M. 2006 Making inferences about the location of hidden food: Social dog, causal ape. J. Comp. Psychol. 120, 38-47. (doi:10.1037/07357036.120.1.38)

15. Call J, Hare B, Carpenter M, Tomasello M. 2004 'Unwilling' versus 'unable': chimpanzees' understanding of human intentional action. Dev. Sci. 7, 488-498. (doi:10.1111/j.14677687.2004.00368.x)

16. Jacobson SL, Hopper LM. 2019 Hardly habitual: chimpanzees and gorillas show flexibility in their motor responses when presented with a causally-clear task. PeerJ 7, e6195.

(doi:10.7717/peerj.6195) 
17. Osthaus B, Lea SEG, Slater AM. 2005 Dogs (Canis lupus familiaris) fail to show understanding of means-end connections in a string-pulling task. Anim. Cogn. 8, 37-47.

(doi:10.1007/s10071-004-0230-2)

18. Müller CA, Riemer S, Virányi Z, Huber L, Range F. 2014 Dogs learn to solve the support problem based on perceptual cues. Anim. Cogn. 17, 1071-1080. (doi:10.1007/s10071-0140739-y)

19. Morand-Ferron J, Cole EF, Quinn JL. 2016 Studying the evolutionary ecology of cognition in the wild: a review of practical and conceptual challenges: Evolutionary ecology of cognition in the wild. Biol. Rev. 91, 367-389. (doi:10.1111/brv.12174)

20. Overington SE, Cauchard L, Côté K-A, Lefebvre L. 2011 Innovative foraging behaviour in birds: What characterizes an innovator? Behav. Processes 87, 274-285. (doi:10.1016/j.beproc.2011.06.002)

21. Griffin AS, Guez D. 2014 Innovation and problem solving: A review of common mechanisms. Behav. Processes 109, 121-134. (doi:10.1016/j.beproc.2014.08.027)

22. Jelbert SA, Taylor AH, Gray RD. 2015 Investigating animal cognition with the Aesop's Fable paradigm: Current understanding and future directions. Commun. Integr. Biol. 8, e1035846. (doi:10.1080/19420889.2015.1035846)

23. Völter CJ, Call J. 2012 Problem solving in great apes (Pan paniscus, Pan troglodytes, Gorilla gorilla, and Pongo abelii): the effect of visual feedback. Anim. Cogn. 15, 923-936. (doi:10.1007/s10071-012-0519-5)

24. Taylor AH, Medina FS, Holzhaider JC, Hearne L, Hunt GR, Gray RD. 2010 An Investigation into the Cognition Behind Spontaneous String Pulling in New Caledonian Crows. PLOS ONE 5, e9345. (doi:10.1371/journal.pone.0009345)

25. Griffin AS, Guez D. 2015 Innovative problem solving in nonhuman animals: the effects of group size revisited. Behav. Ecol. 26, 722-734. (doi:10.1093/beheco/aru238)

26. Cheke LG, Bird CD, Clayton NS. 2011 Tool-use and instrumental learning in the Eurasian jay (Garrulus glandarius). Anim. Cogn. 14, 441-455. (doi:10.1007/s10071-011-0379-4)

27. Amici F, Widdig A, Lehmann J, Majolo B. 2019 A meta-analysis of interindividual differences in innovation. Anim. Behav. 155, 257-268. (doi:10.1016/j.anbehav.2019.07.008)

28. Lermite F, Peneaux C, Griffin AS. 2017 Personality and problem-solving in common mynas (Acridotheres tristis). Behav. Processes 134, 87-94. (doi:10.1016/j.beproc.2016.09.013)

29. Thornton A, Samson J. 2012 Innovative problem solving in wild meerkats. Anim. Behav. 83, 1459-1468. (doi:10.1016/j.anbehav.2012.03.018)

30. van Horik JO, Madden JR. 2016 A problem with problem solving: motivational traits, but not cognition, predict success on novel operant foraging tasks. Anim. Behav. 114, 189-198. (doi:10.1016/j.anbehav.2016.02.006)

31. Benson-Amram S, Holekamp KE. 2012 Innovative problem solving by wild spotted hyenas. Proc. R. Soc. B Biol. Sci. 279, 4087-4095. (doi:10.1098/rspb.2012.1450) 
32. Greenberg RS. 2003 The role of neophobia and neophilia in the development of innovative behaviour of birds.

33. Stanton L, Davis E, Johnson S, Gilbert A, Benson-Amram S. 2017 Adaptation of the Aesop's Fable paradigm for use with raccoons (Procyon lotor): considerations for future application in non-avian and non-primate species. Anim. Cogn. 20, 1147-1152. (doi:10.1007/s10071-0171129-z)

34. Young JK, Touzot L, Brummer SP. 2019 Persistence and conspecific observations improve problem-solving abilities of coyotes. PLOS ONE 14, e0218778. (doi:10.1371/journal.pone.0218778)

35. Smirnova A, Zorina Z, Obozova T, Wasserman E. 2015 Crows Spontaneously Exhibit Analogical Reasoning. Curr. Biol. 25, 256-260. (doi:10.1016/j.cub.2014.11.063)

36. Hofmann MM, Cheke LG, Clayton NS. 2016 Western scrub-jays (Aphelocoma californica) solve multiple-string problems by the spatial relation of string and reward. Anim. Cogn. 19, 1103-1114. (doi:10.1007/s10071-016-1018-x)

37. Davidson G, Miller R, Loissel E, Cheke LG, Clayton NS. 2017 The development of support intuitions and object causality in juvenile Eurasian jays (Garrulus glandarius). Sci. Rep. 7, 40062. (doi:10.1038/srep40062)

38. Albiach-Serrano A, Call J. 2014 A reversed-reward contingency task reveals causal knowledge in chimpanzees (Pan troglodytes). Anim. Cogn. 17, 1167-1176. (doi:10.1007/s10071-0140749-9)

39. Lampe M, Bräuer J, Kaminski J, Virányi Z. 2017 The effects of domestication and ontogeny on cognition in dogs and wolves. Sci. Rep. 7, 11690. (doi:10.1038/s41598-017-12055-6)

40. Müller CA. 2010 Do anvil-using banded mongooses understand means-end relationships? A field experiment. Anim. Cogn. 13, 325-330. (doi:10.1007/s10071-009-0281-5)

41. Rasolofoniaina B, Razafy P, Razafimahatratra E, Kappeler PM. 2019 Feeding ecology of the bokiboky, Mungotictis decemlineata (family Eupleridae). Malagasy Nature 13, 152-161.

42. Razafimanantsoa L. 2003 Mungotictis decemlineata, narrow-striped mongoose. In The natural history of Madagascar., pp. 1357-1360. Chicago: The University of Chicago Press.

43. Schneider TC, Kappeler PM. 2016 Gregarious sexual segregation: the unusual social organization of the Malagasy narrow-striped mongoose (Mungotictis decemlineata). Behav. Ecol. Sociobiol. 70, 913-926. (doi:10.1007/s00265-016-2113-3)

44. Friard O, Gamba M. 2016 BORIS: a free, versatile open-source event-logging software for video/audio coding and live observations. Methods Ecol. Evol. 7, 1325-1330. (doi:10.1111/2041-210X.12584)

45. Rasolofoniaina, B. N., Kappeler, P. M., \& Fichtel, C. 2020. Neophobia and social facilitation in narrow-striped mongooses. Anim Cogn. 1-11.

46. Rasolofoniaina, B., Kappeler, P. M., \& Fichtel, C. 2020. Wild narrow-striped mongooses use social information to enhance behavioural flexibility. Ethol. DOI: 10.1111/eth.13123 
47. Henke-von der Malsburg J, Fichtel C. 2018 Are generalists more innovative than specialists? A comparison of innovative abilities in two wild sympatric mouse lemur species. 5, 180480.

48. R Core Team. 2017 R: A language and environment for statistical computing. Vienna, Austria: R Foundation for Statistical Computing. See URL https://www.R-project.org/.

49. Bates D, Mächler M, Bolker B, Walker S. 2014 Fitting linear mixed-effects models using Ime4. ArXiv Prepr. ArXiv14065823

50. Nakagawa, S., \& Schielzeth, H. 2010. Repeatability for Gaussian and non-Gaussian data: A practical guide for biologists. Biol. Rev. https://doi.org/10.1111/j.1469-185X.2010.00141.x

51. von Bayern AMP, Heathcote RJP, Rutz C, Kacelnik A. 2009 The Role of Experience in Problem Solving and Innovative Tool Use in Crows. Curr. Biol. 19, 1965-1968.

(doi:10.1016/j.cub.2009.10.037)

52. Cole EF, Cram DL, Quinn JL. 2011 Individual variation in spontaneous problem-solving performance among wild great tits. Anim. Behav. 81, 491-498.

(doi:10.1016/j.anbehav.2010.11.025)

53. Forss SIF, Koski SE, van Schaik CP. 2017 Explaining the Paradox of Neophobic Explorers: The Social Information Hypothesis. Int. J. Primatol. 38, 799-822. (doi:10.1007/s10764-017-99847)

54. Chow PKY, Lea SEG, Leaver LA. 2016 How practice makes perfect: the role of persistence, flexibility and learning in problem-solving efficiency. Anim. Behav. 112, 273-283.

(doi:10.1016/j.anbehav.2015.11.014) 


\section{Chapter 4}

"Neophobia and social facilitation in narrow-striped mongooses"

Bako N. Rasolofoniaina ${ }^{1}$, Peter M. Kappeler ${ }^{1,2}$, Claudia Fichtel $^{2}$

${ }^{1}$ Dept. Sociobiology/Anthropology, Johann-Friedrich-Blumenbach Institute of Zoology and Anthropology, University Göttingen, Germany

${ }^{2}$ Behavioral Ecology and Sociobiology Unit, German Primate Center Leibniz Institute for Primate Research, Göttingen, Germany

This chapter is published in Animal Cognition (2021) 24(1): 165-175 https://doi.org/10.1007/s10071-020-01429-5 


\title{
Neophobia and social facilitation in narrow-striped mongooses
}

\author{
Bako N. Rasolofoniaina ${ }^{1}\left[\right.$. Peter M. Kappeler ${ }^{1,2} \cdot$ Claudia Fichtel $^{2}$
}

Received: 17 November 2019 / Revised: 6 September 2020 / Accepted: 11 September 2020 / Published online: 21 September 2020 (c) The Author(s) 2020

\begin{abstract}
Social learning is widespread in the animal kingdom, but individuals can differ in how they acquire and use social information. Personality traits, such as neophobia, may, for example, promote individual learning strategies. Here, we contribute comparative data on social learning strategies in carnivorans by examining whether narrow-striped mongooses (Mungotictis decemlineata), a group-living Malagasy euplerid, learn socially and whether neophobia influences social learning. To this end, we tested seven wild female groups with a two-option artificial feeding box, using a demonstrator-observer paradigm, and conducted novel object tests to assess neophobia. In five groups, one individual was trained as a demonstrator displaying one of the techniques, whereas the other two groups served as control groups. Neophobia did not co-vary with an individual's propensity to seek social information. However, less neophobic individuals, and individuals that tended to seek social information, learned the task faster. Moreover, individuals in demonstrator groups learned the task faster than those in groups without a demonstrator and used the demonstrated technique more often. Hence, narrow-striped mongooses rely on social facilitation and local or stimulus enhancement to solve new problems. Finally, our results suggest that several individual characteristics should be taken into consideration to obtain a more comprehensive understanding of social learning strategies.
\end{abstract}

Keywords Carnivora $\cdot$ Social facilitation $\cdot$ Neophobia $\cdot$ Attendance bias $\cdot$ Mungotictis decemlineata

\section{Introduction}

Learning by observing others is a mechanism for behavioural plasticity that can shape the behavioural repertoire of an individual (Kendal et al. 2010; Aplin 2016). Social learning is associated with many benefits, from acquiring behavioural traits in different contexts to the establishment of cultural behaviour across populations (Aplin 2016; Whiten and van de Waal 2018). However, social learning also comes with costs, as it can spread incorrect information (Rieucau and Giraldeau 2011). Consequently, individuals should ideally switch flexibly between asocial and social learning strategies (Kendal et al. 2018). To maximize the benefits, an individual should flexibly use social learning strategies to decide from

Bako N. Rasolofoniaina

BRasolofoniaina@dpz.eu

1 Dept. Sociobiology/Anthropology, Johann-Friedrich-Blumenbach Institute of Zoology and Anthropology, University Göttingen, Göttingen, Germany

2 Behavioral Ecology and Sociobiology Unit, German Primate Center Leibniz Institute for Primate Research, Göttingen, Germany whom and when to learn, and which information to acquire (Laland 2004; Kendal et al. 2018). Social learning strategies encompass social information seeking and its use or application in future contexts. For instance, one type of a social learning strategy, the "state-based strategy", depends on the observer's intrinsic characteristics, such as rank, age, and sex, which may influence its decision to learn socially in a given situation (Kendal et al. 2018). Moreover, a statebased strategy will influence an individual's choice to be attentive to a conspecific to seek social information, triggering a preferential attendance bias (Kendal et al. 2018), resulting in directed social learning or a transmission bias (Kendal et al. 2015). As a result, the tendency to seek and use social information can vary at the individual level across group members (Mesoudi et al. 2016; Watson et al. 2018).

One of the main factors driving this variation is animal personality, i.e., individual differences in behaviour that are consistent across time and contexts (Réale et al. 2007; Kurvers et al. 2010a; Mesoudi et al. 2016). Personality traits, such as boldness, neophobia or exploration, appear to influence the tendency to use social information and provide a benefit against danger in a high-risk environment (Greggor et al. 2015; Crane and Ferrari 2017). For example, in a 
social foraging experiment, shyer barnacle geese (Branta leucopsis) were more likely to use social information than their bolder conspecifics because they had fewer opportunities to gather individual information and, hence, relied more on conspecific demonstrators to find high-quality food patches (Kurvers et al. 2010a). In contrast, in great tits (Parus major), bolder individuals were more inclined to profit from social learning because the more fearless individuals hindered shyer individuals from participating in the learning situation (Marchetti and Drent 2000). Furthermore, neophobia can also be transmitted socially as for example in fathead minnows (Pimephales promelas), where naïve observers also learned neophobic responses from a demonstrator in a social learning paradigm (Crane et al. 2015).

Exploration influenced social learning in a study examining mate choice and food choice, with less explorative female zebra finches (Taeniopygia guttata) copying the decision exhibited by a conspecific model even if it would lead to unfavourable choices, such as the choice of a non-preferred male or non-preferred food (Rosa et al. 2012). Although female zebra finches were previously tested for their individual preferences, they still followed the model's choice, indicating that they prioritised social information over personal information (Rosa et al. 2012). In three-spined sticklebacks (Gasterosteus aculeatus), more explorative individuals were more likely to join an unfamiliar demonstrator because less explorative individuals needed more time to familiarize themselves with the new conspecific and were, hence, more sensitive to risk (Nomakuchi et al. 2009). Therefore, personality traits can modify the tendency to learn socially by obtaining access to either personal or social information, as well as the tendency to rely more on social learning in contexts where unfamiliar objects/conspecifics are involved. However, whereas the effect of exploratory behaviours on social learning is well known (summarised in Mesoudi et al. 2016), the effect of neophobia on the tendency to seek social information remains obscure in comparison.

Although social learning is widespread across animals (insects: Slaa et al. 2003; Grüter and Leadbeater 2014; fish: Nomakuchi et al. 2009; Webster and Laland 2017; birds: Marchetti and Drent 2000; Morales Picard et al. 2017; carnivorans: Thornton and Clutton-Brock 2011; primates: Schnoell and Fichtel 2012; van de Waal et al. 2013), it has been less often studied experimentally in social carnivores. For instance, spotted hyenas (Crocuta crocuta) did not learn socially in a problem-solving task (Benson-Amram et al. 2014). For meerkats (Suricata suricatta), however, individuals preferentially chose the landmark in a two-choice task that was also preferred by a demonstrator, indicating inadvertent social learning via stimulus enhancement (Thornton and Malapert 2009). Teaching, a highly derived form of social learning, has been shown in meerkats, with adults providing pups opportunities to interact with live prey to learn prey-handling skills (Thornton and McAuliffe 2006). Moreover, young banded mongooses (Mungos mungo) imitate the foraging technique exhibited by adult individuals (Müller and Cant 2010). Thus, patterns of social learning appear to be highly variable across carnivorans.

To contribute new comparative data to this field of research, we investigated the presence of social learning in narrowstriped mongooses (Mungotictis decemlineata). Specifically, we examined the influence of personality on an individual's probability to learn socially in a social diffusion task. Female narrow-striped mongooses live in stable, hierarchical groups (3.7 \pm 0.4 individuals) (Schneider and Kappeler 2016), and exhibit a generalist and opportunistic feeding ecology (Rasolofoniaina et al. 2019). Group members regularly forage for hidden prey, which may present opportunities for social learning to acquire relevant hunting strategies, exploration of novel food, or space use. In particular, we examined whether an individual's tendency to learn socially is related to individual variation in neophobia, because neophobia is generally thought to hinder individual learning (Webster and Lefebvre 2001).

Using field experiments, we examined individual variation in neophobia by presenting novel objects, and we studied social learning by conducting a social diffusion experiment. Social diffusion experiments are set out to study how founder behaviours spread across multiple individuals in a group (Whiten and Mesoudi 2008). By presenting an artificial feeding apparatus that can be opened by two different techniques and for which demonstrators have been trained to use only one of the two techniques, social learning has been demonstrated in various species (primates: Pesendorfer et al. 2009; van de Waal et al. 2010; Schnoell and Fichtel 2012; Claidière et al. 2013; birds: Morales Picard et al. 2017). To investigate experimentally social learning, we confronted narrow-striped mongooses with such a two-option feeding apparatus. We predicted that: (1) if neophobia positively influences the propensity to observe the demonstrator, more neophobic individuals are expected to spend more time with the demonstrator manipulating the task than less neophobic individuals, (2) If neophobia positively influences social learning, less neophobic individuals are expected to learn the task faster than more neophobic individuals, (3) If narrow-striped mongooses learn socially, we predicted that the presence of a demonstrator should improve the learning speed of observers compared to individuals learning without demonstrator, and (4) individuals are more likely to use the demonstrated technique to open the feeding appartus.

\section{Methods}

\section{Study animals and general testing procedure}

Between November 2014 and September 2017, we studied seven female groups (Table 1) from an individually-marked 
Table 1 Group composition (all female adults and the juveniles and infants of unknown sex) and experimental condition during the social learning task

\begin{tabular}{lll}
\hline Group & Number of individuals & Condition \\
\hline B & 3 ( 3 adults) & Control \\
L & 3 (2 adults and 1 juvenile $)$ & Control \\
C & 6 (4 adults and 2 juveniles $)$ & Pull \\
N & 4 (2 adults, 1 juvenile and 1 infant $)$ & Pull \\
G1 & 2 (1 adult and 1 infant $)$ & Pull \\
L1 & 2 (2 adults) & Slide \\
M & 5 (5 adults) & Slide \\
\hline
\end{tabular}

population of free-ranging narrow-striped mongooses (Schneider and Kappeler 2016) in Kirindy Forest, Madagascar. Individuals in a group were marked either by radio-collars or with specific fur-shaving patterns on the tail. Groups were located within their territory using radio-tracking and were tested opportunistically. For testing, we used the following general experimental procedure: apparatuses were baited with dry cat food out of sight of the individuals, and animals were lured with an acoustic signal, shaking a plastic box containing cat food to the experimental area (Schnoell and Fichtel 2012). The experiment started when the first individual of the group approached one of the apparatuses within a range of $3 \mathrm{~m}$ and ended when the last individual left the arena.

\section{Novel object test}

Neophobia was assessed by presenting a novel object next to a wooden plate containing food. Both objects were placed in the middle of a metal ring, allowing an accurate estimate of the distance between the subject and the novel object. Individuals were previously habituated to the metal ring before conducting the novel object test. To avoid monopolisation by certain individuals, we presented one experimental set-up per individual. To assess the repeatability of the personality trait "neophobia," we conducted two novel object tests, by presenting either colourful plastic balls or red plastic cups as novel objects. In six groups, we repeated the novel object test after a period of 3 years, whereas in one group, marked at the end of the study, we repeated the novel object test after a period of 4 months. The average time between the two novel object tests was $12.5 \pm 12.02$ (mean $\pm \mathrm{SD}$ ) months. We tested 33 individuals in the first novel object test but only 15 individuals in the second novel object test, due to individual losses over the 3 years or a lack of motivation of some individuals to approach the experimental area.

Based on video-recordings, we measured the following behaviours from the two novel object tests: latency to enter the metal ring, latency to contact the novel object, and latency to feed next to the novel object. We estimated the repeatability of each individual latency with individuals that participated in both novel object tests $(N=15)$, using the package "rptR" (Nakagawa and Schielzeth 2010). Before the analyses, we log-transformed the variables to achieve normality. We computed point estimates of repeatability $R, p$ values, standard errors $\mathrm{SE}$, and the confidence intervals with bootstrapping. The significant repeatable latency to feed next to the novel object was retained and defined as "neophobia." Individuals exhibiting longer latencies were categorised as more neophobic, whereas those with shorter latencies were the less neophobic ones.

\section{Social learning experimental set-up}

A problem-solving feeding apparatus (Fig. 1) was constructed similar to an apparatus that has been used in a study of social learning in vervet monkeys (Chlorocebus aethiops) (van de Waal and Bshary 2011). The apparatus consisted of a wooden box $(9.5 \mathrm{~cm} \times 13.6 \mathrm{~cm})$, with a transparent plexiglass door, fixed on a wooden plate $(13 \mathrm{~cm} \times 17 \mathrm{~cm})$. The door could be opened via two opening mechanisms, by either pulling or sliding the plexiglass door. We first trained a demonstrator by presenting only one box that could be opened by one technique only. Following this training, we conducted the group experiment by presenting several boxes that could be opened by both techniques and we presented one box for each group member. In total, we tested seven groups: five groups in which a demonstrator was trained to open the box with either the pull ( $N=3$ groups) or the slide technique ( $N=2$ groups), and two groups in which no demonstrator was trained served as control groups. For the control groups $(N=2)$, we used boxes that could be opened by both techniques.

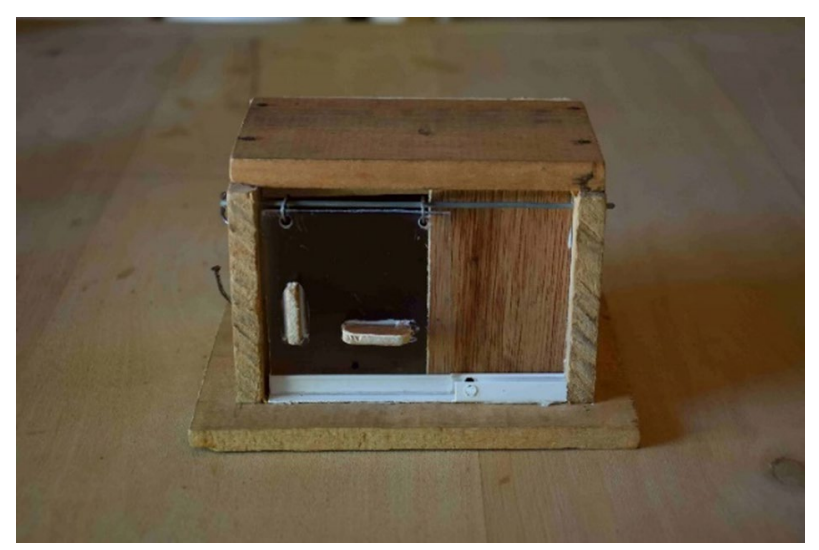

Fig. 1 Two-option foraging apparatus used to assess social learning. The door can be opened by either sliding or pulling 


\section{Demonstrator training procedure}

To train the demonstrator, only one feeding apparatus was presented, which was monopolized across sessions and groups by the oldest and dominant female of a group, and she served as the demonstrator (Schneider and Kappeler 2016). In three groups, we trained the demonstrator to open the apparatus with the pull technique by blocking the slide technique, whereas in the other two groups, we trained the demonstrator to open the apparatus with the slide technique. For the training, we presented the boxes once per day and the demonstrator could perform only one trial over the course of 20 days, resulting in 20 trials performed by the demonstrator. To ensure that they had learned the task, each demonstrator had to open the box more often than expected by chance by reaching a learning criterion of $80 \%$ successful trials.

Since groups of narrow-striped mongooses always forage together (Schneider and Kappeler 2016), other group members (observers) were present in the experimental arena and could approach the demonstrator while she manipulated the apparatus. To assess the propensity to seek social information, we placed a metal ring $(50 \mathrm{~cm}$ diameter, the same metal ring used during the novel object tests) around the feeding apparatus during the presentation, allowing us to measure the time spent close to the demonstrator for each observer. To prevent observers from manipulating the boxes during the training of demonstrators, the hinge of the door was built tight, so that it stayed open and did not close automatically after the demonstrator let the door loose. In addition, only one piece of cat food was placed in the box for the demonstrator, preventing observers from scrounging.

\section{Group testing procedure}

After the demonstrator had learned the task, we tested the entire group. We presented several boxes corresponding to the number of individuals in a group to avoid monopolisation of the apparatuses by the dominant female. The boxes were now baited with ten pieces of dry cat food to allow individuals to perform several trials repeatedly while both opening mechanisms were available. This time the door of the boxes closed automatically after the individual let the door loose, so that they had to open it again to obtain access to another reward. For the group testing procedure, each presentation of the apparatuses per group was considered as one session. Within a session, an individual could perform several trials. Subjects were tested until they reached a learning criterion of $80 \%$ of successful trials out of a minimum of 15 trials. Since several pieces of dry cat food were available, the apparatuses were not re-baited after each trial and were only removed after the last individual left the experimental arena.

\section{Video analyses}

During the experiments, subjects were video-taped with a camcorder (SONY HDR-CX 240), and videos were analysed using Boris (Friard and Gamba 2016). From the demonstrator training sessions, we assessed social learning opportunities, which were defined as the time an observer spent together with a demonstrator within the metal ring, while the demonstrator was actively manipulating the boxes. To measure individual learning performance, we scored individual learning speed during the demonstrator training sessions and the group testing sessions. Learning speed was defined as the number of trials needed by an individual to reach the learning criterion, which was $80 \%$ of successful trials.

\section{Statistical analyses}

We conducted all analyses using $\mathrm{R}$ statistical software ( $\mathrm{R}$ Core Team 2017). First, to examine whether social learning opportunities co-varied with neophobia, we conducted Spearman's correlation test between neophobia and social learning opportunities. Second, we examined whether the learning speed of observers in the demonstrator groups was predicted by neophobia and social learning opportunities by fitting a GLMM with a Poisson structure, using the package lme4 (Bates et al. 2014). Learning speed corresponds to the number of trials required by an individual to reach the learning criterion ( $80 \%$ of correct trials). Learning speed was fitted as the response variable and neophobia and social learning opportunities were fitted as fixed factors. We initially included the interaction term between fixed factors and we checked its significance using likelihood test ratio. When non-significant, the interaction between fixed factors was dropped from the analysis and the single terms were kept in the model. As the members of a group were present at the experimental arena during each test, we tested multiple individuals together at the same time. We, therefore, included group identity as random factor in the model.

Third, we examined whether learning speed was influenced by the presence of a demonstrator (yes or no). For this analysis, we used a Cox proportional hazards model with learning speed as the dependent variable, treating whether the individual learned the task or not (yes or no) as censored observations. The Cox model was conducted using the R-package "survival" (Therneau 2015).

Fourth, we examined whether observers in the pull and slide groups differed in the proportion of trials during which they used the pull technique using a Mann-Whitney $U$ test. We also performed exact binomial tests to examine whether individuals in both the demonstrator and control groups developed a preference for one technique to solve the twooption task. We defined a preference when individuals used one technique more often than expected by chance to solve 
the two-option task. Moreover, using binomial tests, we examined whether the number of individuals that developed a preference differed from those that did not develop a preference for all groups and in the demonstrator groups only.

For the mixed models, we checked for collinearity between the fixed factors prior to all analyses. For all models, we performed likelihood test ratio for the full-null model comparisons and we visually inspected normality and homoscedasticity with residual plots. For the Cox proportional hazards model, we checked for the violation of proportional hazards.

\section{Results}

\section{Neophobia}

The latency to feed next to the novel object was significantly repeatable over time $(R=0.439, p=0.04)$, whereas the latency to enter the ring $(R=0.001, p=0.149)$ and the latency to contact the novel object $(R=0.073, p=0.44)$ were not repeatable. Hence, we consider the latency to feed next to the novel object as neophobia. Neophobia did not correlate with social learning opportunities however (Spearman's rank correlation test: $r=0.009, p=0.989$ ).

\section{Use of social information for learning}

During the demonstrator training sessions, all five demonstrators learned to open the feeding apparatus. Four out of five demonstrators required 20 trials to learn the task, whereas one demonstrator (from group N) needed 28 trials. On average, the demonstrators needed $21.6 \pm 3.6$ (mean $\pm \mathrm{SD}$ ) trials to learn the task. Demonstrators needed on average $5.24 \mathrm{~s}$ (median, IQR: $4.77, N=3$ ) to open the door using the pull technique and $4.42 \mathrm{~s}$ (median, IQR: $5.27, N=2$ ) using the slide technique, suggesting that both techniques were equally difficult. During the group testing sessions, five out of seven observers in the pull groups and three out of four observers in the slide groups learned the task within $31 \pm 16($ mean $\pm S D)$ trials. In the control groups, four individuals participated, but only one individual learned the task after 55 trials.

The learning speed of observers co-varied with the presence of a demonstrator ( $p=0.037$, Table 2$)$, with individuals in demonstrator groups learning the task faster compared to individuals in control groups (Fig. 2). During the demonstrator training sessions, observers spent on average $6.7 \pm 13.7$ min (mean $\pm \mathrm{SD}$ ) within the metal ring together with the demonstrator, our measure of social learning opportunities. We found that learning speed was influenced by both neophobia ( $p=0.011$; Table $3 a)$ and social learning

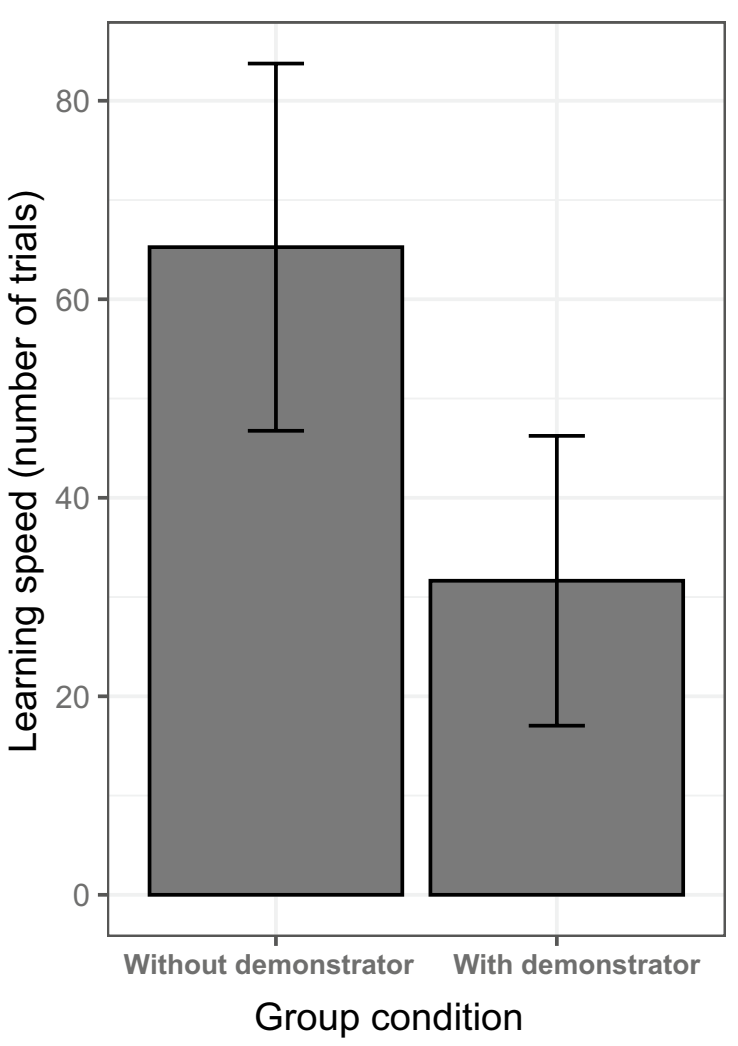

Fig. 2 Difference in learning speed between individuals provided with demonstrators (pull and slide groups) and individuals without demonstrators (control groups): individuals in groups with a demonstrator learned the task faster

Table 2 Result of the Cox's proportional hazards model assessing the effect of the presence of the demonstrator on individuals' learning performances $(N=15)$

\begin{tabular}{|c|c|c|c|c|c|c|c|}
\hline Model & Fixed effect & Censor variable & $B \pm \mathrm{SE}$ & $Z$ & e $(95 \% \mathrm{CI})$ & $P$ value & $\begin{array}{l}\text { Test for the proportional } \\
\text { hazards }\end{array}$ \\
\hline $\begin{array}{l}\text { Effect of the presence of } \\
\text { demonstrator on learning } \\
\text { speed }\end{array}$ & Learning speed & Learning (yes or no) & $2.32 \pm 1.11$ & 2.08 & $10.23(1.15 ; 90.8)$ & 0.0369 & 0.486 \\
\hline
\end{tabular}

$B$ beta coefficient; $S E$ standard error; $z$ Wald statistic value; $P$ p value; e: exponentially transformed parameter estimates show the proportional change of hazard ratio, that is, the probability of solving the task, in response to unit change of predictors.; $C I$ confidence interval of the hazard ratio Bold value indicates statistically significant result at the significance threshold $p<0.05$ 
opportunities ( $p<0.001$; Table 3a), with less neophobic individuals and individuals seeking social learning opportunities for longer learning faster. Since one observer had a much longer latency to feed next to the novel object compared to the other individuals, we repeated the model without this outlier and obtained similar results for both neophobia ( $p=0.022$; Fig. 3 ; Table $3 b)$ and social learning opportunities ( $p<0.001$; Fig. 4 ; Table $3 b)$.

We also found that the proportion trials in which they used the pull technique differed between pull and slide groups, with observers in pull groups using the pull technique more often whereas observers in the slide groups used the pull technique less often and, hence, the slide technique more often (Mann Whitney $U$ test, $W=25, p=0.042$, Fig. 5). All demonstrators maintained the technique learned during the group testing sessions, although three out of five demonstrators also discovered the other technique (Table 4). Overall, independent of whether individuals reached the learning criterion or not, eight individuals developed a preference for one technique and six exhibited no preference (binomial test, $p=0.795$, Table 4). In the demonstrator groups, seven individuals developed a preference, whereas only one developed a preference in the control groups $(N=1$, one-tailed binomial test, $p=0.035)$. However, from the seven individuals that developed a preference, five preferred the demonstrated technique whereas two individuals exhibited a preference for the other technique (one-tailed binomial test, $p=0.227$ ).

\section{Discussion}

We investigated the effect of neophobia on social learning in wild narrow-striped mongooses. Neophobia did not correlate with the propensity to seek social information. Less neophobic individuals and those that spent more time with the demonstrators during the demonstrator's training sessions learned the task faster, suggesting that personality and social facilitation enhanced learning. The improvement of learning performance in the presence of a demonstrator indicates that local or stimulus enhancement may have fostered the acquisition of the different opening techniques. Moreover, the proportion of animals using the pull technique differed between observers in the pull and slide groups, indicating that individuals in the pull groups used the demonstrated technique more often, and five out of seven individuals developed a preference for the demonstrated technique. Hence, narrow-striped mongooses appear to rely on inadvertent social learning processes, such as social facilitation and local or stimulus enhancement, to deal with new challenges, such as the artificial feeding boxes.

In contrast to other species (Kurvers et al. 2010b), neophobia did not co-vary with the observers' propensity to seek social information during the training sessions. However, both, neophobia and the tendency to seek social information influenced learning speed. Less neophobic individuals learned faster, supporting the hypothesis that fast personality types learn faster than slow personality types in a new situation (Sih and Del Giudice 2012). Moreover, the tendency to seek social information varied across individuals, indicating an attendance bias, which has been recognised to indicate directed social learning or transmission bias (Kendal et al. 2015). Narrow-striped mongooses that were more likely to seek social information also learned the task faster. Since the demonstrator was the dominant female of each group, the attendance bias might result from social inhibition by dominant females, constraining some observer's tendency to approach her closely to avoid aggression (Schneider and Kappeler 2016).

Similarly, in meerkats and chimpanzees (Pan troglodytes), the rank of demonstrators influenced the tendency of lowerranking individuals to seek social information during social learning (meerkats: Thornton and Malapert 2009; chimpanzees: Watson et al. 2017). Moreover, in Amazonian parrots (Amazonia amazonica), individuals receiving aggression at an artificial feeding apparatus interacted less often with the apparatus, thereby constraining their social learning opportunities (Morales Picard et al. 2017). In chacma baboons (Papio ursinus), boldness/neophobia did not co-vary with the tendency to pay attention to a demonstrator in a social learning experiment (Carter et al. 2014). As in our study, less neophobic individuals had greater learning success, but the tendency to seek social information did not influence learning success in baboons. Since the social learning task was relatively easy to solve, chacma baboons probably did not need much social information to solve the task, which benefitted bolder individuals that were more likely to interact with the novel food or feeding apparatus in solving the task faster (Carter et al. 2014). Hence, personality, but also the use of social information, can influence learning strategies when individuals are confronted with a new challenge.

Similarly, as several other species, such as red-fronted lemurs (Eulemur rufifrons; Schnoell and Fichtel 2012), Amazonian parrots (Morales et al. 2017) or blue tits (Cyanistes caeruleus; Aplin et al. 2013), narrow-striped mongooses in demonstrator groups learned the task faster than those in groups without a demonstrator, suggesting that the presence of a knowledgeable individual may have facilitated learning via local or stimulus enhancement (Hoppit and Laland 2008).

Narrow-striped mongooses also discovered the alternative technique to open the box. Individuals belonging to the demonstrator groups performed the demonstrated technique more often than the other one. Our findings here echo results from previous studies in which observers tended to adopt the technique displayed by the demonstrators or knowledgeable individuals (meerkats: Thornton and Malapert 2009, banded 


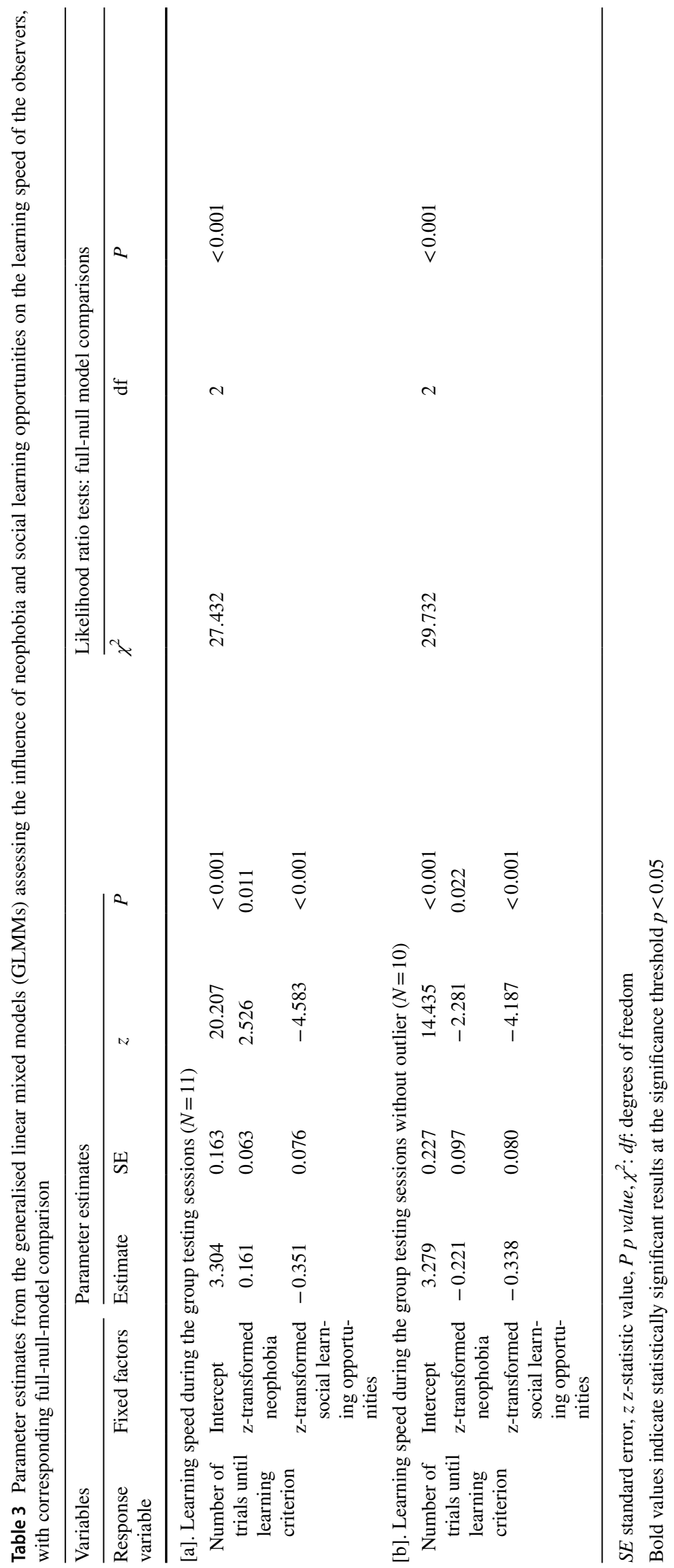




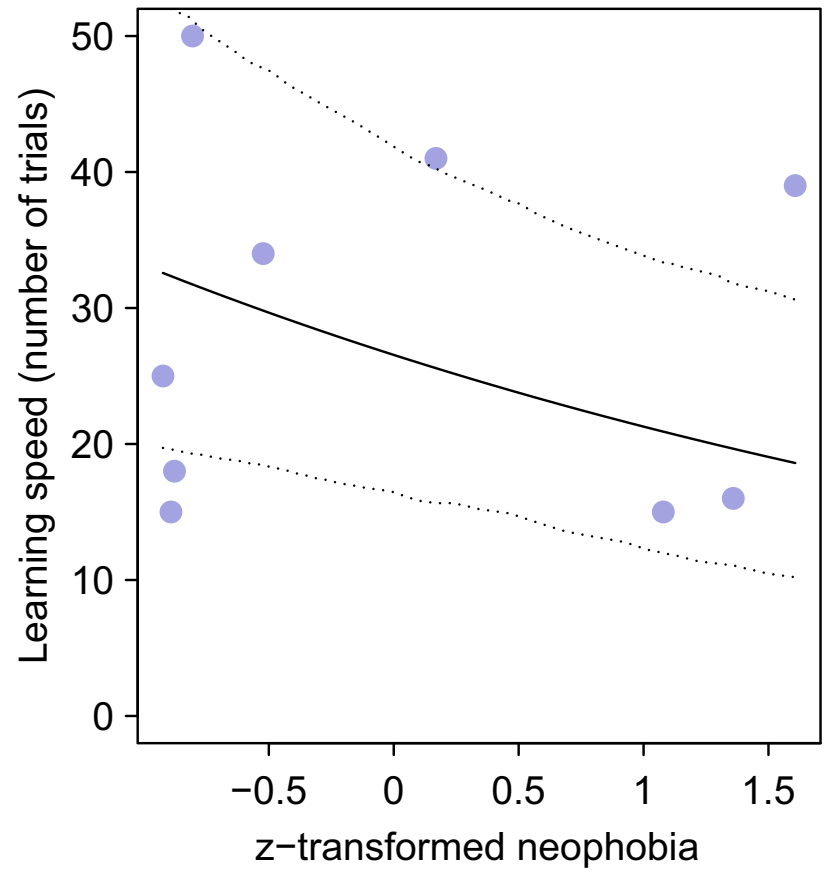

Fig.3 Influence of neophobia on individual learning speed during the testing sessions. Less neophobic individuals learned the task faster. The $\mathrm{X}$-axis depicts the latency to feed close to a novel object as proxy of neophobia, with negative values representing less neophobic individuals and positive values for the more neophobic ones. Each circle represents an individual that learned the discrimination learning task. The continuous line depicts the fitted model, and the dotted lines depict its bootstrapped $95 \%$ confidence intervals

mongooses: Müller and Cant 2010, red-fronted lemurs: Schnoell and Fichtel 2012, and vervet monkeys: van de Waal et al. 2013). However, in the pull groups, only 2 out of 4 individuals that developed a preference preferred the pull technique. In the slide groups, all individuals that developed a preference, preferred the demonstrated slide technique. Hence, despite the fact that observers in the demonstrator groups used the demonstrated technique more often, not all individuals developed a preference for the demonstrated technique.

To summarize, we found that neophobia but also social information influenced problem-solving abilities in narrow-striped mongooses. Less neophobic individuals and those that tended to seek social information learned the task faster and the presence of a demonstrator facilitated learning, indicating the use of inadvertent social learning strategies, such as social facilitation and local or stimulus enhancement, to solve problems. Hence, our results emphasize the importance of also considering personality traits to obtain a more comprehensive view of social learning strategies. Finally, similar to other mongooses (Thornton and Malapert 2009), narrow-striped mongooses rely on the use of social information to solve problems, informing

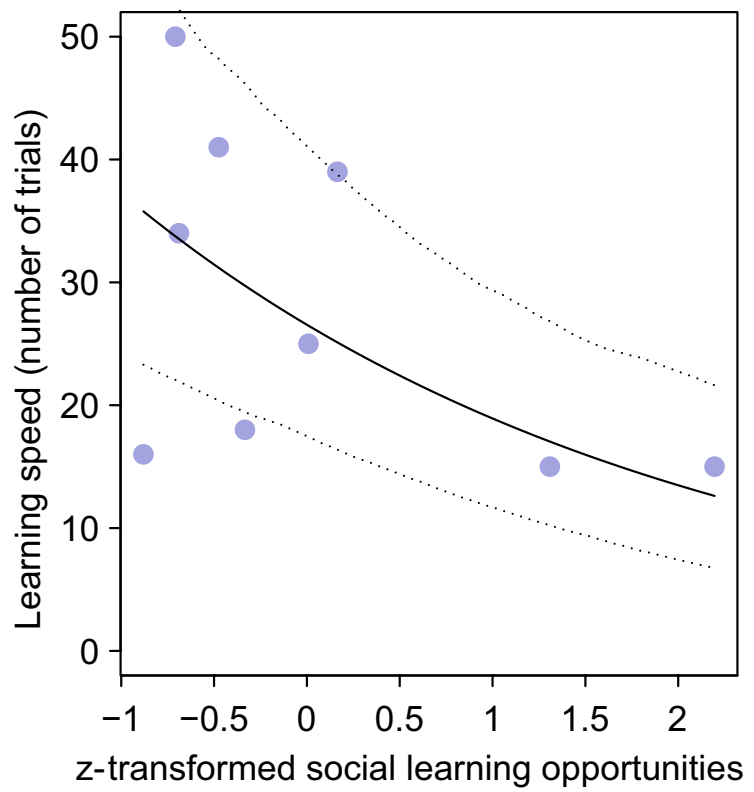

Fig. 4 Influence of the tendency to seek social information on learning speed. Individuals who spent more time with the demonstrators within the metal ring solved the task faster. Each circle represents an individual that learned the discrimination learning task. The continuous line depicts the fitted model, and the dotted lines depict its bootstrapped $95 \%$ confidence intervals

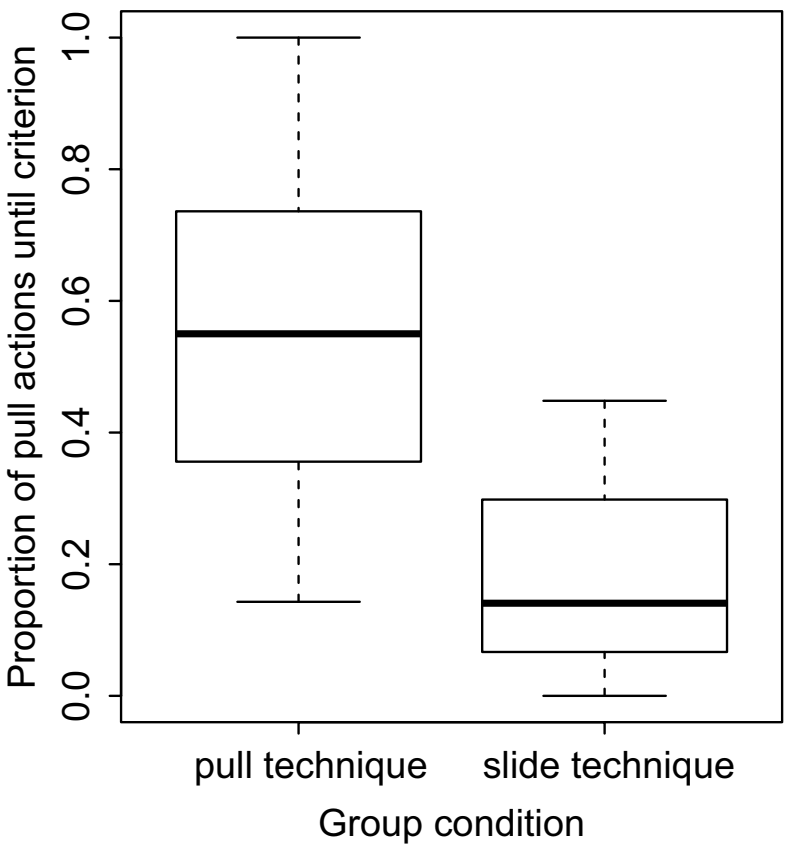

Fig. 5 Proportion of pull actions made by individuals in the pull and slide groups. Individuals in the pull condition performed the pull actions more often compared to individuals in the slide groups

our understanding of social learning among carnivorans with different social systems. 
Table 4 Results of the exact binomial tests to assess preferences for sliding or pulling techniques for each tested individual

\begin{tabular}{|c|c|c|c|c|c|c|}
\hline Group & ID & Role & Learner & $\begin{array}{l}\text { Pull actions } \\
\text { performed }\end{array}$ & $\begin{array}{l}\text { Slide actions } \\
\text { performed }\end{array}$ & $p$ value \\
\hline \multicolumn{7}{|c|}{ Groups assigned to the pull condition } \\
\hline \multirow[t]{2}{*}{ G1 } & 44 & Demonstrator & - & 14 & 1 & $<0.001$ \\
\hline & 97 & Observer & No & 8 & 1 & 0.03 \\
\hline \multirow[t]{5}{*}{$\mathrm{C}$} & 76 & Demonstrator & - & 13 & 0 & $<0.001$ \\
\hline & 15 & Observer & Yes & 11 & 33 & 0.001 \\
\hline & 22 & Observer & Yes & 22 & 18 & 0.635 \\
\hline & 86 & Observer & Yes & 7 & 5 & 0.774 \\
\hline & 87 & Observer & No & 4 & 24 & $<0.001$ \\
\hline \multirow[t]{3}{*}{$\mathrm{N}$} & 95 & Demonstrator & - & 14 & 0 & $<0.001$ \\
\hline & 94 & Observer & Yes & 6 & 7 & 1 \\
\hline & 99 & Observer & Yes & 20 & 0 & $<0.001$ \\
\hline \multicolumn{7}{|c|}{ Groups assigned to the slide condition } \\
\hline \multirow[t]{4}{*}{ M } & 40 & Demonstrator & - & 2 & 11 & 0.02 \\
\hline & 81 & Observer & Yes & 4 & 26 & $<0.001$ \\
\hline & 89 & Observer & Yes & 4 & 23 & $<0.001$ \\
\hline & 90 & Observer & Yes & 0 & 12 & $<0.001$ \\
\hline \multirow[t]{2}{*}{ L1 } & 75 & Demonstrator & - & 2 & 18 & $<0.001$ \\
\hline & 96 & Observer & No & 13 & 16 & 0.711 \\
\hline \multicolumn{7}{|c|}{ Groups assigned to the control condition } \\
\hline \multirow[t]{3}{*}{ B } & 13 & - & No & 11 & 21 & 0.11 \\
\hline & 66 & - & Yes & 18 & 26 & 0.291 \\
\hline & 88 & - & No & 19 & 46 & 0.001 \\
\hline $\mathrm{L}$ & 77 & - & No & 16 & 17 & 1 \\
\hline
\end{tabular}

Bold values indicate statistically significant results at the significance threshold $p<0.5$
Acknowledgements We would like to thank Léonard Razafimanantsoa and Rodin Rasoloarison for administrative and logistic support, Remy d'Ampataka for his help during fieldwork and the staff of the Kirindy Forest research station for their support. We appreciate the collaboration with the Département de Biologie Animale of the University of Antananarivo, the Ministère de $1^{\prime}$ Environnement, de $1^{\prime}$ Ecologie, de la Mer et des Forêts and the CNFEREF Morondava for authorizing our research in Kirindy. We are grateful to Debbie Kelly and four anonymous reviewers for their insightful comments on the earlier versions of this manuscript.

Author contributions B.N.R and C.F. designed the study. B.N.R conducted the experiments and conducted the videos analyses. B.N.R. and C.F. analysed the data. B.N.R., P.M.K. and C.F. wrote the paper. All authors read and approved the final manuscript.

Funding Open Access funding enabled and organized by Projekt DEAL. This study was funded by the "DAAD: Deutscher Akademischer Austauschdienst" (funding program/-ID: 57129429).

\section{Compliance with ethical standards}

Conflict of interest The authors declare that they have no conflict of interest.
Ethical approval All procedures performed in this study were in accordance with the ethical standards of the Ministère de 1'Environnement, de 1`Ecologie, de la Mer et des Forêts.

Electronic supplementary material supplementary material is available online at https://doi.org/10.6084/m9.figshare.12482021.

Open Access This article is licensed under a Creative Commons Attribution 4.0 International License, which permits use, sharing, adaptation, distribution and reproduction in any medium or format, as long as you give appropriate credit to the original author(s) and the source, provide a link to the Creative Commons licence, and indicate if changes were made. The images or other third party material in this article are included in the article's Creative Commons licence, unless indicated otherwise in a credit line to the material. If material is not included in the article's Creative Commons licence and your intended use is not permitted by statutory regulation or exceeds the permitted use, you will need to obtain permission directly from the copyright holder. To view a copy of this licence, visit http://creativecommons.org/licenses/by/4.0/.

\section{References}

Aplin L (2016) Understanding the multiple factors governing social learning and the diffusion of innovations. Curr Opin Behav Sci 12:59-65. https://doi.org/10.1016/j.cobeha.2016.09.003 
Aplin L, Sheldon BC, Morand-Ferron J (2013) Milk bottles revisited: social learning and individual variation in the blue tit, Cyanistes caeruleus. Anim Behav 85:1225-1232. https://doi.org/10.1016/j. anbehav.2013.03.009

Bates D, Mächler M, Bolker B, Walker S (2014) Fitting linear mixedeffects models using lme4. ArXiv Prepr ArXiv 14:65823

Benson-Amram S, Heinen VK, Gessner A et al (2014) Limited social learning of a novel technical problem by spotted hyenas. Behav Processes 109:111-120. https://doi.org/10.1016/j.bepro c.2014.09.019

Carter AJ, Marshall HH, Heinsohn R, Cowlishaw G (2014) Personality predicts the propensity for social learning in a wild primate. PeerJ 2:e283. https://doi.org/10.7717/peerj.283

Claidière N, Messer EJ, Hoppitt W, Whiten A (2013) Diffusion dynamics of socially learned foraging techniques in squirrel monkeys. Curr Biol 23(13):1251-1255

Crane AL, Ferrari MCO (2017) Patterns of predator neophobia: a meta-analytic review. Proc R Soc B Biol Sci 284:20170583. https://doi.org/10.1098/rspb.2017.0583

Crane AL, Mathiron AGE, Ferrari MCO (2015) Social learning in a high-risk environment: incomplete disregard for the 'minnow that cried pike' results in culturally transmitted neophobia. Proc R Soc B Biol Sci 282:20150934. https://doi.org/10.1098/ rspb.2015.0934

Friard O, Gamba M (2016) BORIS: a free, versatile open-source event-logging software for video/audio coding and live observations. Methods Ecol Evol 7:1325-1330. https://doi. org/10.1111/2041-210X.12584

Greggor AL, Thornton A, Clayton NS (2015) Neophobia is not only avoidance: improving neophobia tests by combining cognition and ecology. Curr Opin Behav Sci 6:82-89. https://doi.org/10.1016/j. cobeha.2015.10.007

Grüter C, Leadbeater E (2014) Insights from insects about adaptive social information use. Trends Ecol Evol 29:177-184. https://doi. org/10.1016/j.tree.2014.01.004

Heyes CM (1994) Social learning in animals: categories and mechanisms. Biol Rev 69:207-231

Holekamp KE, Sakai ST, Lundrigan BL (2007) Social intelligence in the spotted hyena (Crocuta crocuta). Philos Trans R Soc B Biol Sci 362:523-538. https://doi.org/10.1098/rstb.2006.1993

Hoppitt W, Laland KN (2008) Social processes influencing learning in animals: a review of the evidence. Adv Stud Behav 38:105-165

Kendal RL, Boogert NJ, Rendell L et al (2018) Social learning strategies: bridge-building between fields. Trends Cogn Sci 22:651665. https://doi.org/10.1016/j.tics.2018.04.003

Kendal R, Hopper LM, Whiten A et al (2015) Chimpanzees copy dominant and knowledgeable individuals: implications for cultural diversity. Evol Hum Behav 36:65-72. https://doi.org/10.1016/j. evolhumbehav.2014.09.002

Kendal RL, Galef BG, Van Schaik CP (2010) Social learning research outside the laboratory: how and why? Learn Behav 38:187-194. https://doi.org/10.3758/LB.38.3.187

Kurvers RHJM, Prins HHT, van Wieren SE et al (2010a) The effect of personality on social foraging: shy barnacle geese scrounge more. Proc R Soc B Biol Sci 277:601-608. https://doi.org/10.1098/ rspb.2009.1474

Kurvers RHJM, Van Oers K, Nolet BA et al (2010b) Personality predicts the use of social information: personality and social information use. Ecol Lett 13:829-837. https://doi.org/10.111 1/j.1461-0248.2010.01473.x

Laland KN (2004) Social learning strategies. Learn Behav 32:4-14

Marchetti C, Drent PJ (2000) Individual differences in the use of social information in foraging by captive great tits. Anim Behav 60:131140. https://doi.org/10.1006/anbe.2000.1443
Mesoudi A, Chang L, Dall SRX, Thornton A (2016) The evolution of individual and cultural variation in social learning. Trends Ecol Evol 31:215-225. https://doi.org/10.1016/j.tree.2015.12.012

Morales Picard A, Hogan L, Lambert ML et al (2017) Diffusion of novel foraging behaviour in Amazon parrots through social learning. Anim Cogn 20:285-298. https://doi.org/10.1007/s1007 1-016-1049-3

Müller CA, Cant MA (2010) Imitation and traditions in wild Banded Mongooses. Curr Biol 20:1171-1175. https://doi.org/10.1016/j. cub.2010.04.037

Nakagawa S, Schielzeth H (2010) Repeatability for Gaussian and nonGaussian data: a practical guide for biologists. Biol Rev no-no. https://doi.org/10.1111/j.1469-185X.2010.00141.X

Nomakuchi S, Park PJ, Bell MA (2009) Correlation between exploration activity and use of social information in three-spined sticklebacks. Behav Ecol 20:340-345. https://doi.org/10.1093/behec o/arp001

Pesendorfer MB, Gunhold T, Schiel A et al (2009) The maintenance of traditions in marmosets: individual habit, not social conformity? A field experiment. PLoS ONE 4:e4472. https://doi.org/10.1371/ journal.pone.0004472

R Core Team (2017) R: A language and environment for statistical computing. R Foundation for Statistical Computing, Vienna, Austria

Rasolofoniaina B, Razafy P, Razafimahatratra E, Kappeler PM (2019) Feeding ecology of the bokiboky, Mungotictis decemlineata (family Eupleridae). Malagasy Nature 13:152-161

Réale D, Reader SM, Sol D et al (2007) Integrating animal temperament within ecology and evolution. Biol Rev 82:291-318. https ://doi.org/10.1111/j.1469-185X.2007.00010.x

Rieucau G, Giraldeau L-A (2011) Exploring the costs and benefits of social information use: an appraisal of current experimental evidence. Philos Trans R Soc B Biol Sci 366:949-957. https:// doi.org/10.1098/rstb.2010.0325

Rosa P, Nguyen V, Dubois F (2012) Individual differences in sampling behaviour predict social information use in zebra finches. Behav Ecol Sociobiol 66:1259-1265. https://doi.org/10.1007/s0026 5-012-1379-3

Schneider TC, Kappeler PM (2016) Gregarious sexual segregation: the unusual social organization of the Malagasy narrow-striped mongoose (Mungotictis decemlineata). Behav Ecol Sociobiol 70:913-926. https://doi.org/10.1007/s00265-016-2113-3

Schnoell AV, Fichtel C (2012) Wild redfronted lemurs (Eulemur rufifrons) use social information to learn new foraging techniques. Anim Cogn 15:505-516. https://doi.org/10.1007/s1007 1-012-0477-y

Sih A, Del Giudice M (2012) Linking behavioural syndromes and cognition: a behavioural ecology perspective. Philos Trans R Soc B Biol Sci 367:2762-2772. https://doi.org/10.1098/rstb.2012.0216

Slaa EJ, Wassenberg J, Biesmeijer JC (2003) The use of field-based social information in eusocial foragers: local enhancement among nestmates and heterospecifics in stingless bees. Ecol Entomol 28:369-379. https://doi.org/10.1046/j.1365-2311.2003.00512.x

Therneau T (2015) A package for survival analysis in S. Version 2.38. https://CRAN.R-project.org/package=survival. Accessed 06 Nov 2019

Thornton A, Clutton-Brock T (2011) Social learning and the development of individual and group behaviour in mammal societies. Philos Trans R Soc B Biol Sci 366:978-987. https://doi. org/10.1098/rstb.2010.0312

Thornton A, Malapert A (2009) Experimental evidence for social transmission of food acquisition techniques in wild meerkats. Anim Behav 78:255-264. https://doi.org/10.1016/j.anbehav.2009.04.021

Thornton A, McAuliffe K (2006) Teaching in Wild Meerkats. Science 313:227-229. https://doi.org/10.1126/science.1128727 
van de Waal E, Bshary R (2011) Social-learning abilities of wild vervet monkeys in a two-step task artificial fruit experiment. Anim Behav 81:433-438

van de Waal E, Claidière N, Whiten A (2013) Social learning and spread of alternative means of opening an artificial fruit in four groups of vervet monkeys. Anim Behav 85:71-76. https://doi. org/10.1016/j.anbehav.2012.10.008

van de Waal E, Renevey N, Favre CM, Bshary R (2010) Selective attention to philopatric models causes directed social learning in wild vervet monkeys. Proc R Soc B 277:2105-2111. https://doi. org/10.1098/rspb.2009.2260

Watson SK, Reamer LA, Mareno MC et al (2017) Socially transmitted diffusion of a novel behavior from subordinate chimpanzees. Am J Primatol 79:e22642. https://doi.org/10.1002/ajp.22642

Watson SK, Vale GL, Hopper LM et al (2018) Chimpanzees demonstrate individual differences in social information use. Anim Cogn 21:639-650. https://doi.org/10.1007/s10071-018-1198-7

Webster MM, Laland KN (2017) Social information use and social learning in non-grouping fishes. Behav Ecol 28:1547-1552. https ://doi.org/10.1093/beheco/arx121
Webster SJ, Lefebvre L (2001) Problem solving and neophobia in a columbiform-passeriform assemblage in Barbados. Anim Behav 62:23-32. https://doi.org/10.1006/anbe.2000.1725

Whiten A, Mesoudi A (2008) Establishing an experimental science of culture: animal social diffusion experiments. Philos Trans R Soc B Biol Sci 363:3477-3488. https://doi.org/10.1098/rstb.2008.0134

Whiten A, van de Waal E (2018) The pervasive role of social learning in primate lifetime development. Behav Ecol Sociobiol. https:// doi.org/10.1007/s00265-018-2489-3

Publisher's Note Springer Nature remains neutral with regard to jurisdictional claims in published maps and institutional affiliations. 


\section{Appendix}

\section{Estimation of " $\mathrm{g}$ " factor in narrow-striped mongooses}

Since we conducted a psychometric test battery consisting of several cognitive tests in the physical and social domain, we estimated the presence of potential general intelligence factor " $g$ " in narrow-striped mongooses. However, individuals' performances from the transparent cylinder task, causal understanding task, problem-solving tasks, and discrimination learning task were included in the analyses, in order to reach the maximum number of individuals that partook in these tasks.

In order to standardise the direction of individual cognitive performances in the psychometric test battery, we considered that a low value of performances indicated good performances. For the three problem-solving tasks, discrimination-learning task, and causal understanding task, we considered learning speed to learn or to solve each task. A shorter time spent in learning or solving a given task indicates a better performance. For every three problem-solving tasks, solving latency was considered as a measurement of performances (see Chapter 2). For the discrimination-learning task (Chapter 1) and the causal understanding task (Chapter 2), learning speed was the measurement of performances. However, for the transparent cylinder task, we considered the number of errors as an indicator of the level of inhibitory control since a low number of errors indicated a higher inhibitory control level.

\section{Statistical analyses}

All following statistical analyses were conducted using R (R Core Team 2017).

First, since we carried out three problem-solving tasks (jar, pull, and rotator tasks), we summarised individuals 'performances from these three problem-solving tasks using an unrotated Principal Analysis Component (PCA) with the "prcomp" function in R. The first Principal Component (PC) resulting from the PCA was included in further analysis.

Next, we conducted a pairwise correlation with Holm adjustment for multiple comparison to the alpha-level of significance (package "psych", Revelle, 2018), to examine whether cognitive performance in one task is related to predicts performance in the other task. 
Then, to investigate whether inter-individual performances could be explained by a single factor (i.e., "g"), we conducted an unrotated PCA with the "prcomp" function in R. Principal Components (PC) with eigenvalue $>1$ was retained as the single factor and which explained more than $40 \%$ of variance.

\section{Results}

Fifteen individuals participated in the three problem-solving tasks (jar, pull, and rotator tasks). The performances of these 15 individuals were summarised using PCA. The first component explained $46.8 \%$ of variance and all three problem-solving tasks loaded negatively on the first component (Table 1a). The first component was retained, and was used furtherly in the analyses.

Ten individuals partook in all the tasks we considered in this analysis. Few of the individuals' performances were positively correlated, which are in 3/6 of the pairwise correlation (PC of problem solving tasks, transparent cylinder task, causal understanding task, and discrimination learning task) (Table 2). In addition, none of the correlations was significant (after Holm correction).

For the PCA of the performances in the three different tests and the first component of the problem solving tasks (PC of problem solving tasks, transparent cylinder task, causal understanding task, and discrimination learning task), two components were extracted with eigenvalues $>1$. The first component explained $46.8 \%$ of the total variances in the tasks performances of the narrow-striped mongooses, and the second component explained 26.8 $\%$ of variances. However, only one task out of four loaded positively onto the first component (Table $1 b)$.

From our results, we found that the performances from all the tasks did not correlate positively. Moreover, low correlations were found between the performances. Hence, we cannot conclude that narrow-striped mongooses possess a "g" factor. 
Table 1. Results of the PCA summarising the performances of the three problem-solving tasks $(a)$, and of the PCA summarising the performances from all the cognitive tasks (b) (PC: principal component).

\begin{tabular}{|lccc|}
\hline \multicolumn{1}{|c|}{ PC1 } & PC2 & PC3 \\
\hline Jar task $\quad$ PCA of the performances from the three problem-solving tasks (jar, pull, and rotator tasks) (N=15) \\
Pull task & -0.368 & -0.770 & -0.520 \\
Rotator task & -0.530 & 0.633 & -0.562 \\
Eigenvalues & -0.763 & -0.068 & 0.642 \\
Variances explained (\%) & 1.41 & 1.170 & 0.41 \\
\hline \multicolumn{1}{|c|}{ b. PCA of the performances from all the cognitive tasks (N=10) } & 39.1 & 13.7 \\
\hline Causal understanding & -0.255 & 0.632 & 0.731 \\
Discrimination learning & -0.299 & -0.734 & 0.526 \\
Transparent cylinder task & -0.678 & -0.112 & -0.128 \\
PC of problem-solving & 0.619 & -0.217 & 0.415 \\
Eigenvalues & 1.87 & 1.07 & 0.83 \\
Variances explained (\%) & 46.8 & 26.8 & 20.9 \\
\hline
\end{tabular}

Table 2. Spearman' correlation matrix of all cognitive task performances. $P$ values with Holm adjustment are between brackets.

\begin{tabular}{lllll|} 
& $\begin{array}{l}\text { Causal } \\
\text { understanding }\end{array}$ & $\begin{array}{l}\text { Discrimination } \\
\text { learning task }\end{array}$ & $\begin{array}{l}\text { Detour reaching } \\
\text { task }\end{array}$ & $\begin{array}{l}\text { PC problem-solving } \\
\text { performances }\end{array}$ \\
\cline { 2 - 4 } $\begin{array}{l}\text { Causal understanding } \\
\text { Discrimination learning } \\
\text { task }\end{array}$ & & $0.20(p=1)$ & $0.36(p=1)$ & $-0.44(p=0.99)$ \\
$\begin{array}{l}\text { Transparent cylinder task } \\
\text { PC problem-solving } \\
\text { performances }\end{array}$ & & & $0.37(p=1)$ & $0.00(p=1)$ \\
\hline
\end{tabular}




\section{Chapter 5: GENERAL DISCUSSION}

In the present thesis, I investigated the cognitive performances belonging to the domaingeneral cognition, physical and social cognition of wild narrow-striped mongooses, $M$. decemlineata. Overall, my findings indicate that narrow-striped mongooses show behavioural flexibility, are able to produce novel behaviour in a new problem context and rely significantly on social information. Moreover, I aimed to examine the proximate factors that might influence individuals' differences in these cognitive performances. I found that individual differences in cognitive performances were driven by neophobia, inhibitory control, and social information.

In this last section of my dissertation, I will discuss my results on the cognitive performances of narrow-striped mongooses in learning and behavioural flexibility, innovative problemsolving and social learning. Then, I will discuss the implication of neophobia briefly on cognitive performances. Next, I will discuss my findings with the cognitive performances of other carnivore species. After that, I will address the result of the estimation of the " $\mathrm{g}$ " factor in M. decemlineata. Furthermore, I will draw attention to the limitations encountered in establishing psychometric test battery in the wild. Finally, I will highlight potential directions for future studies that could enhance the understanding of the evolution of cognition in carnivores.

\section{Individual differences in cognitive performances in narrow-striped mongooses}

The overall results of my study show that narrow-striped mongooses perform in behavioural flexibility and innovative problem-solving as aspects of domain-general cognition, and in social learning as an aspect of social cognition. Individual differences in cognitive performances are driven primarily by neophobia, inhibitory control level, and the use of social information. In the previous chapters, I have already discussed the findings on factors explaining individual differences in cognitive abilities in this species. In the following section, I would like to address the possible explanations between the cognitive performances of $M$. decemlineata and its socio-ecological characteristics. 
Individuals' abilities to respond to either social or ecological changes belong to domaingeneral cognitive abilities (Sol et al. 2016b). In Chapter 2, I investigated the ability of narrowstriped mongooses to be behaviourally flexible and the factors that co-varied with individual differences in learning and flexibility. I found that narrow-striped mongooses could discriminate between visual cues and could learn flexibly in an altered situation. During the discrimination learning, inhibitory control was necessary for learning. Specifically, individuals exhibiting a higher level of inhibitory control were faster learners during the discrimination learning task. Inhibitory control is a cognitive trait component of executive function (correlates of behaviours involved in behavioural control), which is linked to psychological processes, such as attention and working memory (Zelazo et al. 1997). Since inhibitory control is involved in many cognitive processes, its variation may underline variation in other individuals' cognitive performances (Lucon-Xiccato et al. 2019). As the individuals need to inhibit the tendency to manipulate the wrong lid to learn faster, this could explain the influence of inhibitory control on discrimination learning performance. However, individual's performances did not correlate either with neophobia or social information. My findings demonstrate that neophobia does not explain learning and that narrow-striped mongooses applied individual learning during the discrimination learning task.

Interestingly, individuals relied on social information to be flexible during the reversal learning task (Chapter 2). Specifically, individuals that witnessed more often correct trials made by other conspecifics during the experiments were more flexible. My result indicates that $M$. decemlineata relied on social information when the situation became more challenging and that social context modulates individuals' learning strategies. This reliance on social information suggests that $M$. decemlineata benefits from group-living to maximize their efficiency during foraging activities and cope with ecological challenges. However, individuals' performances during the reversal learning task did not covariate with neophobia, indicating that neophobia is not involved in behavioural flexibility in narrow-striped mongooses. Besides, inhibitory control did not covariate with reversal learning performances. Because $M$. decemlineata relied on social information to solve the reversal learning task, inhibitory control was not needed for learning the task.

Narrow-striped mongooses exhibited problem-solving skills driven by a trial-and-error approach and not by using causal understanding ability (Chapter 3). The "technical 
intelligence hypothesis" posits that species ability to solve problem-solving is linked to their feeding ecology (Tebbich et al. 2016). For extractive forager species, causal understanding, an aspect of physical cognition, should primarily influence ability in resource extraction (Bräuer et al. 2006). The narrow-striped mongoose is an extractive forager manipulating strata such as deadwood and trees to find food (Rasolofoniaina et al. 2019). However, my finding failed to support the prediction that causal understanding ability underlines problemsolving abilities in narrow-striped mongooses. Probably because the causal understanding ability assessed in my study did not address the same causal cue involved in the foraging problem-solving task. Therefore, the task itself could be the reason for the result here. Future works will benefit from more elaborated task design such as including the causal feature involved in the problem-solving task to examine this aspect.

Neophobia did not influence individual variation in problem-solving performances. A recent meta-analysis suggested that the influence of neophobia might manifest more in the latency to approach the tasks in problem-solving (Amici et al. 2019), which is an aspect not addressed in this study. Therefore, this could explain the absence of covariation between neophobia and problem-solving performances here.

Interestingly, persistence did not influence the variation in individuals' problem-solving performances in this study (Chapter 3). The absence of effect of persistence can be explained by the fact that individuals showed the same level of persistence across tasks. Persistence is known to be pronounced in species requiring it during their foraging ecology. For instance, grey wolves (Canis lupus) exhibit higher persistence in problem-solving tasks compared to domestic dogs (C. lupus familiaris), which is probably due to the fact that wolves hunt mobile preys and require higher persistence during this mode of foraging, while dogs are more scavengers (Rao et al. 2018). Since $M$. decemlineata feed mainly on arthropods year-round (Rasolofoniaina et al. 2019), a predictable prey either on distribution or availability, it is possible that $M$. decemlineata does not require so much persistence during foraging activities.

Furthermore, I investigated to what extent is the reliance of narrow-striped mongooses on social information. I found that narrow-striped mongooses rely significantly on social information. Mungotictis decemlineata uses social information to enhance learning in a challenging situation (Chapter 2), and I found that the individuals use social facilitation as 
social learning mechanism for solving a two-ways foraging task (Chapter 4). Naïve narrowstriped mongooses benefited from skilled individuals, with individuals belonging to the groups provided with demonstrators learning the foraging task much faster than the individuals in the control groups. Similarly, coyotes (Canis latrans) solved much faster and were more successful in solving a foraging task when provided with demonstrators (Young et al. 2019). Moreover, in the current study, individuals showed a tendency to adopt the technique demonstrated by the skilled individuals for solving the foraging task. This pattern is also found in meerkats, for instance (Thornton and Malapert 2009). Together, my results support the idea that the presence of proficient individuals modifies the ability of other individuals to improve their foraging efficiency and to acquire a trait via exposure to social information (Galef and Giraldeau 2001).

Neophobia influenced individual's social-learning strategy by facilitating learning, although it did not influence the tendency to watch a demonstrator to acquire social information (Chapter 4). This counterintuitive effect of neophobia on the tendency to seek for social information might be explained by the fact that several intrinsic factors may influence simultaneously individual's social learning strategy. Since only one box was available for the demonstrator during the experiment, social rank might have influenced the tendency of the observers to approach the demonstrator (Chapter 4). Several studies show that the identities of both the demonstrator and the observers can influence social learning (Reader and Laland 2003a). Considering the matrilineal hierarchy that rules the female unit in narrow-striped mongooses (Schneider and Kappeler 2016), social rank is a possible factor that may explain social information seeking in this context. For instance, in great tits (Parus major), during a social feeding context, proactive individuals were also the dominant individuals that approached first a feeding platform (Bibi et al. 2019). Likewise, in coyotes, observers were the subordinates and the more neophobic individuals (Young et al. 2019). In the current study, the dominant female in each group was the demonstrator during the social learning experiment (Chapter 4). However, the dominant female was not always the oldest in the group, but sometimes a younger adult (personal observation). It could be that dominance is related to other intrinsic characteristic such as personality traits or reproductive status for $M$. decemlineata. Therefore, it would be interesting for further 
studies to consider more intrinsic factors from demonstrators and observers simultaneously when examining social-learning strategy.

The use of social information differs across tasks in narrow-striped mongooses. Social learning influenced behavioural flexibility and learning of a foraging task (Chapter 2 and 4), but it did not affect innovative problem-solving ability (Chapter 3 ). Individual learning is a costly process due to increased energy expenditure and exposure to predation (Dukas and Ratcliffe 2009). Moreover, individuals in the female unit synchronise their activity, forage and roam in close proximity, and den together (Schneider 2015), presenting several opportunities for social learning for the individuals. Furthermore, species are known to rely flexibly on social information (Kendal et al. 2018). In the current study, narrow-striped mongooses use social information depending on the context, which supports the idea of flexible use of social learning in this species.

\section{Relationship between neophobia and individual cognitive performances}

Neophobia is a behavioural trait beneficial for an individual by limiting its exposure to danger, but also it can be costly by preventing the exploration of resources (Greggor et al. 2015). During my study, I assessed behaviours relating to neophobia in M. decemlineata and the latency to feed next to the novel object was repeatable after an average time of $12.5 \pm$ 12.02 months (Chapters 2, 3, and 4), indicating consistent individual differences in neophobia through time. However, medium repeatability was found between the measurements of the first and second novel object tests. A possible explanation for this can arise from the testing design. Indeed, the long interval between the two measurements could have decreased the repeatability (Bell et al. 2009).

Overall, my results indicate that the relationships between neophobia and individual cognitive performances have different directions according to the cognitive task. Neophobia did not correlate with learning performances in the discrimination-and-reversal learning tasks (Chapter 2), but correlated positively with individual's performances in the social learning foraging task (Chapter 4). Specifically, more neophobic individuals were low performers in the social learning task (Chapter 4). Concerning the problem-solving tasks, neophobia did not affect the likelihood of solving the tasks (Chapter 3 ). 
These mixed findings in the current study could be explained by the fact that the relationship between personality traits and cognitive performances is highly variable and does not depend on the cognitive measure investigated (Dougherty and Guillette 2018). Moreover, there are additional factors that co-vary with personality traits, such as individual intrinsic factors (e.g., hormonal levels), which could also influence the relationship between personality traits and cognitive performances (Niemelä and Dingemanse 2018; Dougherty and Guillette 2018). For instance, in rooks (Corvus frugilegus), individuals' neophobia levels differ between breeding and non-breeding seasons, with individuals showing more risktaking toward novel people during the breeding season (Greggor et al. 2016a). Moreover, in rooks, individuals' rank and neophobia are correlated during the breeding season, with subordinates being more risk-takers than dominant individuals (Greggor et al. 2016a). For the current study, the cognitive tasks for the narrow-striped mongooses were conducted only during the dry seasons, which correspond to the mating season of the species (see Albignac 1976). Consequently, neophobia level might have co-vary with the physiology of the females in oestrus.

Furthermore, personality traits can be related to change in the social context (Jolles et al. 2016; Blake et al. 2018). For instance, female great tits (Parus major) are less risk-prone during a social feeding context, when males were around, and showed more vigilance in order to decrease behavioural interference (van Oers et al. 2005). During the current study, the female narrow-striped mongooses were often approached and harassed by the males during the experiments since it was the mating season (Schneider and Kappeler 2016). This might have caused more vigilance for the group members and/or stress during the testing. Therefore, these factors might influence the relationship between personality traits and cognitive performances as well. Further works should consider these proximate mechanisms while examining the influence of personality traits on cognitive performance, which will allow explaining better the variation found on the effect of personality traits.

\section{Comparison to the cognitive abilities of other Carnivore species}

Since I did not carry out a study including a direct comparison of cognitive performances of $M$. decemlineata to those of Carnivore species, I do not claim that the cognitive skills of $M$. decemlineata are equal to the cognitive skills of other carnivores' species here. Therefore, in 
the following section, I will address possible explanations of similarities and dissimilarities to the cognitive skills of $M$. decemlineata that can be found across the carnivore taxon, in relation to their socio-ecological characteristics.

Within the mongooses' families, the meerkats (Suricata suricatta) belong to the family of Herpestidae, which is a closely related taxon to the narrow-striped mongooses (Eupleridae). The Herpestidae and the Eupleridae evolved from a single colonisation by an African ancestor Myr ago (Yoder et al. 2003). Accordingly, the two clades share an ancestral solitary lifestyle, from which group-living evolved independently in both families (Veron et al. 2004; Schneider and Kappeler 2014). The narrow-striped mongooses and the meerkats share few similarities in their ecological characteristics. For instance, concerning diet, both species are generalist and feed mainly on arthropods (Doolan and MacDonald 1996; Rasolofoniaina et al. 2019). However, their habitats differ from the meerkats inhabiting an open habitat (Doolan and MacDonald 1996), while the narrow-striped mongooses are inhabiting a tropical dry forest (Albignac 1976). Despite the differences between the habitats of the narrowstriped mongooses and the meerkats, the predation risks can be assumed to be particularly high for both species (Rood 1983; Clutton-Brock et al. 1999).

The striking difference between the meerkats and the narrow-striped mongooses is about their social organisations. Both species are group-living: the meerkats live in more complex social group, while a sexual segregation characterises the narrow-striped mongooses with the females living in relatively small stable group (Schneider and Kappeler 2014, 2016). Indeed, meerkats live in family extended group (up to 30 individuals) and is characterised with a cooperative breeder system (Clutton-Brock et al. 2002). While concerning the narrowstriped mongooses, the female unit is based on matrilines, comprising related adult females, and juveniles and infant, and a group size of three to four individuals on average (Schneider et al. 2016).

However, the cognitive performances of meerkats and narrow-striped mongooses are relatively similar in some aspects. For instance, to assess innovative problem-solving, the testing design used to test innovation in meerkats was also applied to the narrow-striped mongooses (Chapter 3). Individuals from both species could perform well in the three problem-solving tasks (jar, pull, and rotator tasks) (Thornton and Samson, 2012; Chapter 3). In addition, neither the meerkats nor the narrow-striped mongooses exhibited improvement 
in instrumental learning (Thornton and Samson, 2012; Chapter 3). Concerning social learning, both species relied on social information. Individuals in both species tended to adopt techniques used by demonstrators (Thornton and Malapert, 2009; Chapter 4). Moreover, observing successful individuals led to success in solving the tasks in both studies (Thornton and Malapert, 2009; Chapter 4). However, in the studies on meerkats, clear relationship between proximate factors and cognitive performances were not addressed, limiting the comparison in this direction.

Outside of the mongooses' families, cognitive performances in domain-general cognition and social cognition were investigated in spotted hyenas, racoons, wolves, and dogs. Concerning behavioural flexibility, spotted hyenas (Crocuta crocuta: (Johnson-Ulrich et al. 2018)) and racoons (Procyon lotor: (Daniels et al. 2019)) are good performers like the narrow-striped mongooses. For instance, inhibitory control level promoted behavioural flexibility in narrow-striped mongooses. Similarly, inhibitory control was involved in innovation problem-solving in meerkats (Thornton and Samson 2012). However, inhibitory control did not influence behavioural flexibility in spotted hyenas (Johnson-Ulrich et al. 2018) and racoons (Daniels et al. 2019). These mixed findings could be explained by the fact that inhibitory control is context dependent (Bray et al. 2014; Vernouillet et al. 2018) and was not needed for individual's performances in these studies with contrary outcomes.

\section{Estimation of general intelligence factor " $\mathrm{g}$ " in the M. decemlineata}

The outcomes obtained in estimating the presence of " $\mathrm{g}$ " factor in narrow-striped mongooses do not allow drawing for conclusion. Cognitive performances across the different tasks (detour reaching task, discrimination task, causal understanding task, and problemsolving tasks) did not correlate positively with each other (Appendix). I found weak and nonsignificant correlations between individual performances. Moreover, these cognitive performances did not all positively affect the first principal component obtained from the principal component analysis (PCA), which mirrored the correlation matrix results (Appendix). Specifically, performances in the problem-solving tasks loaded positively, while performances from the other three cognitive tasks (detour reaching task, discrimination task, and causal understanding task) loaded negatively. Similar finding was shown in freeliving males spotted bowerbirds (Ptilonorhynchus maculatus) with the performances on 
problem-solving task did not correlate with other performances from other cognitive tasks (Isden et al. 2013). The fact that individual performances from the problem-solving tasks loaded negatively in the first principal component (PC) indicates that performance in problem-solving did not align with the cognitive performance across the other three cognitive tasks.

Performances in problem-solving tasks were suggested not to address cognitive trait (see Thornton and Samson, 2012), but more the product of motivational trait. Since no effect of persistence was found on individual performances in the three problem-solving tasks (Chapter $\mathbf{3}$ ), the performances as a by-product of motivation is not considered. The failure to obtain positive correlation among the cognitive performances could be because individual variations in the performances in the three cognitive tasks (detour reaching task, discrimination task, and causal understanding task) were not highly pronounced. Since the estimation of " $\mathrm{g}$ " depends on individual variations that should correlate positively across several cognitive tasks, the presence of high behavioural variability is necessary (Isden et al. 2013; Arden and Adams 2016). For instance, in dogs, high variability in performances in a range of tasks (detour tasks, discrimination tasks, and choice tasks), and a phenotypic structure "g" was found to underlie these cognitive performances, with dogs being fast and accurate in several tasks (Arden and Adams 2016). The individual variation obtained in the current study could be because the cognitive tasks used are not complex enough. In order to obtain more pronounced individual variation, one can use more complex cognitive tasks. For example, a more complex task to assess behavioural flexibility would be a set of repeated tasks with different difficulties (e.g., in Huebner and Fichtel, 2015). Thus, further investigations should consider applying more complex cognitive tasks to obtain pronounced individual variation in cognitive performances.

\section{Conclusion and reflections regarding to the evolution of intelligence in carnivores}

In the present thesis, I have investigated the cognitive performances of the narrow-striped mongooses across several cognitive traits, and the factors influencing individual differences in these cognitive performances. The findings of my study offer new insight into the drivers of individual differences in cognitive performances and allow further understanding about the cognitive abilities of carnivore species characterised with a different socio-ecological 
characteristic than other species studied previously. I could show that narrow-striped mongooses performed well in the cognitive traits investigated, such as behavioural flexibility, causal understanding, innovation problem-solving, and social learning. Additionally, I found that neophobia and inhibitory control covaried with individual differences in learning. Moreover, $M$. decemlineata appeared to rely significantly on social information.

However, conducting cognition studies in the wild involves limitations, such as the limited data set and the time constraint in establishing the psychometric test battery. It would be more advantageous to carry cognitive studies with captive animals or wild animals that could be kept temporarily, for example. Besides, this would reduce factors that could not be controlled in the wild. Moreover, conducting the study with captive animals would allow reaching a greater sample size, which is essential for power analyses and will allow addressing more intrinsic factors in the study.

To capture fully the evolution of intelligence in carnivores, it would be useful to investigate individuals' cognitive abilities with the same psychological background in several species of carnivores varying in their socio-ecological characteristics. Previous studies on other carnivore species did not address the same cognitive traits, limiting the comparison that can be inferred from the studies. For instance, wolves and dogs are extensively studied in inhibitory control (e.g., Bray et al., 2014; Marshall-Pescini et al., 2015), problem-solving tasks (e.g., Rao et al., 2018), and human-dogs communication (e.g., Range and Virányi, 2014). However, a detailed study of inhibitory control was not addressed yet in other wild carnivores' species (e.g., bears). Moreover, future works should examine cognitive performances belonging to few cognitive traits or cognitive processes constituting a minitest battery (i.e. only in physical tasks) (Shaw and Schmelz 2017), in order to obtain the same data on the same cognitive trait in several species. This will provide a better comprehension of the factors influencing cognitive traits across species. Furthermore, how cognitive abilities in carnivores are linked to natural behaviours and fitness are lacking. It would be interesting to examine this aspect to understand the adaptive value of a cognitive trait. 


\section{REFERENCES}

Abelson ES (2019) Big brains reduce extinction risk in Carnivora. Oecologia 191:721-729. https://doi.org/10.1007/s00442-019-04527-5

Albiach-Serrano A, Call J (2014) A reversed-reward contingency task reveals causal knowledge in chimpanzees (Pan troglodytes). Anim Cogn 17:1167-1176. https://doi.org/10.1007/s10071-014-0749-9

Albignac R (1976) L'écologie de Mungotictis decemlineata dans les forêts décidues de l'ouest de Madagascar. La terre et la Vie

Amici F, Aureli F, Call J (2008) Fission-Fusion Dynamics, Behavioral Flexibility, and Inhibitory Control in Primates. Current Biology 18:1415-1419. https://doi.org/10.1016/j.cub.2008.08.020

Amici F, Cacchione T, Bueno-Guerra N (2017) Understanding of object properties by sloth bears, Melursus ursinus ursinus. Animal Behaviour 134:217-222. https://doi.org/10.1016/j.anbehav.2017.10.028

Amici F, Widdig A, Lehmann J, Majolo B (2019) A meta-analysis of interindividual differences in innovation. Animal Behaviour 155:257-268.

https://doi.org/10.1016/j.anbehav.2019.07.008

Aplin L (2016) Understanding the multiple factors governing social learning and the diffusion of innovations. Current Opinion in Behavioral Sciences 12:59-65. https://doi.org/10.1016/j.cobeha.2016.09.003

Aplin LM, Sheldon BC, Morand-Ferron J (2013) Milk bottles revisited: social learning and individual variation in the blue tit, Cyanistes caeruleus. Animal Behaviour 85:12251232. https://doi.org/10.1016/j.anbehav.2013.03.009

Arden R, Adams MJ (2016) A general intelligence factor in dogs. Intelligence 55:79-85. https://doi.org/10.1016/j.intell.2016.01.008

Audet J-N, Lefebvre L (2017) What's flexible in behavioral flexibility? Behavioral Ecology. https://doi.org/10.1093/beheco/arx007

Auersperg AMI, Gajdon GK, von Bayern AMP (2012) A new approach to comparing problem solving, flexibility and innovation. Communicative \& Integrative Biology 5:140-145. https://doi.org/10.4161/cib.18787

Auersperg AMI, von Bayern AMI, Weber S, et al (2014) Social transmission of tool use and tool manufacture in Goffin cockatoos (Cacatua goffini). Proceedings of the Royal Society B: Biological Sciences 281:20140972-20140972.

https://doi.org/10.1098/rspb.2014.0972 
Banerjee K, Chabris CF, Johnson VE, et al (2009) General Intelligence in Another Primate: Individual Differences across Cognitive Task Performance in a New World Monkey (Saguinus oedipus). PLoS ONE 4:e5883.

https://doi.org/10.1371/journal.pone.0005883

Bates D, Mächler M, Bolker B, Walker S (2014) Fitting linear mixed-effects models using Ime4. arXiv preprint arXiv:14065823

Bell AM, Hankison SJ, Laskowski KL (2009) The repeatability of behaviour: a meta-analysis. Animal Behaviour 77:771-783. https://doi.org/10.1016/j.anbehav.2008.12.022

Benson-Amram S, Dantzer B, Stricker G, et al (2016) Brain size predicts problem-solving ability in mammalian carnivores. Proceedings of the National Academy of Sciences 113:2532-2537. https://doi.org/10.1073/pnas.1505913113

Benson-Amram S, Heinen VK, Gessner A, et al (2014) Limited social learning of a novel technical problem by spotted hyenas. Behavioural Processes 109:111-120. https://doi.org/10.1016/j.beproc.2014.09.019

Benson-Amram S, Holekamp KE (2012) Innovative problem solving by wild spotted hyenas. Proceedings of the Royal Society B: Biological Sciences 279:4087-4095. https://doi.org/10.1098/rspb.2012.1450

Beran MJ (2015) The comparative science of "self-control": what are we talking about? Frontiers in psychology 6:51

Beran MJ, Hopkins WD (2018) Self-Control in Chimpanzees Relates to General Intelligence. Current Biology 28:574-579.e3. https://doi.org/10.1016/j.cub.2017.12.043

Bibi N, Wei Y, Xu H, et al (2019) Personality is associated with dominance in a social feeding context in the great tit. Behav 156:1419-1434. https://doi.org/10.1163/1568539X00003572

Biondi LM, Bó MS, Vassallo Al (2010) Inter-individual and age differences in exploration, neophobia and problem-solving ability in a Neotropical raptor (Milvago chimango). Animal Cognition 13:701-710. https://doi.org/10.1007/s10071-010-0319-8

Blake CA, Andersson ML, Hulthén K, et al (2018) Conspecific boldness and predator species determine predation-risk consequences of prey personality. Behavioral Ecology and Sociobiology 72:. https://doi.org/10.1007/s00265-018-2544-0

Boogert NJ, Anderson RC, Peters S, et al (2011) Song repertoire size in male song sparrows correlates with detour reaching, but not with other cognitive measures. Animal Behaviour 81:1209-1216. https://doi.org/10.1016/j.anbehav.2011.03.004

Boogert NJ, Madden JR, Morand-Ferron J, Thornton A (2018) Measuring and understanding individual differences in cognition. Philosophical Transactions of the Royal Society B: Biological Sciences 373:20170280. https://doi.org/10.1098/rstb.2017.0280 
Borrego N, Gaines M (2016) Social carnivores outperform asocial carnivores on an innovative problem. Animal Behaviour 114:21-26.

https://doi.org/10.1016/j.anbehav.2016.01.013

Bousquet CAH, Petit O, Arrivé M, et al (2015) Personality tests predict responses to a spatiallearning task in mallards, Anas platyrhynchos. Animal Behaviour 110:145-154. https://doi.org/10.1016/j.anbehav.2015.09.024

Bräuer J, Kaminski J, Riedel J, et al (2006) Making inferences about the location of hidden food: Social dog, causal ape. Journal of Comparative Psychology 120:38-47. https://doi.org/10.1037/0735-7036.120.1.38

Bray EE, MacLean EL, Hare BA (2014) Context specificity of inhibitory control in dogs. Animal Cognition 17:15-31. https://doi.org/10.1007/s10071-013-0633-z

Brust V, Guenther A (2015) Domestication effects on behavioural traits and learning performance: comparing wild cavies to guinea pigs. Animal Cognition 18:99-109. https://doi.org/10.1007/s10071-014-0781-9

Buechel SD, Boussard A, Kotrschal A, et al (2018) Brain size affects performance in a reversallearning test. Proceedings of the Royal Society B: Biological Sciences 285:20172031. https://doi.org/10.1098/rspb.2017.2031

Bugnyar T (2013) Social cognition in ravens. Comparative Cognition \& Behavior Reviews 8:112. https://doi.org/10.3819/ccbr.2013.80001

Burkart JM, Schubiger MN, van Schaik CP (2016) The evolution of general intelligence. Behavioral and Brain Sciences 1-65. https://doi.org/10.1017/S0140525X16000959

Byrne RW (1997) The technical intelligence hypothesis: an additional evolutionary stimulus to intelligence. In: Machiavellian intelligence II, A. Whiten \& R. Byrne. pp 289-311

Byrne RW (1996) Machiavellian intelligence. Evolutionary Anthropology: Issues, News, and Reviews 5:172-180. https://doi.org/10.1002/(SICI)1520-6505(1996)5:5<172::AIDEVAN6>3.0.CO;2-H

Call J, Hare B, Carpenter M, Tomasello M (2004) "Unwilling" versus "unable": chimpanzees' understanding of human intentional action. Developmental Sci 7:488-498. https://doi.org/10.1111/j.1467-7687.2004.00368.x

Carere C, Locurto C (2011) Interaction between animal personality and animal cognition. Current Zoology 57:491-498

Carter AJ, Marshall HH, Heinsohn R, Cowlishaw G (2014) Personality predicts the propensity for social learning in a wild primate. PeerJ 2:e283. https://doi.org/10.7717/peerj.283

Cauchard L, Lefebvre L, Overington S, Morand-Ferron J (2009) Innovation in groups: does the proximity of others facilitate or inhibit performance? Behaviour 146:1543-1564. https://doi.org/10.1163/156853909X450131 
Cauchoix M, Hermer E, Chaine AS, Morand-Ferron J (2017) Cognition in the field: comparison of reversal learning performance in captive and wild passerines. Scientific Reports 7:. https://doi.org/10.1038/s41598-017-13179-5

Cheke LG, Bird CD, Clayton NS (2011) Tool-use and instrumental learning in the Eurasian jay (Garrulus glandarius). Anim Cogn 14:441-455. https://doi.org/10.1007/s10071-0110379-4

Chiappe D, MacDonald K (2005) The Evolution of Domain-General Mechanisms in Intelligence and Learning. The Journal of General Psychology 132:5-40. https://doi.org/10.3200/GENP.132.1.5-40

Chittka L, Skorupski P, Raine NE (2009) Speed-accuracy tradeoffs in animal decision making. Trends in Ecology \& Evolution 24:400-407. https://doi.org/10.1016/j.tree.2009.02.010

Chow PKY, Lea SEG, Leaver LA (2016) How practice makes perfect: the role of persistence, flexibility and learning in problem-solving efficiency. Animal Behaviour 112:273-283. https://doi.org/10.1016/j.anbehav.2015.11.014

Clutton-Brock TH, Gaynor D, Mcllrath GM, et al (1999) Predation, group size and mortality in a cooperative mongoose, Suricata suricatta. J Anim Ecology 68:672-683. https://doi.org/10.1046/j.1365-2656.1999.00317.x

Clutton-Brock TH, Russell AF, Sharpe LL, et al (2002) Evolution and development of sex differences in cooperative behavior in meerkats. Science 297:253-256

Cole EF, Cram DL, Quinn JL (2011) Individual variation in spontaneous problem-solving performance among wild great tits. Animal Behaviour 81:491-498. https://doi.org/10.1016/j.anbehav.2010.11.025

Cole EF, Quinn JL (2012) Personality and problem-solving performance explain competitive ability in the wild. Proceedings of the Royal Society B: Biological Sciences 279:11681175. https://doi.org/10.1098/rspb.2011.1539

Coppens CM, de Boer SF, Koolhaas JM (2010) Coping styles and behavioural flexibility: towards underlying mechanisms. Philosophical Transactions of the Royal Society B: Biological Sciences 365:4021-4028. https://doi.org/10.1098/rstb.2010.0217

Crane AL, Ferrari MCO (2017) Patterns of predator neophobia: a meta-analytic review. Proceedings of the Royal Society B: Biological Sciences 284:20170583. https://doi.org/10.1098/rspb.2017.0583

Dalesman S (2018) Habitat and social context affect memory phenotype, exploration and covariance among these traits. Philosophical Transactions of the Royal Society B: Biological Sciences 373:20170291. https://doi.org/10.1098/rstb.2017.0291

Dall SRX, Houston AI, McNamara JM (2004) The behavioural ecology of personality: consistent individual differences from an adaptive perspective. Ecology Letters 7:734-739. https://doi.org/10.1111/j.1461-0248.2004.00618.x 
Damas-Moreira I, Oliveira D, Santos JL, et al (2018) Learning from others: an invasive lizard uses social information from both conspecifics and heterospecifics. 5

Daniels SE, Fanelli RE, Gilbert A, Benson-Amram S (2019) Behavioral flexibility of a generalist carnivore. Anim Cogn 22:387-396. https://doi.org/10.1007/s10071-019-01252-7

Davidson G, Miller R, Loissel E, et al (2017) The development of support intuitions and object causality in juvenile Eurasian jays (Garrulus glandarius). Sci Rep 7:40062. https://doi.org/10.1038/srep40062

Deaner RO, Isler K, Burkart J, van Schaik C (2007) Overall Brain Size, and Not Encephalization Quotient, Best Predicts Cognitive Ability across Non-Human Primates. Brain, Behavior and Evolution 70:115-124. https://doi.org/10.1159/000102973

Deary IJ, Penke L, Johnson W (2010) The neuroscience of human intelligence differences. Nat Rev Neurosci 11:201-211. https://doi.org/10.1038/nrn2793

Doolan SP, MacDonald DW (1996) Diet and foraging behaviour of group-living meerkats, Suricata suricatta, in the southern Kalahari. Journal of Zoology 239:697-716

Dougherty LR, Guillette LM (2018) Linking personality and cognition: a meta-analysis. Philosophical Transactions of the Royal Society B: Biological Sciences 373:20170282. https://doi.org/10.1098/rstb.2017.0282

Ducatez S, Audet JN, Lefebvre L (2015a) Problem-solving and learning in Carib grackles: individuals show a consistent speed-accuracy trade-off. Animal Cognition 18:485496. https://doi.org/10.1007/s10071-014-0817-1

Ducatez S, Clavel J, Lefebvre L (2015b) Ecological generalism and behavioural innovation in birds: technical intelligence or the simple incorporation of new foods? Journal of Animal Ecology 84:79-89. https://doi.org/10.1111/1365-2656.12255

Duffield C, Wilson AJ, Thornton A (2015) Desperate Prawns: Drivers of Behavioural Innovation vary across Social Contexts in Rock Pool Crustaceans. PLoS ONE 10:e0139050. https://doi.org/10.1371/journal.pone.0139050

Dukas R, Ratcliffe JM (eds) (2009) Cognitive ecology II. University of Chicago Press.

Dunbar RIM, Shultz S (2007) Evolution in the Social Brain. Science 317:1344-1347. https://doi.org/10.1126/science.1145463

Dunbar RIM, Shultz S (2017) Why are there so many explanations for primate brain evolution? Philosophical Transactions of the Royal Society B: Biological Sciences 372:20160244. https://doi.org/10.1098/rstb.2016.0244

Fedorova N, Evans CL, Byrne RW (2017) Living in stable social groups is associated with reduced brain size in woodpeckers ( Picidae ). Biology Letters 13:20170008. https://doi.org/10.1098/rsbl.2017.0008 
Forss SIF, Koski SE, van Schaik CP (2017) Explaining the Paradox of Neophobic Explorers: The Social Information Hypothesis. International Journal of Primatology 38:799-822. https://doi.org/10.1007/s10764-017-9984-7

Friard O, Gamba M (2016) BORIS: a free, versatile open-source event-logging software for video/audio coding and live observations. Methods in Ecology and Evolution 7:13251330. https://doi.org/10.1111/2041-210X.12584

Fristoe TS, Iwaniuk AN, Botero CA (2017) Big brains stabilize populations and facilitate colonization of variable habitats in birds. Nat Ecol Evol 1:1706-1715. https://doi.org/10.1038/s41559-017-0316-2

Gager Y (2019) Information transfer about food as a reason for sociality in bats. Mam Rev 49:113-120. https://doi.org/10.1111/mam.12146

Galef BG, Giraldeau L-A (2001) Social influences on foraging in vertebrates: causal mechanisms and adaptive functions. Animal Behaviour 61:3-15. https://doi.org/10.1006/anbe.2000.1557

Galsworthy MJ, Paya-Cano JL, Monleon S, Plomin R (2002) Evidence for general cognitive ability $(\mathrm{g})$ in heterogeneous stock mice and an analysis of potential confounds. Genes Brain Behav 1:88-95. https://doi.org/10.1034/j.1601-183X.2002.10204.x

Gamer M, Lemon J, Fellows I, Singh P (2012) Package "irr": Various Coefficients of Interrater Reliability and Agreement

Gibelli J, Dubois F (2017) Does personality affect the ability of individuals to track and respond to changing conditions? Behavioral Ecology 28:101-107. https://doi.org/10.1093/beheco/arw137

Greenberg R (2003) The Role of Neophobia and Neophilia in the Development of Innovative Behaviour of Birds. In: Reader SM, Laland KN (eds) Animal Innovation. Oxford University Press, pp 175-196

Greggor AL, Jolles JW, Thornton A, Clayton NS (2016a) Seasonal changes in neophobia and its consistency in rooks: the effect of novelty type and dominance position. Animal Behaviour 121:11-20. https://doi.org/10.1016/j.anbehav.2016.08.010

Greggor AL, Mclvor GE, Clayton NS, Thornton A (2016b) Contagious risk taking: social information and context influence wild jackdaws' responses to novelty and risk. Sci Rep 6:27764. https://doi.org/10.1038/srep27764

Greggor AL, Thornton A, Clayton NS (2015) Neophobia is not only avoidance: improving neophobia tests by combining cognition and ecology. Current Opinion in Behavioral Sciences 6:82-89. https://doi.org/10.1016/j.cobeha.2015.10.007

Griffin AS, Diquelou M, Perea M (2014) Innovative problem solving in birds: a key role of motor diversity. Animal Behaviour 92:221-227. https://doi.org/10.1016/j.anbehav.2014.04.009 
Griffin AS, Guez D (2014) Innovation and problem solving: A review of common mechanisms. Behavioural Processes 109:121-134. https://doi.org/10.1016/j.beproc.2014.08.027

Griffin AS, Guez D (2015) Innovative problem solving in nonhuman animals: the effects of group size revisited. Behavioral Ecology 26:722-734. https://doi.org/10.1093/beheco/aru238

Griffin AS, Guillette LM, Healy SD (2015) Cognition and personality: an analysis of an emerging field. Trends in Ecology \& Evolution 30:207-214. https://doi.org/10.1016/j.tree.2015.01.012

Grüter C, Leadbeater E (2014) Insights from insects about adaptive social information use. Trends in Ecology \& Evolution 29:177-184. https://doi.org/10.1016/j.tree.2014.01.004

Guenther A, Brust V, Dersen M, Trillmich F (2014) Learning and personality types are related in cavies (Cavia aperea). Journal of Comparative Psychology 128:74-81. https://doi.org/10.1037/a0033678

Guez D, Griffin AS (2016) Unraveling the key to innovative problem solving: a test of learning versus persistence. Behavioral Ecology 27:1449-1460. https://doi.org/10.1093/beheco/arw055

Guido JM, Biondi LM, Vasallo Al, Muzio RN (2017) Neophobia is negatively related to reversal learning ability in females of a generalist bird of prey, the Chimango Caracara, Milvago chimango. Animal Cognition 20:591-602. https://doi.org/10.1007/s10071017-1083-9

Guillette LM, Hahn AH, Hoeschele M, et al (2015) Individual differences in learning speed, performance accuracy and exploratory behaviour in black-capped chickadees. Anim Cogn 18:165-178. https://doi.org/10.1007/s10071-014-0787-3

Guillette LM, Naguib M, Griffin AS (2017) Individual differences in cognition and personality. Behavioural Processes 134:1-3. https://doi.org/10.1016/j.beproc.2016.12.001

Hawkins CE, Racey PA (2008) Food Habits of an Endangered Carnivore, Cryptoprocta Ferox, in the Dry Deciduous Forests of Western Madagascar. Journal of Mammalogy 89:6474. https://doi.org/10.1644/06-MAMM-A-366.1

Henke-von der Malsburg J, Fichtel C (2018) Are generalists more innovative than specialists? A comparison of innovative abilities in two wild sympatric mouse lemur species. $5: 180480$

Herborn KA, Heidinger BJ, Alexander L, Arnold KE (2014) Personality predicts behavioral flexibility in a fluctuating, natural environment. Behavioral Ecology 25:1374-1379. https://doi.org/10.1093/beheco/aru131

Herrmann E, Hernández-Lloreda MV, Call J, et al (2010) The Structure of Individual Differences in the Cognitive Abilities of Children and Chimpanzees. Psychol Sci 21:102-110. https://doi.org/10.1177/0956797609356511 
Hofmann MM, Cheke LG, Clayton NS (2016) Western scrub-jays (Aphelocoma californica) solve multiple-string problems by the spatial relation of string and reward. Anim Cogn 19:1103-1114. https://doi.org/10.1007/s10071-016-1018-x

Holekamp KE (2007) Questioning the social intelligence hypothesis. Trends in Cognitive Sciences 11:65-69. https://doi.org/10.1016/j.tics.2006.11.003

Holekamp KE, Benson-Amram S (2017) The evolution of intelligence in mammalian carnivores. Interface Focus 7:20160108. https://doi.org/10.1098/rsfs.2016.0108

Holekamp KE, Sakai ST, Lundrigan BL (2007) Social intelligence in the spotted hyena ( Crocuta crocuta ). Philosophical Transactions of the Royal Society B: Biological Sciences 362:523-538. https://doi.org/10.1098/rstb.2006.1993

Horschler DJ, Hare B, Call J, et al (2019) Absolute brain size predicts dog breed differences in executive function. Anim Cogn 22:187-198. https://doi.org/10.1007/s10071-01801234-1

Huber L, Gajdon GK (2006) Technical intelligence in animals: the kea model. Animal Cognition 9:295-305. https://doi.org/10.1007/s10071-006-0033-8

Huebner F, Fichtel C (2015) Innovation and behavioral flexibility in wild redfronted lemurs (Eulemur rufifrons). Animal Cognition 18:777-787. https://doi.org/10.1007/s10071015-0844-6

Isden J, Panayi C, Dingle C, Madden J (2013) Performance in cognitive and problem-solving tasks in male spotted bowerbirds does not correlate with mating success. Animal Behaviour 86:829-838. https://doi.org/10.1016/j.anbehav.2013.07.024

Jacobson SL, Hopper LM (2019) Hardly habitual: chimpanzees and gorillas show flexibility in their motor responses when presented with a causally-clear task. PeerJ 7:e6195. https://doi.org/10.7717/peerj.6195

Jelbert SA, Taylor AH, Gray RD (2015) Investigating animal cognition with the Aesop's Fable paradigm: Current understanding and future directions. Communicative \& Integrative Biology 8:e1035846. https://doi.org/10.1080/19420889.2015.1035846

Johnson-Ulrich L (2017) The Social Intelligence Hypothesis. In: Shackelford TK, WeekesShackelford VA (eds) Encyclopedia of Evolutionary Psychological Science. Springer International Publishing, Cham, pp 1-7

Johnson-Ulrich L, Holekamp KE (2019) Group size and social rank predict inhibitory control in spotted hyaenas. Animal Behaviour S0003347219303884.

https://doi.org/10.1016/j.anbehav.2019.11.020

Johnson-Ulrich L, Johnson-Ulrich Z, Holekamp K (2018) Proactive behavior, but not inhibitory control, predicts repeated innovation by spotted hyenas tested with a multi-access box. Animal Cognition 21:379-392. https://doi.org/10.1007/s10071-018-1174-2 
Jolles JW, Aaron Taylor B, Manica A (2016) Recent social conditions affect boldness repeatability in individual sticklebacks. Animal Behaviour 112:139-145. https://doi.org/10.1016/j.anbehav.2015.12.010

Kabadayi C, Bobrowicz K, Osvath M (2018) The detour paradigm in animal cognition. Animal Cognition 21:21-35. https://doi.org/10.1007/s10071-017-1152-0

Kappeler PM, Fichtel C (2012) A 15-year perspective on the social organization and life history of sifaka in Kirindy Forest. In: Long-term field studies of primates. Springer, Berlin, Heidelberg, pp 101-121

Katsnelson E, Motro U, Feldman MW, Lotem A (2011) Individual-learning ability predicts social-foraging strategy in house sparrows. Proceedings of the Royal Society B: Biological Sciences 278:582-589. https://doi.org/10.1098/rspb.2010.1151

Kendal R, Hopper LM, Whiten A, et al (2015) Chimpanzees copy dominant and knowledgeable individuals: implications for cultural diversity. Evolution and Human Behavior 36:65-72. https://doi.org/10.1016/j.evolhumbehav.2014.09.002

Kendal RL, Boogert NJ, Rendell L, et al (2018) Social Learning Strategies: Bridge-Building between Fields. Trends in Cognitive Sciences 22:651-665. https://doi.org/10.1016/j.tics.2018.04.003

Kendal RL, Galef BG, Van Schaik CP (2010) Social learning research outside the laboratory: How and why? Learning \& Behavior 38:187-194. https://doi.org/10.3758/LB.38.3.187

Kittler K, Kappeler PM, Fichtel C (2018) Instrumental problem-solving abilities in three lemur species (Microcebus murinus, Varecia variegata, and Lemur catta). Journal of Comparative Psychology 132:306-314. https://doi.org/10.1037/com0000113

Kotrschal A, Buechel SD, Zala SM, et al (2015) Brain size affects female but not male survival under predation threat. Ecology Letters 18:646-652. https://doi.org/10.1111/ele.12441

Kotrschal A, Rogell B, Bundsen A, et al (2013) The benefit of evolving a larger brain: bigbrained guppies perform better in a cognitive task. Animal Behaviour 86:e4-e6. https://doi.org/10.1016/j.anbehav.2013.07.011

Krasheninnikova A, Berardi R, Lind $M-A$, et al (2019) Primate cognition test battery in parrots. Behav 156:721-761. https://doi.org/10.1163/1568539X-00003549

Kurvers RHJM, Prins HHT, van Wieren SE, et al (2010a) The effect of personality on social foraging: shy barnacle geese scrounge more. Proceedings of the Royal Society B: Biological Sciences 277:601-608. https://doi.org/10.1098/rspb.2009.1474

Kurvers RHJM, Van Oers K, Nolet BA, et al (2010b) Personality predicts the use of social information: Personality and social information use. Ecology Letters 13:829-837. https://doi.org/10.1111/j.1461-0248.2010.01473.x 
Laland KN (2004) Social learning strategies. Learning \& behavior 32:4-14

Lampe M, Bräuer J, Kaminski J, Virányi Z (2017) The effects of domestication and ontogeny on cognition in dogs and wolves. Sci Rep 7:11690. https://doi.org/10.1038/s41598017-12055-6

Lefebvre L (2011) Taxonomic counts of cognition in the wild. Biology Letters 7:631-633. https://doi.org/10.1098/rsbl.2010.0556

Lefebvre L, Whittle P, Lascaris E, Finkelstein A (1997) Feeding innovations and forebrain size in birds. Animal Behaviour 53:549-560

Lermite F, Peneaux C, Griffin AS (2017) Personality and problem-solving in common mynas (Acridotheres tristis). Behavioural Processes 134:87-94. https://doi.org/10.1016/j.beproc.2016.09.013

Logan CJ (2016a) Behavioral flexibility and problem solving in an invasive bird. PeerJ 4:e1975. https://doi.org/10.7717/peerj.1975

Logan CJ (2016b) Behavioral flexibility in an invasive bird is independent of other behaviors. PeerJ 4:e2215. https://doi.org/10.7717/peerj.2215

Lucon-Xiccato T, Montalbano G, Bertolucci C (2019) Personality traits covary with individual differences in inhibitory abilities in two species of fish. Current Zoology zoz039. https://doi.org/10.1093/cz/zoz039

MacLean EL, Hare B, Nunn CL, et al (2014) The evolution of self-control. Proceedings of the National Academy of Sciences 111:E2140-E2148

MacLean EL, Sandel AA, Bray J, et al (2013) Group Size Predicts Social but Not Nonsocial Cognition in Lemurs. PLoS ONE 8:e66359. https://doi.org/10.1371/journal.pone.0066359

Madden JR, Langley EJG, Whiteside MA, et al (2018) The quick are the dead: pheasants that are slow to reverse a learned association survive for longer in the wild. Philosophical Transactions of the Royal Society B: Biological Sciences 373:20170297. https://doi.org/10.1098/rstb.2017.0297

Marchetti C, Drent PJ (2000) Individual differences in the use of social information in foraging by captive great tits. Animal Behaviour 60:131-140. https://doi.org/10.1006/anbe.2000.1443

Marshall-Pescini S, Virányi Z, Range F (2015) The Effect of Domestication on Inhibitory Control: Wolves and Dogs Compared. PLOS ONE 10:e0118469. https://doi.org/10.1371/journal.pone.0118469

Mazza V, Eccard JA, Zaccaroni M, et al (2018) The fast and the flexible: cognitive style drives individual variation in cognition in a small mammal. Animal Behaviour 137:119-132. https://doi.org/10.1016/j.anbehav.2018.01.011 
Mesoudi A, Chang L, Dall SRX, Thornton A (2016) The Evolution of Individual and Cultural Variation in Social Learning. Trends in Ecology \& Evolution 31:215-225. https://doi.org/10.1016/j.tree.2015.12.012

Mikhalevich I, Powell R, Logan C (2017) Is behavioural flexibility evidence of cognitive complexity? How evolution can inform comparative cognition. Interface Focus 7:20160121. https://doi.org/10.1098/rsfs.2016.0121

Morales Picard A, Hogan L, Lambert ML, et al (2017) Diffusion of novel foraging behaviour in Amazon parrots through social learning. Animal Cognition 20:285-298. https://doi.org/10.1007/s10071-016-1049-3

Morand-Ferron J, Cole EF, Quinn JL (2016) Studying the evolutionary ecology of cognition in the wild: a review of practical and conceptual challenges: Evolutionary ecology of cognition in the wild. Biol Rev 91:367-389. https://doi.org/10.1111/brv.12174

Müller CA (2010) Do anvil-using banded mongooses understand means-end relationships? A field experiment. Animal Cognition 13:325-330. https://doi.org/10.1007/s10071009-0281-5

Müller CA, Cant MA (2010) Imitation and Traditions in Wild Banded Mongooses. Current Biology 20:1171-1175. https://doi.org/10.1016/j.cub.2010.04.037

Müller CA, Riemer S, Virányi Z, et al (2016) Inhibitory control, but not prolonged objectrelated experience appears to affect physical problem-solving performance of pet dogs. PLoS One 11:e0147753

Müller CA, Riemer S, Virányi Z, et al (2014) Dogs learn to solve the support problem based on perceptual cues. Animal Cognition 17:1071-1080. https://doi.org/10.1007/s10071014-0739-y

Nakagawa, S., \& Schielzeth, H. 2010. Repeatability for Gaussian and non-Gaussian data: A practical guide for biologists. Biological Reviews. https://doi.org/10.1111/j.1469185X.2010.00141.x

Navarrete AF, Reader SM, Street SE, et al (2016) The coevolution of innovation and technical intelligence in primates. Philosophical Transactions of the Royal Society B: Biological Sciences 371:20150186. https://doi.org/10.1098/rstb.2015.0186

Nawroth C, Baciadonna L, McElligott AG (2016) Goats learn socially from humans in a spatial problem-solving task. Animal Behaviour 121:123-129. https://doi.org/10.1016/j.anbehav.2016.09.004

Nawroth C, Prentice PM, McElligott AG (2017) Individual personality differences in goats predict their performance in visual learning and non-associative cognitive tasks. Behavioural Processes 134:43-53. https://doi.org/10.1016/j.beproc.2016.08.001

Niemelä PT, Dingemanse NJ (2018) Meta-analysis reveals weak associations between intrinsic state and personality. Proc R Soc B 285:20172823.

https://doi.org/10.1098/rspb.2017.2823 
Noble DWA, Carazo P, Whiting MJ (2012) Learning outdoors: male lizards show flexible spatial learning under semi-natural conditions. Biology Letters 8:946-948. https://doi.org/10.1098/rsbl.2012.0813

Nomakuchi S, Park PJ, Bell MA (2009) Correlation between exploration activity and use of social information in three-spined sticklebacks. Behavioral Ecology 20:340-345. https://doi.org/10.1093/beheco/arp001

O'Connell S, Dunbar RIM (2005) The perception of causality in chimpanzees (Pan spp.). Anim Cogn 8:60-66. https://doi.org/10.1007/s10071-004-0231-1

Osthaus B, Lea SEG, Slater AM (2005) Dogs (Canis lupus familiaris) fail to show understanding of means-end connections in a string-pulling task. Anim Cogn 8:37-47. https://doi.org/10.1007/s10071-004-0230-2

Overington SE, Cauchard L, Côté K-A, Lefebvre L (2011a) Innovative foraging behaviour in birds: What characterizes an innovator? Behavioural Processes 87:274-285. https://doi.org/10.1016/j.beproc.2011.06.002

Overington SE, Griffin AS, Sol D, Lefebvre L (2011b) Are innovative species ecological generalists? A test in North American birds. Behavioral Ecology 22:1286-1293. https://doi.org/10.1093/beheco/arr130

Overington SE, Morand-Ferron J, Boogert NJ, Lefebvre L (2009) Technical innovations drive the relationship between innovativeness and residual brain size in birds. Animal Behaviour 78:1001-1010. https://doi.org/10.1016/j.anbehav.2009.06.033

Pérez-Barbería FJ, Shultz S, Dunbar RIM (2007) EVIDENCE FOR COEVOLUTION OF SOCIALITY AND RELATIVE BRAIN SIZE IN THREE ORDERS OF MAMMALS. Evolution 61:28112821. https://doi.org/10.1111/j.1558-5646.2007.00229.x

Pitnick S, Jones KE, Wilkinson GS (2006) Mating system and brain size in bats. Proceedings of the Royal Society B: Biological Sciences 273:719-724.

https://doi.org/10.1098/rspb.2005.3367

Plotnik JM, Clayton NS (2015) Convergent cognitive evolution across animal taxa: comparisons of chimpanzees, corvids, and elephants. In: The conceptual mind: new directions in the study of concepts. pp 29-56

Pollen AA, Dobberfuhl AP, Scace J, et al (2007) Environmental Complexity and Social Organization Sculpt the Brain in Lake Tanganyikan Cichlid Fish. Brain Behav Evol 70:21-39. https://doi.org/10.1159/000101067

Pritchard DJ, Hurly TA, Tello-Ramos MC, Healy SD (2016) Why study cognition in the wild (and how to test it)?: Cognition in the wild. Journal of the Experimental Analysis of Behavior 105:41-55. https://doi.org/10.1002/jeab.195

R Core Team (2017) R: A language and environment for statistical computing. R Foundation for Statistical Computing, Vienna, Austria 
Range F, Virányi Z (2014) Wolves Are Better Imitators of Conspecifics than Dogs. PLoS ONE 9:e86559. https://doi.org/10.1371/journal.pone.0086559

Rao A, Bernasconi L, Lazzaroni M, et al (2018) Differences in persistence between dogs and wolves in an unsolvable task in the absence of humans. PeerJ 6:e5944. https://doi.org/10.7717/peerj.5944

Rasolofoniaina, B. N., Kappeler, P. M., \& Fichtel, C. (2021). Neophobia and social facilitation in narrow-striped mongooses. Animal Cognition 24(1): 165-175

Rasolofoniaina, B., Kappeler, P. M., \& Fichtel, C. (2020). Wild narrow-striped mongooses use social information to enhance behavioural flexibility. Etholology. DOI: 10.1111/eth.13123

Rasolofoniaina B, Razafy P, Razafimahatratra E, Kappeler PM (2019) Feeding ecology of the bokiboky, Mungotictis decemlineata (family Eupleridae). Malagasy Nature 13:152161

Razafimanantsoa L (2003) Mungotictis decemlineata, narrow-striped mongoose. In: The natural history of Madagascar. The University of Chicago Press, Chicago, pp 13571360

Reader S (2003) Innovation and social learning: individual variation and brain evolution. Animal Biology 53:147-158. https://doi.org/10.1163/157075603769700340

Reader SM, Hager Y, Laland KN (2011) The evolution of primate general and cultural intelligence. Philosophical Transactions of the Royal Society B: Biological Sciences 366:1017-1027. https://doi.org/10.1098/rstb.2010.0342

Reader SM, Laland K (2003a) Diffusion of foraging innovations in the guppy. Animal Behaviour 60:175-180

Reader SM, Laland KN (2003b) Animal Innovation: An Introduction. In: Reader SM, Laland KN (eds) Animal Innovation. Oxford University Press, pp 3-36

Reale D, Dingemanse NJ, Kazem AJN, Wright J (2010) Evolutionary and ecological approaches to the study of personality. Philosophical Transactions of the Royal Society B: Biological Sciences 365:3937-3946. https://doi.org/10.1098/rstb.2010.0222

Réale D, Reader SM, Sol D, et al (2007) Integrating animal temperament within ecology and evolution. Biological Reviews 82:291-318. https://doi.org/10.1111/j.1469185X.2007.00010.x

Revelle W (2018) psych: Procedures for Personality and Psychological Research. Northwestern University, Evanston, Illinois, USA

Rieucau G, Giraldeau L-A (2011) Exploring the costs and benefits of social information use: an appraisal of current experimental evidence. Philosophical Transactions of the Royal Society B: Biological Sciences 366:949-957. https://doi.org/10.1098/rstb.2010.0325 
Riley JL, Noble DWA, Byrne RW, Whiting MJ (2017) Does social environment influence learning ability in a family-living lizard? Animal Cognition 20:449-458. https://doi.org/10.1007/s10071-016-1068-0

Rood JP (1983) The social system of the dwarf mongoose. Advances in the study of mammalian behavior 454-488

Rosa P, Nguyen V, Dubois F (2012) Individual differences in sampling behaviour predict social information use in zebra finches. Behavioral Ecology and Sociobiology 66:1259-1265. https://doi.org/10.1007/s00265-012-1379-3

Rosati AG (2017) Foraging Cognition: Reviving the Ecological Intelligence Hypothesis. Trends in Cognitive Sciences 21:691-702. https://doi.org/10.1016/j.tics.2017.05.011

Roth G, Dicke U (2005) Evolution of the brain and intelligence. Trends in Cognitive Sciences 9:250-257. https://doi.org/10.1016/j.tics.2005.03.005

Rowe C, Healy SD (2014) Measuring variation in cognition. Behavioral Ecology 25:1287-1292. https://doi.org/10.1093/beheco/aru090

Ryer $\mathrm{CH}$, Olla BL (1991) Information transfer and the facilitation and inhibition of feeding in a schooling fish. Environmental Biology of Fishes 30:317-323

Schmitt V, Pankau B, Fischer J (2012) Old world monkeys compare to apes in the primate cognition test battery. PloS one 7:e32024

Schneider TC, Kappeler PM, Pozzi L (2016) Genetic population structure and relatedness in the narrow-striped mongoose ( Mungotictis decemlineata), a social Malagasy carnivore with sexual segregation. Ecology and Evolution 6:3734-3749. https://doi.org/10.1002/ece3.2123

Schneider TC, Kappeler PM (2016) Gregarious sexual segregation: the unusual social organization of the Malagasy narrow-striped mongoose (Mungotictis decemlineata). Behavioral Ecology and Sociobiology 70:913-926. https://doi.org/10.1007/s00265016-2113-3

Schneider TC (2015) Social organisation of the narrow-striped mongoose (Mungotictis decemlineata) in Kirindy Forest C.N.F.E.R.E.F., Madagascar. Georg-August University of Göttingen

Schneider TC, Kappeler PM (2014) Social systems and life-history characteristics of mongooses: Social Systems of Mongooses. Biological Reviews 89:173-198. https://doi.org/10.1111/brv.12050

Schnoell AV, Fichtel C (2012) Wild redfronted lemurs (Eulemur rufifrons) use social information to learn new foraging techniques. Animal Cognition 15:505-516. https://doi.org/10.1007/s10071-012-0477-y 
Serrano-Davies E, O'Shea W, Quinn JL (2017) Individual foraging preferences are linked to innovativeness and personality in the great tit. Behav Ecol Sociobiol 71:161. https://doi.org/10.1007/s00265-017-2389-y

Seyfarth RM, Cheney DL (2015) How sociality shapes the brain, behaviour and cognition. Animal Behaviour 103:187-190. https://doi.org/10.1016/j.anbehav.2015.01.026

Shaw RC (2017) Testing cognition in the wild: factors affecting performance and individual consistency in two measures of avian cognition. Behavioural Processes 134:31-36. https://doi.org/10.1016/j.beproc.2016.06.004

Shaw RC, Boogert NJ, Clayton NS, Burns KC (2015) Wild psychometrics: evidence for 'general' cognitive performance in wild New Zealand robins, Petroica longipes. Animal Behaviour 109:101-111. https://doi.org/10.1016/j.anbehav.2015.08.001

Shaw RC, Schmelz M (2017) Cognitive test batteries in animal cognition research: evaluating the past, present and future of comparative psychometrics. Animal Cognition 20:1003-1018. https://doi.org/10.1007/s10071-017-1135-1

Shettleworth SJ (2009) Cognition, Evolution, and Behavior. 2

Shettleworth SJ (2001) Animal cognition and animal behaviour. Animal Behaviour 61:277286. https://doi.org/10.1006/anbe.2000.1606

Sih A, Del Giudice M (2012) Linking behavioural syndromes and cognition: a behavioural ecology perspective. Philosophical Transactions of the Royal Society B: Biological Sciences 367:2762-2772. https://doi.org/10.1098/rstb.2012.0216

Sinclair ARE, Mduma S, Brashares JS (2003) Patterns of predation in a diverse predator-prey system. Nature 425:288

Slaa EJ, Wassenberg J, Biesmeijer JC (2003) The use of field-based social information in eusocial foragers: local enhancement among nestmates and heterospecifics in stingless bees. Ecological Entomology 28:369-379. https://doi.org/10.1046/j.13652311.2003.00512.x

Smirnova A, Zorina Z, Obozova T, Wasserman E (2015) Crows Spontaneously Exhibit Analogical Reasoning. Current Biology 25:256-260. https://doi.org/10.1016/j.cub.2014.11.063

Smit JAH, van Oers K (2019) Personality types vary in their personal and social information use. Animal Behaviour. https://doi.org/10.1016/j.anbehav.2019.02.002

Smulders TV, Gould KL, Leaver LA (2010) Using ecology to guide the study of cognitive and neural mechanisms of different aspects of spatial memory in food-hoarding animals. Philosophical Transactions of the Royal Society B: Biological Sciences 365:883-900. https://doi.org/10.1098/rstb.2009.0211

Sol D (2009) Revisiting the cognitive buffer hypothesis for the evolution of large brains. Biology Letters 5:130-133. https://doi.org/10.1098/rsbl.2008.0621 
Sol D, Ducatez S, Sayol F (2016a) Cognitive Buffer Hypothesis, The. In: Weekes-Shackelford V, Shackelford TK, Weekes-Shackelford VA (eds) Encyclopedia of Evolutionary Psychological Science. Springer International Publishing, Cham, pp 1-6

Sol D, Duncan RP, Blackburn TM, et al (2005) Big brains, enhanced cognition, and response of birds to novel environments. Proceedings of the National Academy of Sciences of the United States of America 102:5460-5465

Sol D, Sayol F, Ducatez S, Lefebvre L (2016b) The life-history basis of behavioural innovations. Philosophical Transactions of the Royal Society B: Biological Sciences 371:20150187. https://doi.org/10.1098/rstb.2015.0187

Stanton L, Davis E, Johnson S, et al (2017) Adaptation of the Aesop's Fable paradigm for use with raccoons (Procyon lotor): considerations for future application in non-avian and non-primate species. Anim Cogn 20:1147-1152. https://doi.org/10.1007/s10071017-1129-z

Stow MK, Vernouillet A, Kelly DM (2018) Neophobia does not account for motoric selfregulation performance as measured during the detour-reaching cylinder task. Animal Cognition 21:565-574. https://doi.org/10.1007/s10071-018-1189-8

Strasser A, Burkart JM (2012) Can We Measure Brain Efficiency? An Empirical Test with Common Marmosets (Callithrix jacchus). Brain, Behavior and Evolution 80:26-40. https://doi.org/10.1159/000338014

Street SE, Navarrete AF, Reader SM, Laland KN (2017) Coevolution of cultural intelligence, extended life history, sociality, and brain size in primates. Proceedings of the National Academy of Sciences 114:7908-7914. https://doi.org/10.1073/pnas.1620734114

Taborsky B, Oliveira RF (2012) Social competence: an evolutionary approach. Trends in Ecology \& Evolution 27:679-688. https://doi.org/10.1016/j.tree.2012.09.003

Tapp PD (2003) Size and Reversal Learning in the Beagle Dog as a Measure of Executive Function and Inhibitory Control in Aging. Learning \& Memory 10:64-73. https://doi.org/10.1101/Im.54403

Taylor AH, Elliffe D, Hunt GR, Gray RD (2010a) Complex cognition and behavioural innovation in New Caledonian crows. Proceedings of the Royal Society B: Biological Sciences 277:2637-2643. https://doi.org/10.1098/rspb.2010.0285

Taylor AH, Hunt GR, Medina FS, Gray RD (2009) Do New Caledonian crows solve physical problems through causal reasoning? Proc R Soc B 276:247-254. https://doi.org/10.1098/rspb.2008.1107

Taylor AH, Medina FS, Holzhaider JC, et al (2010b) An Investigation into the Cognition Behind Spontaneous String Pulling in New Caledonian Crows. PLoS ONE 5:e9345. https://doi.org/10.1371/journal.pone.0009345 
Tebbich S, Griffin AS, Peschl MF, Sterelny K (2016) From mechanisms to function: an integrated framework of animal innovation. Philosophical Transactions of the Royal Society B: Biological Sciences 371:20150195. https://doi.org/10.1098/rstb.2015.0195

Tebbich S, Stankewitz S, Teschke I (2012) The Relationship Between Foraging, Learning Abilities and Neophobia in Two Species of Darwin's Finches: The Relationship Between Foraging and Learning Abilities in Darwin's Finches. Ethology 118:135-146. https://doi.org/10.1111/j.1439-0310.2011.02001.x

Thornton A (2006) Teaching in Wild Meerkats. Science 313:227-229. https://doi.org/10.1126/science.1128727

Thornton A, Clutton-Brock T (2011) Social learning and the development of individual and group behaviour in mammal societies. Philosophical Transactions of the Royal Society B: Biological Sciences 366:978-987. https://doi.org/10.1098/rstb.2010.0312

Thornton A, Isden J, Madden JR (2014) Toward wild psychometrics: linking individual cognitive differences to fitness. Behavioral Ecology 25:1299-1301. https://doi.org/10.1093/beheco/aru095

Thornton A, Lukas D (2012) Individual variation in cognitive performance: developmental and evolutionary perspectives. Philosophical Transactions of the Royal Society B: Biological Sciences 367:2773-2783. https://doi.org/10.1098/rstb.2012.0214

Thornton A, Malapert A (2009) Experimental evidence for social transmission of food acquisition techniques in wild meerkats. Animal Behaviour 78:255-264. https://doi.org/10.1016/j.anbehav.2009.04.021

Thornton A, Samson J (2012) Innovative problem solving in wild meerkats. Animal Behaviour 83:1459-1468. https://doi.org/10.1016/j.anbehav.2012.03.018

Tomasello M (2000) Primate Cognition: Introduction to the Issue. Cognitive Science 24:351361. https://doi.org/10.1207/s15516709cog2403_1

van de Waal E, Bshary R (2011) Social-learning abilities of wild vervet monkeys in a two-step task artificial fruit experiment. Animal Behaviour 81:433-438

van de Waal E, Claidière N, Whiten A (2013) Social learning and spread of alternative means of opening an artificial fruit in four groups of vervet monkeys. Animal Behaviour 85:71-76. https://doi.org/10.1016/j.anbehav.2012.10.008

van der Bijl W, Thyselius M, Kotrschal A, Kolm N (2015) Brain size affects the behavioural response to predators in female guppies ( Poecilia reticulata). Proceedings of the Royal Society B: Biological Sciences 282:20151132. https://doi.org/10.1098/rspb.2015.1132

van Horik J, Emery NJ (2011) Evolution of cognition: Evolution of cognition. WIREs Cogn Sci 2:621-633. https://doi.org/10.1002/wcs.144 
van Horik JO, Beardsworth CE, Laker PR, et al (2019) Unpredictable environments enhance inhibitory control in pheasants. Anim Cogn 22:1105-1114.

https://doi.org/10.1007/s10071-019-01302-0

van Horik JO, Langley EJG, Whiteside MA, et al (2018) Intra-individual variation in performance on novel variants of similar tasks influences single factor explanations of general cognitive processes. Royal Society Open Science 5:171919.

https://doi.org/10.1098/rsos.171919

van Horik JO, Madden JR (2016) A problem with problem solving: motivational traits, but not cognition, predict success on novel operant foraging tasks. Animal Behaviour 114:189-198. https://doi.org/10.1016/j.anbehav.2016.02.006

van Oers K, Klunder M, Drent PJ (2005) Context dependence of personalities: risk-taking behavior in a social and a nonsocial situation. Behavioral Ecology 16:716-723. https://doi.org/10.1093/beheco/ari045

Vernouillet AAA, Stiles LR, Andrew McCausland J, Kelly DM (2018) Individual performance across motoric self-regulation tasks are not correlated for pet dogs. Learning \& Behavior 46:522-536. https://doi.org/10.3758/s13420-018-0354-x

Veron G, Colyn M, Dunham AE, et al (2004) Molecular systematics and origin of sociality in mongooses (Herpestidae, Carnivora). Molecular Phylogenetics and Evolution 30:582598. https://doi.org/10.1016/S1055-7903(03)00229-X

Veron G, Dupré D, Jennings AP, et al (2017) New insights into the systematics of Malagasy mongoose-like carnivorans (Carnivora, Eupleridae, Galidiinae) based on mitochondrial and nuclear DNA sequences. Journal of Zoological Systematics and Evolutionary Research 55:250-264. https://doi.org/10.1111/jzs.12168

Völter CJ, Call J (2012) Problem solving in great apes (Pan paniscus, Pan troglodytes, Gorilla gorilla, and Pongo abelii): the effect of visual feedback. Anim Cogn 15:923-936. https://doi.org/10.1007/s10071-012-0519-5

Völter CJ, Tinklenberg B, Call J, Seed AM (2018) Comparative psychometrics: establishing what differs is central to understanding what evolves. Philosophical Transactions of the Royal Society B: Biological Sciences 373:20170283.

https://doi.org/10.1098/rstb.2017.0283

von Bayern AMP, Heathcote RJP, Rutz C, Kacelnik A (2009) The Role of Experience in Problem Solving and Innovative Tool Use in Crows. Current Biology 19:1965-1968. https://doi.org/10.1016/j.cub.2009.10.037

Vonk J (2016a) Bigger brains may make better problem-solving carnivores. Learning \& Behavior 44:99-100. https://doi.org/10.3758/s13420-016-0222-5

Vonk J (2016b) Advances in Animal Cognition. Behavioral Sciences 6:27. https://doi.org/10.3390/bs6040027 
Vonk J, Beran MJ (2012) Bears 'count' too: quantity estimation and comparison in black bears, Ursus americanus. Animal Behaviour 84:231-238.

https://doi.org/10.1016/j.anbehav.2012.05.001

Vonk J, Galvan M (2014) What do Natural Categorization Studies Tell us about the Concepts of Apes and Bears? ABC 1:309. https://doi.org/10.12966/abc.08.07.2014

Vonk J, Johnson-Ulrich Z (2014) Social and nonsocial category discriminations in a chimpanzee (Pan troglodytes) and American black bears (Ursus americanus). Learning \& Behavior 42:231-245. https://doi.org/10.3758/s13420-014-0141-2

Wascher CAF, Kulahci IG, Langley EJG, Shaw RC (2018) How does cognition shape social relationships? Philosophical Transactions of the Royal Society B: Biological Sciences 373:20170293. https://doi.org/10.1098/rstb.2017.0293

Watson SK, Reamer LA, Mareno MC, et al (2017) Socially transmitted diffusion of a novel behavior from subordinate chimpanzees. American Journal of Primatology 79:e22642. https://doi.org/10.1002/ajp.22642

Watson SK, Vale GL, Hopper LM, et al (2018) Chimpanzees demonstrate individual differences in social information use. Animal Cognition 21:639-650. https://doi.org/10.1007/s10071-018-1198-7

Webster MM, Laland KN (2017) Social information use and social learning in non-grouping fishes. Behavioral Ecology 28:1547-1552. https://doi.org/10.1093/beheco/arx121

Webster MM, Ward AJW (2011) Personality and social context. Biological Reviews 86:759773. https://doi.org/10.1111/j.1469-185X.2010.00169.x

Webster SJ, Lefebvre L (2001) Problem solving and neophobia in a columbiform-passeriform assemblage in Barbados. Animal Behaviour 62:23-32. https://doi.org/10.1006/anbe.2000.1725

Whiten A, Mesoudi A (2008) Establishing an experimental science of culture: animal social diffusion experiments. Philosophical Transactions of the Royal Society B: Biological Sciences 363:3477-3488. https://doi.org/10.1098/rstb.2008.0134

Whiten A, van de Waal E (2018) The pervasive role of social learning in primate lifetime development. Behavioral Ecology and Sociobiology 72:. https://doi.org/10.1007/s00265-018-2489-3

Yoder AD, Burns MM, Zehr S, et al (2003) Single origin of Malagasy Carnivora from an African ancestor. Nature 421:734-737

Young JK, Touzot L, Brummer SP (2019) Persistence and conspecific observations improve problem-solving abilities of coyotes. PLOS ONE 14:e0218778.

https://doi.org/10.1371/journal.pone.0218778

Zelazo PD, Carter A, Reznick JS, Frye D (1997) Early Development of Executive Function: A Problem-Solving Framework. Review of General Psychology 1:198-226 
Zidar J, Balogh A, Favati A, et al (2017) A comparison of animal personality and coping styles in the red junglefowl. Animal Behaviour 130:209-220.

https://doi.org/10.1016/j.anbehav.2017.06.024 


\section{ACKNOWLEDGEMENTS}

Most important, this project is achieved thanks to many people and entities:

First, I am very grateful to Claudia Fichtel and Peter Kappeler for having giving me the opportunity to conduct my doctoral studies in the Department of Sociobiology and Anthropology at the University of Göttingen, and to carry out my field work at the field station of DPZ in Kirindy forest Madagascar. Thank you for your trust, your supports, and all yours constructive comments during this project.

Second, I am thankful to Dietmar Zinner for having accepting to be my second thesis committee member, Oliver Shülke for accepting to be the second reviewer of my dissertation, Mark Maraun and Tanya Behne for agreeing to be part of the examination board.

I would like to thank Rodin Rasoloarison and Leon Razafimanantsoa for all their helps in administrative and logistic matters, which made this project feasible, to Remy d'Ampataka who was helping me in data collection. I am also thankful to the staff of Kirindy that gave me endurable time in Kirindy during these long months of field works.

This work was funded by the "DAAD: Deutscher Akademischer Austauschdienst" (funding program/-ID: 57129429), and was made feasible with the collaboration with the University of Antananarivo that agreed to give the research permit for the field works conducted in Kirindy forest.

I am thankful to Simon Brettschneider for all his help in administrative matters at the office, and to Henning Lahmann for his big help in data mining. My appreciation goes to all members of the Behavioural Ecology and Sociobiology unit in the DPZ, and the Department of Sociobiology and Anthropology at the University of Göttingen. Thank you for all your helps.

I would like to thank the students who helped me in data collection and analyses in Kirindy and in Göttingen: Maria Woitow and Jana Sophie-Wilken. 
I greatly thank Hasina Josué Rakotoniaina for his invaluable helps, advices and constructive comments since the start of this project. To Franziska Hübner, Colleen Illing, and Katja Rudolph, thank you for your comments and advices. Thanks to Falk for all the laughs during this whole adventure.

Ho an'i Dada sy Neny, Dina sy Eric, Rindra, ary Ntsoa, misaotra betsaka tamin'ny fanohanana rehetra nomenareo ahy. 


\section{DECLARATION}

I hereby declare that all parts of my thesis titled "Cognition in the narrow-striped mongooses (Mungotictis decemlineata), a Malagasy carnivore species" were written by myself. Assistance of third parties was only accepted if scientifically justifiable and acceptable in regard to the examination regulations. Assistance or contributions to the individual chapters are indicated and all sources have been quoted.

Göttingen, 16. January 2020

Bako Nandrianina Rasolofoniaina 